\title{
Determinantes da qualidade da informação contábil no contexto internacional
}

The determinants of the quality of accounting information in the international context

Determinantes de la calidad de la información contable en el contexto internacional

\section{Sady Mazzioni}

Doutor em Ciências Contábeis e Administração pela Universidade Regional de Blumenau FURB

Professor do Mestrado em Ciências Contábeis e Administração na Universidade Comunitária da Região de Chapecó - Unochapecó

Endereço: Rua Francisco Norberto Bonher, n॰ 55 E, Bairro Jardim Itália

CEP: 89.802-530 - Chapecó/SC - Brasil

E-mail: sady@unochapeco.edu.br

Telefone: + 55 (49) 3321-8243

\section{Roberto Carlos Klann}

Doutor em Ciências Contábeis e Administração pela Universidade Regional de Blumenau FURB

Professor do Programa de Pós-Graduação em Ciências Contábeis da Universidade Regional de Blumenau - FURB

Rua Antônio da Veiga, n॰140, sala D 202, Bairro Victor Konder

CEP: 89.012-900 - Blumenau/SC - Brasil

E-mail: rklann@furb.br

Telefone: + 55 (47) 3321-0565

Artigo recebido em 03/01/2016. Revisado por pares em 05/05/2016. Reformulado em 16/06/2016. Recomendado para publicação em 19/06/2016 por Sandra Rolim Ensslin (Editora Científica). Publicado em 26/08/2016. 


\section{Determinantes da qualidade da informação contábil no contexto internacional}

The determinants of the quality of accounting information in the international context

Determinantes de la calidad de la información contable en el contexto internacional

\section{Sady Mazzioni}

Doutor em Ciências Contábeis e Administração pela Universidade Regional de Blumenau FURB

Professor do Mestrado em Ciências Contábeis e Administração na Universidade Comunitária da Região de Chapecó - Unochapecó

Endereço: Rua Francisco Norberto Bonher, n॰ 55 E, Bairro Jardim Itália

CEP: 89.802-530 - Chapecó/SC - Brasil

E-mail: sady@unochapeco.edu.br

Telefone: + 55 (49) 3321-8243

\section{Roberto Carlos Klann}

Doutor em Ciências Contábeis e Administração pela Universidade Regional de Blumenau FURB

Professor do Programa de Pós-Graduação em Ciências Contábeis da Universidade Regional de Blumenau - FURB

Rua Antônio da Veiga, n॰140, sala D 202, Bairro Victor Konder

CEP: 89.012-900 - Blumenau/SC - Brasil

E-mail: rklann@furb.br

Telefone: + 55 (47) 3321-0565

Artigo recebido em 03/01/2016. Revisado por pares em 05/05/2016. Reformulado em 16/06/2016. Recomendado para publicação em 19/06/2016 por Sandra Rolim Ensslin (Editora Científica). Publicado em 26/08/2016. 


\title{
Resumo
}

O objetivo do estudo é analisar a influência do grau de internacionalização das empresas, em conjunto com as normas reguladoras e os incentivos empresariais, na qualidade das informações contábeis. Para tanto, foi realizada pesquisa descritiva, documental e quantitativa com 1.406 empresas localizadas em doze países. A amostra considerou empresas que divulgaram informações sobre suas receitas e ativos no exterior, além das demais informações necessárias para operacionalizar os atributos de qualidade dos accruals, persistência, previsibilidade e suavização dos resultados. Após a mensuração individual de cada atributo por empresa, elaborou-se um ranking da qualidade da informação contábil, com base no método de análise multicritério TOPSIS e da técnica da entropia. Os resultados indicaram que, ao se considerar o ambiente legal, o nível de percepção da corrupção e a origem legal dos países hospedeiros das empresas, a menor alavancagem financeira e a maior intensidade na internacionalização das empresas se mostraram fatores determinantes para o melhor posicionamento no ranking da qualidade da informação contábil.

Palavras-chave: Normas reguladoras. Incentivos empresariais. Internacionalização das empresas.

\begin{abstract}
The objective of the study is to analyze the influence of the degree of internationalization of companies, together with regulatory standards and business incentives, the quality of accounting. For this purpose, descriptive, documentary and quantitative survey was conducted with 1,406 companies located in twelve countries. The sample considered companies released information about their income and assets abroad, in addition to other information needed to operationalize the attributes quality of accruals, persistence, predictability and smoothing. After individual measurement of each attribute by company, elaborated a ranking of the quality of accounting information, from the multi-criteria analysis method TOPSIS and entropy technique. The results indicated that, when considering the legal environment, the level of perception of corruption and the legal origin of the host countries of companies, lower financial leverage and the greater intensity in the internationalization of companies have proved decisive factors for the better position in the ranking the quality of accounting information.
\end{abstract}

Keywords: Regulatory standards. Business incentives. Internationalization of the companies.

\section{Resumen}

El objetivo del estudio es analizar la influencia del grado de internacionalización de las empresas, junto con las normas reguladoras y con los incentivos empresariales, in la calidad de la información contable. Por lo tanto, la investigación descriptiva, documental y cuantitativa se realizó con 1.406 empresas ubicadas en doce países. La muestra fue considerada por las compañías con información sobre sus ingresos y activos en el exterior, además de otra información necesaria para poner en práctica los atributos de calidad de acumulaciones, la persistencia, la previsibilidad y suavización de los resultados. Después de la medición individual de cada atributo por compañía, fue elaborado un ranking de calidad de la información contable, desde el método de análisis multicriterio TOPSIS y la técnica de la entropía. Los resultados indicaron que, al considerar el entorno legal, el nivel de percepción de la corrupción y el origen legal de los países anfitriones de las empresas, un menor apalancamiento financiero y la mayor intensidad en la internacionalización de las empresas han demostrado ser factores decisivos para la mejor posición en el ranking la calidad de la información contable.

Palabras clave: Normas reguladoras. Incentivos empresariales. Internacionalización de las empresas.

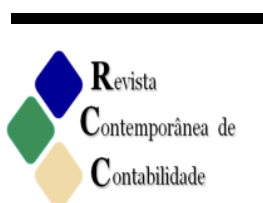

ISSN 2175-8069, UFSC, Florianópolis, v. 13, n. 29, p. 03-32, mai. /ago. 2016 


\section{Introdução}

A qualidade dos resultados contábeis ou, de modo mais geral, a qualidade das demonstrações contábeis não tem uma definição precisa, mas pode ser definida como a medida na qual os resultados divulgados representam fielmente a situação econômica subjacente da empresa reportada e o grau em que os resultados apresentados refletem os conceitos básicos de contabilidade (YOON, 2007; CHEN et al., 2010).

A análise da qualidade da informação contábil manifesta relevância pela aceitação de que a informação de qualidade reduz o grau de incerteza e a assimetria da informação entre preparadores e usuários das demonstrações contábeis, além de melhorar a eficiência do mercado de capitais relacionada à gestão do risco, dada a maior possibilidade de compreensão da informação contábil reportada (BIDDLE; HILARY, 2006). A qualidade da informação contábil está relacionada com o grau de funcionalidade da contabilidade como mecanismo para impedir a expropriação dos recursos (ANTUNES et al., 2008).

A qualidade da informação contábil é influenciada por diversos fatores regulatórios, a exemplo dos padrões de contabilidade de elevada qualidade, com destaque para a adoção das normas internacionais de contabilidade (BARTH; LANDSMAN; LANG, 2008; IATRIDIS, 2010; HOUQE et al., 2012), a origem do sistema legal do país (LA PORTA et al., 1998; BUSHMAN; PIOTROSKI, 2006; SODERSTROM; SUN, 2007; LA PORTA; LOPEZ-DESILANES; SHLEIFER, 2008), a existência de leis para proteção do mercado de valores mobiliários e sua efetiva aplicação (HOUQE et al., 2012), a proteção legal dos interesses de acionistas minoritários (LA PORTA et al., 1998; HOUQE et al., 2012), aplicação efetiva das normas de contabilidade e auditoria (HOUQE et al., 2012), eficiência e integridade do ambiente legal sobre os negócios (LA PORTA et al., 1998; HOUQE et al., 2012), a influência do sistema tributário na intensidade do alinhamento entre o lucro contábil e o lucro tributável (SODERSTROM; SUN, 2007; HOUQE et al., 2012).

Embora algumas evidências empíricas demostrem que padrões de alta qualidade (por exemplo, IFRS) geralmente melhoram a qualidade contábil (BARTH; LANDSMAN; LANG, 2008; DASKE et al., 2008), outros resultados investigativos sugerem que as normas têm um papel limitado para determinar a qualidade dos relatórios contábeis (BURGSTAHLER; HAIL; LEUZ, 2006; DASKE et al., 2007; LEUZ, 2003).

Padrões de contabilidade geralmente concedem substancial flexibilidade para as empresas. As mensurações são muitas vezes baseadas em informações privadas, e a aplicação das normas envolve julgamento. Gestores corporativos podem usar o poder discricionário nos relatórios para transmitir informações sobre o desempenho econômico da empresa, mas também podem fazer uso indevido dos critérios quando é do seu interesse. Por essa razão, os incentivos dos relatórios são suscetíveis de desempenhar um papel fundamental na determinação da informatividade dos números contábeis reportados (BURGSTAHLER; HAIL; LEUZ, 2006).

As empresas são motivadas por determinados incentivos na divulgação dos números contábeis que exercem influência sobre a qualidade dos relatórios, a exemplo da concentração de propriedade (BARTH; LANDSMAN; LANG, 2008; GAIO, 2010; CHEN et al., 2010; ISIDRO; RAONIC, 2012), da alavancagem financeira (BARTH; LANDSMAN; LANG, 2008; KOHLBECK; WARFIELD 2010), da presença em listagem estrangeira (DING; JEANJEAN; STOLOWY, 2008; BARTH; LANDSMAN; LANG, 2008; ISIDRO; RAONIC, 2012), do desempenho econômico (BURGSTAHLER; HAIL; LEUZ, 2006; IATRIDIS, 
2010), do nível de desenvolvimento econômico do país (BURGSTAHLER; HAIL; LEUZ, 2006; GAIO, 2010; ISIDRO; RAONIC, 2012), do nível de desenvolvimento financeiro do país (GAIO, 2010; ISIDRO; RAONIC, 2012) e do nível de combate à corrupção (LA PORTA et al., 1998), dentre outros incentivos influenciadores.

As empresas que têm operações diversificadas no exterior possuem maiores incentivos para fornecer informação financeira abrangente para seus clientes estrangeiros, fornecedores e potenciais investidores (ISIDRO; RAONIC, 2012). Além disso, a concorrência internacional para o capital criou incentivos para melhorar a qualidade e a comparabilidade da informação contábil (LAND; LANG, 2002), e os investidores institucionais e estrangeiros preferem as demonstrações financeiras de alta qualidade ao fazer investimentos internacionais (BRADSHAW; BUSHEE; MILLER, 2004).

A expansão internacional aumenta a complexidade do processamento de informações para analistas, investidores e auditores. Além disso, o elevado risco relacionado com a internacionalização não se relaciona apenas à empresa, mas tem implicações para os usuários das demonstrações financeiras. Desse modo, a diversificação internacional gera maior necessidade informativa que cria um incentivo para que as empresas proporcionem mais informações (RUSANESCU, 2013).

Nesse contexto, a investigação pretende responder ao seguinte problema de pesquisa: Qual a influência do grau de internacionalização das empresas, em conjunto com as normas reguladoras e os incentivos empresariais, na qualidade das informações contábeis? O objetivo é analisar a influência do grau de internacionalização das empresas, em conjunto com as normas reguladoras e os incentivos empresariais, na qualidade das informações contábeis.

A relevância da investigação está atrelada à produção de resultados que são de interesse de profissionais como contadores, consultores, analistas de mercado, auditores, responsáveis pela elaboração de normas contábeis e pesquisadores. Para as empresas, os resultados são importantes pela possibilidade de se avaliar como a interação com mercados externos causa influência nas escolhas das políticas contábeis, reforçando a premissa de que a informação contábil de elevada qualidade pode mitigar os problemas de agência decorrentes da assimetria de informação entre as empresas e os investidores (BALL; KOTHARI; ROBIN, 2000).

A investigação apresenta, ao menos, três importantes fatores distintos: (i) considera um contexto internacional, avaliando a influência de fatores normativos (origem e ambiente legal dos países e a carga tributária) e de incentivos empresariais (retorno sobre ativos, alavancagem financeira, nível de transparência, desenvolvimento econômico e financeiro dos países de origem das empresas) na qualidade da informação reportada; (ii) adicionalmente, utiliza a intensidade da internacionalização das atividades empresariais como uma determinante explicativa da qualidade da informação contábil; e (iii) os atributos da qualidade são tomados em conjunto, formando um ranking por empresa. Consideradas em conjunto, essas características do estudo representam uma contribuição importante para o debate sobre a qualidade da informação reportada no contexto internacional.

\section{Revisão da Literatura}

A subseção de atributos da qualidade da informação contábil aborda quatro atributos de base contábil utilizados no estudo: qualidade dos accruals, persistência, previsibilidade e

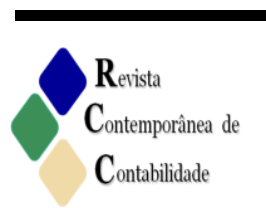

ISSN 2175-8069, UFSC, Florianópolis, v. 13, n. 29, p. 03-32, mai. /ago. 2016 
suavização dos lucros. Na subseção de determinantes da qualidade da informação contábil, discute-se a implicação dos fatores normativos e dos incentivos empresariais sobre a qualidade da informação contábil.

\subsection{Atributos da Qualidade da Informação Contábil}

A literatura contábil fornece evidências de que as características operacionais das empresas estão associadas com as várias proxies da qualidade dos resultados contábeis, incluindo a escolha dos princípios de contabilidade (LINDAHL, 1989), as propriedades dos lucros, como a persistência, a volatilidade (LEV, 1983) e os accruals (DECHOW, 1994).

Não há uma concordância ou abordagem superior geralmente aceita para medir a qualidade dos resultados contábeis em decorrência de que os atributos podem ser mutuamente incompatíveis ou sobrepostos, serem interligados e não poderem ser considerados separadamente (YOON, 2007). Embora não exista acordo sobre a definição de qualidade da informação contábil, os estudos geralmente desenvolvem medidas de qualidade pelo uso dos lucros divulgados e de componentes dos lucros, definindo o construto como "qualidade dos resultados contábeis" ou "qualidade dos accruals" (HRIBAR; KRAVET; WILSON, 2014).

As definições da qualidade dos resultados contábeis incluem a elevada persistência dos lucros em uma série temporal; lucros que representam com precisão as implicações econômicas das operações subjacentes; a proporção de lucros em relação aos fluxos de caixa operacionais; accruals de capital de giro mapeados nos fluxos de caixa do passado, presente e futuro (MCNICHOLS, 2002). Em relação à qualidade dos relatórios, em termos abstratos, pode ser interpretada como a utilidade das demonstrações financeiras para os investidores, credores, administradores e todas as outras partes contratantes com a empresa (BALL; SHIVAKUMAR, 2005).

Francis et al. (2004), seguidos por Yoon (2007) e Gaio (2010), examinaram a qualidade dos resultados contábeis com diversos fatores explicativos, segregando os atributos baseados em contabilidade (mensurados utilizando apenas informação contábil) dos atributos baseados em mercado (as proxies desses constructos são baseadas nas relações entre valores de mercado e dados contábeis). Nesse estudo, são considerados quatro atributos de base contábil, que consideram o caixa ou os lucros como o constructo de referência e, consequentemente, são mensurados utilizando apenas informação contábil.

Em termos de atributos baseados na Contabilidade, a literatura contábil considera a mensuração da qualidade dos accruals pelo mapeamento de accruals correntes nos fluxos de caixa ou alguma medida dos accruals anormais (DECHOW; DICHEV 2002; FRANCIS et al., 2005). As medidas de persistência dos lucros normalmente consideram o coeficiente de inclinação estimado em uma regressão de lucros correntes sobre os lucros defasados (LEV, 1983). As medidas de previsibilidade dos lucros focam sobre os erros de previsão de um modelo de séries temporais de lucros (LIPE, 1990), enquanto medidas de suavização são baseadas na volatilidade dos lucros em relação a algum ponto de referência, tais como os fluxos de caixa (LEUZ; NANDA; WYSOCKI, 2003).

Os accruals, ou as acumulações contábeis por regime de competência, podem ser entendidos como a diferença entre o lucro líquido e o fluxo de caixa operacional líquido, ou seja, são constituídos pelos valores integrantes das contas de resultado que entraram no cômputo do lucro, mas não implicam necessária movimentação de recursos financeiros (MARTINEZ, 2008). 
Os accruals refletem as escolhas para fins de reporte, enquanto os fluxos de caixa refletem, de modo mais fundamental, os ganhos e as perdas financeiras. Os accruals e a qualidade dos resultados contábeis estão relacionados, e as mudanças transitórias, no fluxo de caixa operacional, ocorrem pela manipulação gerencial provocada na variação dos itens de capital de giro ao longo do tempo, conduzindo para ganhos de menor qualidade (BALL; SHIVAKUMAR, 2005).

Embora uma correlação negativa com o fluxo de caixa seja um resultado "natural" dos accruals contábeis (DECHOW, 1994), maiores magnitudes dessa correlação podem indicar uma suavização dos lucros reportados que não refletem o desempenho econômico das empresas (MYERS; MYERS; SKINNER, 2006). A existência de acumulações contábeis (accruals) extremas se configura como de baixa qualidade, pois representa um componente menos persistente dos resultados (DECHOW; GE; SCHRAND, 2010).

A persistência dos lucros é vista como uma medida de sustentabilidade dos lucros, em que lucros persistentes são vistos como desejáveis porque são recorrentes, tornando-os mais previsíveis, reforçando seu papel na avaliação de capital e ajudando os analistas financeiros a prestar um serviço valioso para os investidores (PENMAN; ZHANG, 2002). A persistência também possui uma ligação direta com o risco da informação, porque mais persistência está associada a um fluxo de ganhos mais sustentável. Como consequência, se os ganhos são persistentes, os investidores demonstram menos preocupações sobre a extensão em que as alterações nos ganhos dos períodos futuros poderão ocorrer, e isso reduz incertezas (FRANCIS et al., 2004).

Os lucros atuais devem ser um bom indicador dos lucros futuros. Sua qualidade pode ser entendida como a probabilidade de que uma empresa possa ter lucros atuais persistentes no futuro (PENMAN; ZHANG, 2002). Mais persistência dos ganhos é considerada uma característica de qualidade superior de contabilidade (KOHLBECK; WARFIELD, 2010).

A previsibilidade dos lucros é definida como a habilidade de prever lucros futuros com base nos seus valores do passado (LIPE, 1990; FRANCIS et al., 2004; YOON, 2007). Isso é uma medida importante, uma vez que lida com o quão bem os lucros passados podem explicar os lucros atuais. Assim, a medida utiliza uma perspectiva puramente contábil, tornando-se um complemento ideal da relevância. Se os lucros do passado são boas estimativas dos lucros correntes, então a previsibilidade é tida para ser elevada. Essa característica está baseada na contabilidade, ou seja, considera as relações entre os números contábeis (lucros passados para lucros correntes), embora ignore as informações que estão fora do regime contábil, a exemplo da percepção do mercado sobre os lucros divulgados (SCHIEMANN; GUENTHER, 2013).

Os analistas financeiros visualizam os lucros como tendo alta qualidade quando se pode esperar uma repetição de forma consistente e com um alto grau de previsibilidade. Os ganhos voláteis possuem a tendência de serem ganhos extremos e tendem a reverter-se para a média mais rapidamente (FREEMAN; OHLSON; PENMAN, 1982), o que constituiu uma explicação alternativa para que ganhos voláteis sejam menos persistentes.

A suavização dos lucros é uma medida baseada na sua volatilidade em relação ao fluxo de caixa, considerando as diferenças temporais das entradas ou saídas dos recursos e o reconhecimento das receitas e despesas no resultado (DECHOW; DICHEV, 2002), tendo-se que uma relação mais baixa indica mais suavização do fluxo de lucros em relação aos fluxos de caixa (DECHOW; GE; SCHRAN, 2010).

Em uma perspectiva teórica, Almeida et al. (2012) argumentam que quanto maior for a suavização de resultados pela redução na variabilidade dos lucros com o uso de accruals,

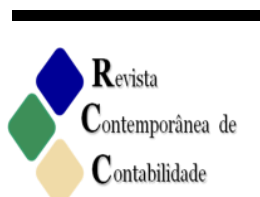

ISSN 2175-8069, UFSC, Florianópolis, v. 13, n. 29, p. 03-32, mai. /ago. 2016 
menor será a capacidade do retorno das ações em reconhecer oportunamente as perdas econômicas futuras contidas nos lucros. A suavização dos resultados é derivada da visão de que os gerentes usam as informações privadas sobre resultados futuros para suavizar as flutuações transitórias (FRANCIS et al., 2004).

A suavização é tipicamente vista como um atributo desejável dos lucros, pois os analistas financeiros e investidores observam a volatilidade dos lucros como indesejável e indicativo de baixa qualidade dos resultados contábeis. Os accruals permitem um adequado registro das transações econômicas e melhoram a qualidade dos resultados contábeis. Contudo, os gestores podem usá-los de um modo oportunista e assim comprometer a qualidade dos resultados contábeis (GAIO, 2010).

\subsubsection{Determinantes da Qualidade da Informação Contábil}

Com base na visão de que a contabilidade não existe no vácuo (HOUQE et al., 2012), mas é um produto do seu ambiente (ARMSTRONG et al., 2010), pode-se compreender melhor que a qualidade da informação contábil é influenciada por diversos fatores regulatórios, mas os incentivos empresariais também são proxies utilizadas para explicar os números contábeis reportados ao redor do mundo.

O Quadro 1 apresenta, resumidamente, algumas determinantes utilizadas na literatura prévia e consideradas nesse estudo, com as possíveis implicações na qualidade da informação contábil reportada pelas empresas.

Quadro 1 - Determinantes da qualidade da informação contábil

\begin{tabular}{|c|c|}
\hline Determinante & Implicação na Qualidade da Informação Contábil \\
\hline Origem Legal & $\begin{array}{l}\text { Em países de origem common law o propósito dos emissores de padrões contábeis é } \\
\text { satisfazer as necessidades de informação dos investidores (SODERSTROM; SUN, } \\
\text { 2007), ao passo que nos países code law a contabilidade serve de medida para dividir } \\
\text { os lucros entre o governo (impostos), acionistas (dividendos), bancos (juros) e } \\
\text { trabalhadores (salários e benefícios) (BALL; KOTHARI; ROBIN, 2000). }\end{array}$ \\
\hline Ambiente Legal & $\begin{array}{l}\text { A eficiência do sistema jurídico tem um efeito significativo na restrição do } \\
\text { gerenciamento de resultados pelo gestor, apresentando-se de forma mais reduzida em } \\
\text { países com um sistema jurídico eficiente (HAW et al., 2004). }\end{array}$ \\
\hline $\begin{array}{l}\text { Carga } \\
\text { Tributária }\end{array}$ & $\begin{array}{l}\text { Uma ligação estreita entre os resultados contábeis e os resultados tributáveis pode } \\
\text { comprometer os incentivos das empresas para reportar o verdadeiro desempenho } \\
\text { econômico (ALFORD et al., 1993). }\end{array}$ \\
\hline $\begin{array}{l}\text { Alavancagem } \\
\text { Financeira }\end{array}$ & $\begin{array}{l}\text { As empresas altamente alavancadas podem ter riscos e custos de agência mais } \\
\text { elevados, que podem contribuir negativamente para a qualidade dos resultados } \\
\text { contábeis (GAIO, 2010) e podem criar incentivos para manipular números contábeis, } \\
\text { a fim de demonstrar que possuem capacidade de cumprir os compromissos com as } \\
\text { dívidas (DEFOND; JIAMBALVO, 1994). }\end{array}$ \\
\hline $\begin{array}{c}\text { Retorno sobre } \\
\text { Ativos }\end{array}$ & $\begin{array}{l}\text { O fraco desempenho operacional fornece incentivos para as empresas envolverem-se } \\
\text { em gerenciamento de resultados (DOYLE; GE; MCVAY, 2007). Para evitar as } \\
\text { reações negativas, os gestores podem gerenciar propositadamente as informações } \\
\text { financeiras para retratar uma imagem melhor do desempenho empresarial } \\
\text { (BURGSTAHLER; DICHEV, 1997). }\end{array}$ \\
\hline Corrupção & $\begin{array}{l}\text { Em países com elevada corrupção, os contratos geralmente são realizados de forma } \\
\text { privada para evitar o controle social e político. Em tais ambientes, os relatórios } \\
\text { financeiros não são frequentemente utilizados para reduzir a assimetria de informação } \\
\text { (SODERSTROM; SUN, 2007). }\end{array}$ \\
\hline $\begin{array}{l}\text { Desenvolvimento } \\
\text { Econômico }\end{array}$ & $\begin{array}{l}\text { Os países com fraco desenvolvimento econômico não conseguem dispor de } \\
\text { infraestrutura adequada para suportar a verificação externa confiável da informação }\end{array}$ \\
\hline
\end{tabular}




\begin{tabular}{|c|l|}
\hline & contábil (BALL, 2001). \\
\hline $\begin{array}{c}\text { Desenvolvimento } \\
\text { do Mercado }\end{array}$ & Em sistemas financeiros orientados para o mercado há maior demanda por \\
Financeiro & financeiros orientados para os bancos. O baixo desenvolvimento do mercado \\
& financeiro pode limitar os benefícios para melhorar a qualidade dos ganhos, porque \\
& nesses ambientes é difícil e oneroso captar recursos (BALL; ROBIN; WU, 2003). \\
\hline
\end{tabular}

Fonte: Dados da pesquisa.

Adicionalmente às determinantes apresentadas no Quadro 1 e utilizadas na literatura, esse estudo considera a internacionalização das empresas como fator explicativo da qualidade da informação contábil. Nessa investigação, adota-se a abordagem econômica de internacionalização, baseada na intensidade da participação das atividades internacionais, representada pelo grau de internacionalização das empresas (UNCTAD, 1995), ou seja, considerou-se internacionalizada a empresa que divulgou, voluntariamente, informações sobre ativos no exterior e vendas para o exterior.

Empresas mais internacionalizadas em suas atividades podem ser requeridas a apresentar níveis mais elevados de evidenciação devido à sua maior complexidade operacional ou por exigência de seu arranjo de financiamento. A maior exposição ao mercado de capitais, de produtos ou de trabalho aumenta a demanda por melhor divulgação (WEBB; CAHAN; SUN, 2008).

A interação com mercados estrangeiros está associada com maior transparência e melhor evidenciação (KHANNA; PALEPU; SRINIVASAN, 2004). As empresas multinacionais, com atividades globalizadas, se mostraram mais dispostas a seguir as normas internacionais de Contabilidade para fortalecer a transparência, a confiabilidade e a consistência da Contabilidade (LUO, 2005).

Empresas com atuação em países com mercados de capitais mais desenvolvidos são mais propensas a levantar seus fundos externamente e escolher melhores padrões de qualidade dos lucros (GAIO, 2010). As forças de mercado enfrentadas por empresas de capital aberto provavelmente são maiores quando o mercado de capitais de um país é ativo e fortemente desenvolvido, incentivando as empresas a divulgar lucros de maior qualidade (BURGSTAHLER; HAIL; LEUZ, 2006).

Com base nessas considerações, apresenta-se a seguinte hipótese de estudo:

$\mathrm{H}_{1}$ - A qualidade da informação contábil é influenciada positivamente pelo grau de internacionalização das empresas, em conjunto com as normas reguladoras e os incentivos empresariais.

\section{Procedimentos Metodológicos}

A composição da população de pesquisa foi definida considerando-se as empresas de capital aberto, localizadas nos vinte países com maior Produto Interno Bruto (PIB), em 2013, conforme o World Development Indicators (2014), produzido pelo The World Bank. O critério para definição da amostra foi a exigência de a empresa possuir a divulgação dos dados necessários para operacionalizar as variáveis ao longo de todos os anos investigados.

A coleta do tipo documental ocorreu com base nos dados contábeis, financeiros, tributários e de mercado divulgados pelas empresas investigadas e aqueles produzidos por

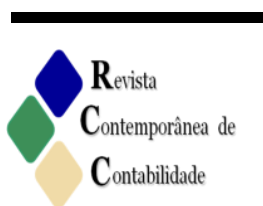

ISSN 2175-8069, UFSC, Florianópolis, v. 13, n. 29, p. 03-32, mai. /ago. 2016 
organismos internacionais, para o período de 2005 a 2012. Considerando a estrutura das variáveis, foram exigidos dados anteriores e posteriores a esses períodos.

Com base nas informações recuperadas na base de dados Thomson Datastream Index Service (2014), optou-se em considerar apenas os países que apresentaram mais de dez empresas com as variáveis necessárias para operacionalizar os modelos teóricos, resultando em uma amostra final composta por 1.406 empresas de doze países, a saber: Alemanha, Austrália, Brasil, Canadá, China, Estados Unidos, Holanda, Índia, Indonésia, Japão, Reino Unido, Suíça.

Pelos critérios adotados na pesquisa, Arábia Saudita, Coreia do Sul, Espanha, França, Itália, México, Turquia e Rússia não ficaram representados na amostra final. Uma das razões principais para o número final de empresas, considerado na pesquisa, é a utilização das informações relacionadas à intensidade de internacionalização das empresas. Ocorre que a divulgação das informações necessárias para operacionalizar tal variável é voluntária (montante de vendas no exterior e montante de ativos no exterior), conduzindo a um número reduzido de empresas em todos os países pesquisados.

O emprego da quantificação utilizou inicialmente a regressão linear múltipla, com a análise individual por empresa, para calcular cada um dos quatro atributos dos lucros. Para mensurar a qualidade dos accruals, utilizou-se a abordagem de Dechow e Dichev (2002):

$$
\mathrm{ACT}_{\mathrm{i}, \mathrm{t}}=\varphi_{0, \mathrm{i}}+\varphi_{1, \mathrm{i}} \mathrm{FCO}_{\mathrm{i}, \mathrm{t}-1}+\varphi_{2, \mathrm{i}} \mathrm{FCO}_{\mathrm{i}, \mathrm{t}}+\varphi_{3, \mathrm{i}} \mathrm{FCO}_{\mathrm{i}, \mathrm{t}+1}+\varepsilon_{\mathrm{i}, \mathrm{t}}
$$

Em que:

$\mathrm{ACT}_{\mathrm{i}, \mathrm{t}}=$ accruals correntes totais da firma $i$ no ano $t\left(\Delta \mathrm{AC}_{\mathrm{i}, \mathrm{t}}-\Delta \mathrm{PC}_{\mathrm{i}, \mathrm{t}}-\Delta\right.$ caixa $\mathrm{i}, \mathrm{t}+$ $\left.\triangle \mathrm{FINCP}_{\mathrm{i}, \mathrm{t}}\right)$;

Ativos $_{\mathrm{i}, \mathrm{t}}=$ média dos ativos totais da firma $i$ no ano $t$ e $t-1$.

$\mathrm{FCO}_{\mathrm{i}, \mathrm{t}}=$ fluxo de caixa operacional no ano $t$ calculado como o lucro líquido antes dos itens extraordinários (LLO) menos total dos accruals (TA), onde:

$\mathrm{TA}=\Delta \mathrm{AC}_{\mathrm{i}, \mathrm{t}}-\Delta \mathrm{PC}_{\mathrm{i}, \mathrm{t}}-\Delta$ caixa $_{\mathrm{i}, \mathrm{t}}+\Delta \mathrm{FINCP}_{\mathrm{i}, \mathrm{t}}-\mathrm{DEPAM}_{\mathrm{i}, \mathrm{t}}$;

$\Delta \mathrm{AC}_{\mathrm{i}, \mathrm{t}}=$ variação no ativo circulante da firma $i$ entre o ano $t-1$ e o ano $t$; $\Delta \mathrm{PC}_{\mathrm{i}, \mathrm{t}}=$ variação no passivo circulante da firma $i$ entre o ano $t-1$ e o ano $t$;

$\Delta$ Caixa $_{\mathrm{i}, \mathrm{t}}=$ variação no caixa e equivalentes de caixa da firma $i$ entre o ano $t-1$ e o ano $t$; $\Delta \mathrm{FINCP}_{\mathrm{i}, \mathrm{t}}=$ variação dos financiamentos de CP da firma $i$ entre o ano $t-1 \mathrm{e} \mathrm{o}$ ano $t$; DEPAM $_{\mathrm{i}, \mathrm{t}}=$ despesas de depreciação e amortização da firma $i$ no ano $t$;

As variáveis $\mathrm{ACT}_{\mathrm{i}, \mathrm{t}}, \mathrm{FCO}_{\mathrm{i}, \mathrm{t}-1}, \mathrm{FCO}_{\mathrm{i}, \mathrm{t}}$ e $\mathrm{FCO}_{\mathrm{i}, \mathrm{t}+1}$ são escaladas pelos ativos totais.

Depois de estimar a Equação (1) para cada empresa $i$, utilizou-se, como medida de qualidade dos accruals, o desvio padrão dos resíduos: $\mathrm{QA}_{\mathrm{i}}=\sigma\left(\varepsilon_{\mathrm{it}}\right)$. Valores mais elevados de QA indicam accruals de menor qualidade, pois menor variação nos accruals correntes é explicada pelos fluxos de caixa operacionais realizados (FRANCIS et al., 2004). Accruals de menor qualidade implicam um nível de lucros de menor qualidade (GAIO, 2010).

Para computar a persistência dos lucros foi utilizada para cada empresa o modelo proposto por Francis et al. (2004):

$\mathrm{X}_{\mathrm{i}, \mathrm{t}}=\phi_{0, \mathrm{i}}+\phi_{1, \mathrm{i}} \mathrm{X}_{\mathrm{i}, \mathrm{t}-1}+\varepsilon_{\mathrm{i}, \mathrm{t}}$

(Equação 2) 
Em que:

$\mathrm{X}_{\mathrm{i}, \mathrm{t}}=$ lucro líquido antes dos itens extraordinários da firma $i$ no ano $t$ dividido pela média ponderada do número de ações em circulação durante o ano $t$.

$\mathrm{X}_{\mathrm{i}, \mathrm{t}-1}=$ lucro líquido antes dos itens extraordinários da firma $i$ no ano $t$ dividido pela média ponderada do número de ações em circulação durante o ano $t-1$.

Depois de estimar a Equação (2) para cada empresa $i$, a medida de persistência dos lucros é o coeficiente de inclinação estimado da regressão: PERS $=\phi_{1 \mathrm{i}}$. Os valores de $\phi_{1, \mathrm{i}}$ próximos de 1 implicam lucros altamente persistentes, enquanto que os valores de $\phi_{1, \mathrm{i}}$ perto de 0 implicam lucros altamente transitórios (FRANCIS et al., 2004). Lucros persistentes são vistos como lucros de qualidade mais elevada porque são mais sustentáveis (GAIO, 2010).

A medida da previsibilidade dos lucros utilizada nessa pesquisa considera o desvio padrão dos resíduos (PREV $=\varepsilon_{\mathrm{it}}$ ), a partir da aplicação da Equação (2) para cada empresa (FRANCIS et al., 2004; YOON, 2007). Valores menores de resíduos $\left(\varepsilon_{\mathrm{i}, t}\right)$ implicam lucros de qualidade mais elevada e mais previsíveis, enquanto valores maiores implicam resultados menos previsíveis.

Para o cálculo da suavização, utilizou-se o modelo proposto por Leuz, Nanda e Wysocki (2003):

$\mathrm{SUAV}=\sigma\left(\right.$ lucro operacional $\left._{\mathrm{it}}\right) / \sigma\left(\right.$ fluxo de caixa operacional $\left._{i t}\right)$

(Equação 3).

Em que:

$\mathrm{FCO}=$ Lucro Líquido - Accruals

Accruals $=\left\{\left[\mathrm{Ac}_{\mathrm{t}}-\mathrm{Disp}_{\mathrm{t}}\right)-\left(\mathrm{PC}_{\mathrm{t}}-\mathrm{EmpCP}_{\mathrm{t}}\right)\right]-\left[\left(\mathrm{Ac}_{\mathrm{t}-1}-\mathrm{Disp}_{\mathrm{t}-1}\right)-\left(\mathrm{PC}_{\mathrm{t}-1}-\mathrm{EmpCP}_{\mathrm{t}-1}\right)\right]-$ DeprAmort $\left.{ }_{t}\right\}$

$\mathrm{AC}_{\mathrm{t}}=$ Ativo circulante no ano $\mathrm{t}$; Disp $\mathrm{t}_{\mathrm{t}}=$ Disponibilidades no ano $\mathrm{t} ; \mathrm{PC}_{\mathrm{t}}=$ Passivo circulante no ano $t ; \mathrm{EmpCP}_{\mathrm{t}}=$ Empréstimos de curto prazo em $\mathrm{t} ; \mathrm{AC}_{\mathrm{t}-1}=$ Ativo circulante no ano $\mathrm{t}-1$; Disp $_{\mathrm{t}-1}=$ Disponibilidades no ano $\mathrm{t}-1 ; \mathrm{PC}_{\mathrm{t}-1}=$ Passivo circulante no ano $\mathrm{t}-1 ; \mathrm{EmpCP}_{\mathrm{t}-1}=$ Empréstimos de curto prazo em t-1. As variáveis de lucro operacional e fluxo de caixa foram divididas pelos ativos totais do início do ano.

A medida de suavização (SUAV) indica que valores abaixo de 1 correspondem a maior variabilidade no fluxo de caixa operacional em relação aos lucros, implicando o uso de accruals para suavizar os resultados contábeis. Valores mais elevados dessa variável indicam lucros menos suavizados (GAIO, 2010). Para os propósitos deste estudo, é assumido que a suavização é um atributo desejado dos lucros e, assim, menor suavização dos lucros implica menor qualidade dos lucros (GAIO, 2010).

Após o cálculo de cada atributo individualmente, utilizou-se a análise multicritério Technique for Order Preference by Smilarity to Ideal Solution - TOPSIS (BULGURCU, 2012), com uso da técnica da entropia (ZELENY, 1982) para definição do peso de cada vetor, para construir o ranking agregado da qualidade da informação contábil, resultando em escores individuais entre 0 e 1 . O TOPSIS é baseado no ranking de alternativas para obter a melhor seleção alternativa, a qual está próxima da solução ideal, levando em consideração a distância

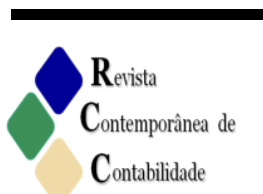

ISSN 2175-8069, UFSC, Florianópolis, v. 13, n. 29, p. 03-32, mai. /ago. 2016 
da solução ideal e da solução anti-ideal (BULGURCU, 2012). De acordo com essa técnica, a melhor alternativa deveria ser aquela que está mais próxima da solução ideal e o mais distante da solução ideal negativa (BENITEZ; MARTIN; ROMAN, 2007).

Para a definição do peso de cada atributo no ranking da qualidade da informação contábil, utilizou-se o conceito da entropia associado ao método TOPSIS. A entropia refere-se à incerteza probabilística relacionada a uma distribuição de probabilidade, de modo que quanto mais dispersa a distribuição de probabilidade, maior incerteza refletirá. Nesse sentido, o grau de incerteza é reflexo de uma determinada distribuição, e distintas distribuições estão associadas a distintos graus de improbabilidade (MATTOS; VEIGA, 2002).

O ranking da qualidade dos lucros por empresa foi elaborado com base nos valores de cada uma das quatro variáveis individuais baseadas nos atributos de contabilidade. Com o uso da metodologia TOPSIS, os vetores (pesos) obtidos por meio da técnica da entropia foram: $\mathrm{QA}=0,0480 ; \mathrm{PERS}=0,3183 ; \mathrm{PREV}=0,0212 ; \mathrm{SUAV}=0,6125$.

Quanto menor a entropia no conjunto de dados, maior o peso do atributo. Assim, os atributos de SUAV e PERS demonstraram menor entropia e maior peso, evidenciando que a suavização dos lucros e a persistência, comparados com os demais indicadores, causaram o maior efeito surpresa ao apresentar maior diversidade de informação entre as empresas investigadas. As variáveis explicativas utilizadas são aquelas apresentadas na Tabela 1.

Tabela 1 - Variáveis Explicativas

\begin{tabular}{|c|c|c|}
\hline Variáveis Explicativas & Métrica & Fonte \\
\hline Origem Legal & $\begin{array}{l}\text { ORIGEM = variável dummy, sendo } 1 \text { para o país com sistema } \\
\text { common law e } 0 \text { para code law. }\end{array}$ & $\begin{array}{l}\text { Bushman e } \\
\text { Piotroski (2006) }\end{array}$ \\
\hline Carga Tributária & $\begin{array}{l}\text { CTRIB = Escala de } 0 \text { (alta) a } 10 \text { (baixa) para taxa de imposto } \\
\text { marginal; }\end{array}$ & $\begin{array}{l}\text { Economic Freedom } \\
\text { of the World (2013) }\end{array}$ \\
\hline Ambiente Legal & $\begin{array}{l}\text { AMBIENTE = Escala de } 1 \text { a } 7 \text {, sendo } 1 \text { para ambiente pouco } \\
\text { desenvolvido e } 7 \text { para ambiente altamente desenvolvido. }\end{array}$ & $\begin{array}{l}\text { World Economic } \\
\text { Forum (2013) }\end{array}$ \\
\hline $\begin{array}{l}\text { Alavancagem } \\
\text { Financeira }\end{array}$ & $A L A V=\frac{\text { Passivo Circulante }+ \text { Passivo Näo Circulante }}{\text { Ativo total }}$ & $\begin{array}{l}\text { Isidro e Raonic } \\
(2012)\end{array}$ \\
\hline Retorno Sobre Ativos & ROA $=\frac{\text { Lucro Antes dos Juros e dos Impostos }}{\text { Ativo total }}$ & Iatridis (2010) \\
\hline $\begin{array}{l}\text { Índice de Percepção } \\
\text { da Corrupção }\end{array}$ & $\begin{array}{l}\text { IPC }=\text { Escala de } 0 \text { a } 10, \text { sendo } 0 \text { para países altamente } \\
\text { corruptos e } 10 \text { para altamente transparentes. }\end{array}$ & $\begin{array}{l}\text { Transparency } \\
\text { International (2012) }\end{array}$ \\
\hline $\begin{array}{l}\text { Desenvolvimento } \\
\text { Econômico }\end{array}$ & $\mathrm{NDE}=$ Logaritmo natural do produto interno bruto per capita & $\begin{array}{l}\text { The World Bank } \\
\text { (2014) }\end{array}$ \\
\hline $\begin{array}{l}\text { Desenvolvimento do } \\
\text { Mercado Financeiro }\end{array}$ & $\begin{array}{l}\text { NDF = Capitalização no mercado de ações dividido pelo } \\
\text { produto interno bruto. }\end{array}$ & $\begin{array}{l}\text { The World Bank } \\
\text { (2014) }\end{array}$ \\
\hline $\begin{array}{c}\text { Grau de } \\
\text { Internacionalização }\end{array}$ & $\begin{array}{l}\text { Ranking da relação: } \\
\text { G_INTER }=\left(\frac{\text { Vendas Exterior }}{\text { Vendas Totais }}+\frac{\text { Ativos no Exterior }}{\text { Ativos Totais }}\right) / 2\end{array}$ & UNCTAD (1995). \\
\hline
\end{tabular}

Fonte: Dados da pesquisa.

As variáveis de controle utilizadas são aquelas apresentadas na Tabela 2.

13 ISSN 2175-8069, UFSC, Florianópolis, v. 13, n. 29, p. 03-32, mai./ago. 2016 
Tabela 2 - Variáveis de Controle

\begin{tabular}{|c|c|c|}
\hline Variáveis de controle & Métrica & Fonte \\
\hline Tamanho & $\begin{array}{l}\text { TAM = Logaritmo natural do valor contábil do ativo total no } \\
\text { final do período. }\end{array}$ & Gaio (2010) \\
\hline $\begin{array}{l}\text { Crescimento das } \\
\text { vendas }\end{array}$ & $\begin{array}{l}\text { Logaritmo natural da relação: } \\
C V E N D=\left(\frac{\text { Vendas ano } 2-\text { Vendas ano } 1}{\text { Vendas ano } 1} \times 100\right)\end{array}$ & Gaio (2010) \\
\hline Setor econômico & $\begin{array}{l}\text { Variáveis dummies indicando o setor econômico de cada } \\
\text { empresa. }\end{array}$ & $\begin{array}{l}\text { Ball e Shivakumar } \\
(2005)\end{array}$ \\
\hline Empresa de auditoria & $\begin{array}{l}\text { AUDITORIA = variável } d u m m y \text {, sendo } 1 \text { para empresa } \\
\text { auditada por big four e } 0 \text { para as demais; }\end{array}$ & Barth et al. (2008) \\
\hline $\begin{array}{l}\text { Volatilidade do fluxo } \\
\text { de caixa }\end{array}$ & DPFCO $=\left(\frac{\text { Desvio padräo do FCO }}{\text { Ativo total }}\right)$ & Gaio (2010) \\
\hline
\end{tabular}

Fonte: Dados da pesquisa.

A variável AMBIENTE foi construída com base na média linear dos indicadores de aplicação das leis para valores mobiliários, proteção dos interesses de acionistas minoritários, aplicação das normas de contabilidade e auditoria, independência judicial, publicados pelo World Economic Forum (2013). Variáveis dummies também foram utilizadas para considerar a presença de empresas pertencentes aos diferentes setores econômicos (indústria, comércio, serviços).

O modelo econométrico, utilizado para verificar a influência das normas reguladoras e dos incentivos empresariais com a segregação das empresas em diferentes níveis de ambiente legal, é aquele explicitado na Equação (4). Na Equação (5), ocorre a inclusão da variável de internacionalização das empresas.

$$
\begin{aligned}
& \text { QIC }_{i}=\alpha_{0}+\alpha_{1} \text { CTRIB }_{j}+\alpha_{2} \text { ALAV }_{i}+\alpha_{3} \text { ROA }_{i}+\alpha_{4} \text { NDE }_{j}+\alpha_{5} \text { TAM }_{i}+\alpha_{6} \text { CVEND }_{i}+\alpha_{7} \text { IND }_{i}+ \\
& \alpha_{8} \text { COM }_{i}+\alpha_{9} \text { AUDITORIA }_{i}+\alpha_{10} \text { DPFCO }_{i}+\varepsilon_{i}
\end{aligned}
$$

(Equação 4).

$$
\begin{aligned}
& \text { QIC }_{i}=\alpha_{0}+\alpha_{1} \text { CTRIB }_{j}+\alpha_{2} \text { ALAV }_{i}+\alpha_{3} \text { ROA }_{i}+\alpha_{4} \text { NDE }_{j}+\alpha_{5} \text { TAM }_{i}+\alpha_{6} \text { CVEND }_{i}+\alpha_{7} \text { IND }_{i}+ \\
& \alpha_{8} \text { COM }_{i}+\alpha_{9} \text { AUDITORIA }_{i}+\alpha_{10} \text { DPFCO }_{i}+\alpha_{11} \text { G_INTER }_{\mathbf{i}}+\varepsilon_{\mathrm{i}}
\end{aligned}
$$

(Equação 5).

$\mathrm{Na}$ Equação (6), é apresentado o modelo econométrico que analisa a influência das normas reguladoras e dos incentivos empresariais com a segregação das empresas em diferentes níveis de percepção de corrupção do país de origem das empresas. Na Equação (7), ocorre a inclusão da variável de internacionalização das empresas.

$\mathrm{QIC}_{\mathrm{i}}=\alpha_{0}+\alpha_{1} \mathrm{AMBIENTE}_{\mathrm{i}}+\alpha_{2} \mathrm{ALAV}_{\mathrm{i}}+\alpha_{3} \mathrm{ROA}_{\mathrm{i}}+\alpha_{4} \mathrm{NDF}_{\mathrm{j}}+\alpha_{5} \mathrm{TAM}_{\mathrm{i}}+\alpha_{6} \mathrm{CVEND}_{\mathrm{i}}+\alpha_{7} \mathrm{IND}_{\mathrm{i}}+$ $\alpha_{8} \mathrm{COM}_{\mathrm{i}}+\alpha_{9}$ AUDITORIA $_{\mathrm{i}}+\alpha_{10}$ DPFCO $_{\mathrm{i}}+\varepsilon_{\mathrm{i}}$

(Equação 6). 
$\mathrm{QIC}_{\mathrm{i}}=\alpha_{0}+\alpha_{1}$ AMBIENTE $_{\mathrm{i}}+\alpha_{2} \mathrm{ALAV}_{\mathrm{i}}+\alpha_{3} \mathrm{ROA}_{\mathrm{i}}+\alpha_{4} \mathrm{NDF}_{\mathrm{j}}+\alpha_{5} \mathrm{TAM}_{\mathrm{i}}+\alpha_{6} \mathrm{CVEND}_{\mathrm{i}}+\alpha_{7} \mathrm{IND}_{\mathrm{i}}+$ $\alpha_{8}$ COM $_{\mathrm{i}}+\alpha_{9}$ AUDITORIA $_{\mathrm{i}}+\alpha_{10}$ DPFCO $_{\mathrm{i}}+\alpha_{11} \mathrm{G}_{-}$INTER $_{\mathrm{i}}+\varepsilon_{\mathrm{i}}$

(Equação 7).

Na Equação (8), tem-se o modelo que analisa a influência das normas reguladoras e incentivos empresariais, com a segregação pela origem legal dos países de origem das empresas. Na Equação (9), ocorre a inclusão da variável de internacionalização das empresas.

$\mathrm{QIC}_{\mathrm{i}}=\alpha_{0}+\alpha_{1} \mathrm{AMBIENTE}_{\mathrm{i}}+\alpha_{2} \mathrm{CTRIB}_{\mathrm{i}}+\alpha_{3} \mathrm{ALAV}_{\mathrm{i}}+\alpha_{4} \mathrm{ROA}_{\mathrm{i}}+\alpha_{5} \mathrm{NDE}_{\mathrm{j}}+\alpha_{6} \mathrm{TAM}_{\mathrm{i}}+$ $\alpha_{7}$ CVEND $_{i}+\alpha_{8}$ IND $_{i}+\alpha_{9}$ COM $_{i}+\alpha_{10}$ AUDITORIA $_{i}+\alpha_{11}$ DPFCO $_{i}+\varepsilon_{i}$

(Equação 8).

$\mathrm{QIC}_{\mathrm{i}}=\alpha_{0}+\alpha_{1}$ AMBIENTE $_{\mathrm{i}}+\alpha_{2}$ CTRIB $_{\mathrm{i}}+\alpha_{3} \mathrm{ALAV}_{\mathrm{i}}+\alpha_{4} \mathrm{ROA}_{\mathrm{i}}+\alpha_{5} \mathrm{NDE}_{\mathrm{j}}+\alpha_{6} \mathrm{TAM}_{\mathrm{i}}+\alpha_{7} \mathrm{CVEND}_{\mathrm{i}}+$ $\alpha_{8}$ IND $_{\mathrm{i}}+\alpha_{9} \mathrm{COM}_{\mathrm{i}}+\alpha_{10}$ AUDITORIA $_{\mathrm{i}}+\alpha_{11}$ DPFCO $_{\mathrm{i}}+\alpha_{12} \mathrm{G}_{-}$INTER $_{1}+\varepsilon_{\mathrm{i}}$

(Equação 9).

A Equação (10) apresenta a especificação do modelo da relação entre a QIC, normas reguladoras e os incentivos empresariais. Na Equação (11), ocorre a inclusão da variável de internacionalização das empresas.

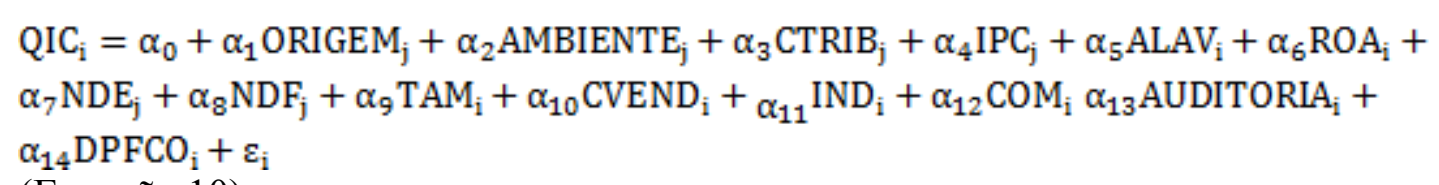

(Equação 10).

QIC $_{i}=\alpha_{0}+\alpha_{1}$ ORIGEM $_{j}+\alpha_{2}$ AMBIENTE $_{j}+\alpha_{3}$ CTRIB $_{j}+\alpha_{4}$ IPC $_{j}+\alpha_{5}$ ALAV $_{i}+\alpha_{6}$ ROA $_{i}+$ $\alpha_{7} \mathrm{NDE}_{\mathrm{j}}+\alpha_{8} \mathrm{NDF}_{\mathrm{j}}+\alpha_{9} \mathrm{TAM}_{\mathrm{i}}+\alpha_{10} \mathrm{CVEND}_{\mathrm{i}}+\alpha_{11} \mathrm{IND}_{\mathrm{i}}+\alpha_{12} \mathrm{COM}_{\mathrm{i}}+\alpha_{13}$ AUDITORIA $_{\mathrm{i}}+$ $\alpha_{14}$ DPFCO $_{i}+\alpha_{15} \mathbf{G}_{-} I N T E R_{i}+\varepsilon_{i}$

(Equação 11).

Para a análise dos resultados foi utilizada a regressão linear multivariada com análise cross-section (transversal). Os modelos econométricos utilizados atenderam aos pressupostos da homoscedasticidade, multicolinearidade e autocorrelação de resíduos. O pressuposto da normalidade ficou abaixo da $\alpha, 5 \%$ em algumas estimativas, porém, considerando o tamanho da amostra, esse pressuposto pode ser relaxado (STEVENSON, 2001).

\section{Análise e Interpretação dos Resultados}

Essa seção contém a descrição e análise dos dados coletados. Inicialmente apresentase o teste de médias para verificar a existência de diferenças na qualidade da informação contábil com base em diferentes contextos. Em seguida, apresentam-se os resultados da aplicação dos modelos econométricos. 


\subsection{Teste de Médias}

O cálculo do Teste t de Student a partir de amostras independentes (não evidenciado) foi elaborado para verificar a existência de diferenças nas médias da qualidade da informação contábil entre os grupos. Para agrupar as empresas, foi utilizado, como critério, a mediana de cada variável, em que o grupo 1 contém as empresas com escores abaixo da mediana, e o grupo 2, as empresas com escore igual ou superior à mediana. Também foram agrupadas as empresas localizadas em países de origem common law (grupo 1) e code law (grupo 2).

Os resultados indicaram que as empresas localizadas em países com carga tributária menor, ambiente legal mais forte, maior desenvolvimento econômico, maior desenvolvimento do mercado financeiro e de origem legal common law apresentaram médias mais elevadas no ranking agregado da QIC. Por outro lado, empresas localizadas em países com menor transparência, apresentaram melhores escores no ranking de QIC. As empresas com maior grau de internacionalização apresentaram níveis mais elevados no ranking da QIC.

Ao se aplicar o teste de Levene e o teste $t$ de igualdade de médias, verificou-se que as características dos países de origem, a exemplo da carga tributária, do ambiente legal, do nível de desenvolvimento econômico e do mercado financeiro, da origem legal e do nível de transparência, conduziram para diferenças estatisticamente significativas entre as empresas no ranking da QIC reportada. Além disso, observa-se que o maior grau de internacionalização das empresas também se constitui em determinante significativa a ser considerada para explicar o posicionamento no ranking da QIC.

\subsection{Ambiente Legal}

Para investigar o comportamento dos resultados em diferentes níveis de ambiente legal, a amostra foi separada em dois grupos, a partir da mediana da variável AMBIENTE $(5,35)$. A Tabela 3 apresenta os resultados para as empresas dos países com nível abaixo da mediana, e a Tabela 4 contempla as empresas localizadas em países com nível igual ou acima da mediana da variável representativa do ambiente legal. Para a coluna (1) das Tabelas 3 e 4, o modelo utilizado é aquele apresentado na Equação (4), e para a coluna (2) a Equação (5).

A Tabela 3 apresenta os resultados da amostra que inclui 446 empresas localizadas no Brasil, na China, na Indonésia e no Japão. Os resultados da Tabela 3 indicam que os modelos utilizados na coluna (1) e na coluna (2) apresentaram relação estatisticamente significativa com a variável dependente ao nível de $5 \%$ e $1 \%$, respectivamente (estatística $\mathrm{F}$ ).

Os resultados da coluna (1) indicaram que a variável ALAV apresentou relação negativa e significativa, e a variável IND demonstrou-se positiva e significativa com o ranking da QIC, ambas a 5\% e com sinal igual ao esperado. A coluna (2) indica que as variáveis ALAV e DPFCO apresentaram relação negativa e significativa com o ranking da QIC, a $10 \%$ e $5 \%$, conforme o esperado.

A variável G_INTER apresentou resultados estatisticamente significativos com a variável dependente ao nível de $1 \%$, reforçando a importância relativa da internacionalização das empresas para explicar o posicionamento no ranking da QIC. 
Determinantes da qualidade da informação contábil no contexto internacional.

Tabela 3 - Determinantes do ranking agregado QIC: ambiente legal < da mediana

\begin{tabular}{|c|c|c|c|c|}
\hline \multicolumn{5}{|c|}{ Variável dependente: Qualidade da Informação Contábil (QIC) } \\
\hline \multirow[b]{2}{*}{ Variáveis explicativas } & \multicolumn{2}{|c|}{ (1) NORMAS E INCENTIVOS } & \multicolumn{2}{|c|}{ (2) NORMAS E INCENTIVOS + G INTER } \\
\hline & Coeficiente B & Estatística $t$ & Coeficiente B & Estatística $t$ \\
\hline Constante & $-1,244$ & $-0,418$ & $-0,686$ & $-0,239$ \\
\hline CTRIB & 0,133 & 0,487 & 0,184 & 0,698 \\
\hline ALAV & $-0,120$ & $-2,282 * *$ & $-0,097$ & $-1,907 *$ \\
\hline ROA & $-0,125$ & $-1,042$ & $-0,154$ & $-1,329$ \\
\hline NDE & $-0,013$ & $-0,035$ & $-0,129$ & $-0,361$ \\
\hline TAM & 0,049 & 1,099 & 0,046 & 1,071 \\
\hline CVEND & $-0,050$ & $-0,653$ & $-0,019$ & $-0,260$ \\
\hline IND & 0,271 & $2,180 * *$ & 0,009 & 0,074 \\
\hline $\mathrm{COM}$ & $-0,016$ & $-0,115$ & $-0,060$ & $-0,436$ \\
\hline AUDITORIA & 0,126 & 1,103 & 0,131 & 1,187 \\
\hline DPFCO & $-0,002$ & $-0,029$ & $-0,142$ & $-2,178 * *$ \\
\hline G_INTER & & & 0,404 & $5,840 * * *$ \\
\hline Estatística F & \multicolumn{2}{|c|}{$1,967 * *$} & \multicolumn{2}{|l|}{$5,024 * * *$} \\
\hline $\mathrm{R}^{2}$ ajustado & \multicolumn{2}{|c|}{0,021} & \multicolumn{2}{|l|}{0,090} \\
\hline Tolerance & \multicolumn{2}{|c|}{1 até 0,10} & \multicolumn{2}{|l|}{1 até 0,10} \\
\hline VIF & \multicolumn{2}{|c|}{1 até 10} & \multicolumn{2}{|l|}{1 até 10} \\
\hline DW & \multicolumn{2}{|c|}{2,266} & \multicolumn{2}{|l|}{2,303} \\
\hline K-S (sig.) & \multicolumn{2}{|c|}{0,111} & \multicolumn{2}{|l|}{0,058} \\
\hline Pesarán-Pesarán (sig.) & \multicolumn{2}{|c|}{0,434} & \multicolumn{2}{|l|}{0,141} \\
\hline $\mathrm{N}$ & \multicolumn{2}{|c|}{446} & \multicolumn{2}{|l|}{446} \\
\hline
\end{tabular}

Fonte: Dados da pesquisa.

A Tabela 4 apresenta os resultados da amostra que inclui 960 empresas localizadas na Alemanha, na Austrália, no Canadá, nos Estados Unidos, na Índia, na Holanda, no Reino Unido e na Suíça. Os resultados da Tabela 4 indicam que os modelos utilizados na coluna (1) e na coluna (2) apresentaram relação estatisticamente significativa com a variável dependente ao nível de $1 \%$ (estatística $\mathrm{F}$ ).

Tabela 4 - Determinantes do ranking agregado da QIC: ambiente legal $\geq$ da mediana

\begin{tabular}{|c|c|c|c|c|}
\hline \multicolumn{5}{|c|}{ Variável dependente: Qualidade da Informação Contábil (QIC) } \\
\hline \multirow[b]{2}{*}{ Variáveis explicativas } & \multicolumn{2}{|c|}{ (1) NORMAS E INCENTIVOS } & \multicolumn{2}{|c|}{ (2) NORMAS E INCENTIVOS + GI } \\
\hline & Coeficiente B & Estatística $t$ & Coeficiente B & Estatística $t$ \\
\hline Constante & $-1,749$ & $-4,647$ & $-1,746$ & $-4,647$ \\
\hline CTRIB & 0,021 & 0,942 & 0,042 & $1,706^{*}$ \\
\hline ALAV & $-0,157$ & $-4,112 * * *$ & $-0,148$ & $-3,882 * * *$ \\
\hline ROA & 0,013 & 0,268 & 0,012 & 0,257 \\
\hline NDE & 0,291 & $3,830 * * *$ & 0,267 & $3,484 * * *$ \\
\hline TAM & $-0,102$ & $-3,414 * * *$ & $-0,104$ & $-3,476 * * *$ \\
\hline CVEND & 0,021 & 0,621 & 0,021 & 0,616 \\
\hline IND & 0,456 & $6,208 * * *$ & 0,412 & $5,428 * * *$ \\
\hline $\mathrm{COM}$ & 0,296 & $3,336 * * *$ & 0,275 & $3,083 * * *$ \\
\hline
\end{tabular}




\begin{tabular}{|c|c|c|c|c|}
\hline AUDITORIA & 0,106 & 1,147 & 0,093 & 1,000 \\
\hline DPFCO & $-0,021$ & $-0,603$ & $-0,043$ & $-1,177$ \\
\hline G_INTER & & & 0,074 & $2,153^{* *}$ \\
\hline Estatística F & \multicolumn{2}{|c|}{$11,777 * * *$} & \multicolumn{2}{|c|}{$\frac{1}{11,169^{* * *}}$} \\
\hline $\mathrm{R}^{2}$ ajustado & \multicolumn{2}{|c|}{0,101} & \multicolumn{2}{|c|}{0,104} \\
\hline Tolerance & \multicolumn{2}{|c|}{1 até 0,10} & \multicolumn{2}{|c|}{1 até 0,10} \\
\hline VIF & \multicolumn{2}{|c|}{1 até 10} & \multicolumn{2}{|c|}{1 até 10} \\
\hline DW & \multicolumn{2}{|c|}{1,945} & \multicolumn{2}{|c|}{1,944} \\
\hline K-S (sig.) & \multicolumn{2}{|c|}{0,499} & \multicolumn{2}{|c|}{0,462} \\
\hline Pesarán-Pesarán (sig.) & \multicolumn{2}{|c|}{0,300} & \multicolumn{2}{|c|}{0,365} \\
\hline $\mathrm{N}$ & \multicolumn{2}{|c|}{960} & \multicolumn{2}{|c|}{960} \\
\hline \multicolumn{5}{|c|}{ Significativo ao nível de $10 \% * ; 5 \% * * ; 1 \%^{* * *}$} \\
\hline
\end{tabular}

Os resultados da coluna (1) e da coluna (2) indicaram que as variáveis ALAV e TAM apresentaram relações negativas e significativas com a QIC, ao nível de $1 \%$. Já as variáveis NDE, IND e COM corroboram as predições empíricas e manifestaram-se positivamente relacionadas de forma significativa a $1 \%$ com a variável dependente.

A variável G_INTER apresentou resultados estatisticamente significativos com a variável dependente ao nível de 5\%. Assim, uma vez mais se constata a importância relativa da intensidade da internacionalização das empresas para explicar o posicionamento no ranking da QIC. As variáveis de retorno sobre ativos (ROA) e crescimento de vendas (CVEND), não se constituíram em fator explicativo para o posicionamento das empresas no ranking agregado da QIC, tanto em ambientes legais mais fracos (Tabela 3), quanto em ambientes legais mais robustos (Tabela 4).

Conforme o esperado, o poder explicativo das abordagens com empresas localizadas nos países com ambiente legal mais robusto (Tabela 4) se mostrou mais elevado que o daquelas empresas localizadas em países com ambiente legal mais fraco (Tabela 3). Uma possível explicação para os resultados é que, em países com ambiente legal mais robusto, as instituições possuem estruturas mais condizentes para realizar o escrutínio público, tornando mais oneroso para as empresas divulgar números contábeis que não estão atrelados à sua realidade econômica e financeira.

\section{3 Índice de Percepção da Corrupção}

Nessa análise, a amostra foi separada em dois grupos com base na mediana da variável IPC $(7,30)$, com o intuito de investigar os resultados em ambientes com diferentes níveis de percepção da corrupção. A Tabela 5 apresenta os resultados para os países com nível abaixo da mediana, enquanto a Tabela 6 evidencia as empresas localizadas em países com nível igual ou acima da mediana do nível de percepção da corrupção. Para a coluna (1) das Tabelas 5 e 6 , o modelo utilizado é aquele apresentado na Equação (6), enquanto para a coluna (2) foi utilizado o modelo da Equação (7).

A Tabela 5 apresenta os resultados da amostra que inclui 661 empresas do Brasil, dos Estados Unidos, da Índia e da Indonésia. Os resultados da Tabela 5 indicam que os modelos utilizados na coluna (1) e na coluna (2) apresentaram relação estatisticamente significativa com a variável dependente ao nível de $1 \%$ (estatística $\mathrm{F}$ ).

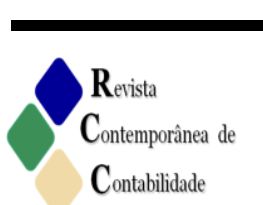

ISSN 2175-8069, UFSC, Florianópolis, v. 13, n. 29, p. 03-32, mai. /ago. 2016 
Determinantes da qualidade da informação contábil no contexto internacional.

Tabela 5 - Determinantes do ranking agregado da QIC: IPC < da mediana

\begin{tabular}{|c|c|c|c|c|}
\hline \multicolumn{5}{|c|}{ Variável dependente: Qualidade da Informação Contábil (QIC) } \\
\hline \multirow[b]{2}{*}{ Variáveis explicativas } & \multicolumn{2}{|c|}{ (1) NORMAS E INCENTIVOS } & \multicolumn{2}{|c|}{ (2) NORMAS, INCENTIVOS + G_INTER } \\
\hline & Coeficiente B & Estatística $t$ & Coeficiente B & Estatística $t$ \\
\hline Constante & 0,031 & 0,025 & 0,286 & 0,237 \\
\hline AMBIENTE & $-0,269$ & $-1,081$ & $-0,282$ & $-1,139$ \\
\hline ALAV & $-0,160$ & $-3,560 * * *$ & $-0,148$ & $-3,290 * * *$ \\
\hline ROA & 0,021 & 0,369 & 0,022 & 0,380 \\
\hline NDF & 0,010 & $3,908 * * *$ & 0,009 & $3,468 * * *$ \\
\hline TAM & $-0,131$ & $-3,648 * * *$ & $-0,130$ & $-3,644 * * *$ \\
\hline CVEND & $-0,004$ & $-0,087$ & $-0,003$ & $-0,075$ \\
\hline IND & 0,480 & $5,365 * * *$ & 0,420 & $4,523 * * *$ \\
\hline $\mathrm{COM}$ & 0,246 & $2,305^{* *}$ & 0,211 & $1,969 * *$ \\
\hline AUDITORIA & 0,170 & 1,588 & 0,154 & 1,434 \\
\hline DPFCO & $-0,010$ & $-0,223$ & $-0,038$ & $-0,853$ \\
\hline G_INTER & & & 0,114 & $2,349 * *$ \\
\hline Estatística F & \multicolumn{2}{|c|}{$10,512 * * *$} & \multicolumn{2}{|c|}{$10,124 * * *$} \\
\hline $\mathrm{R}^{2}$ ajustado & \multicolumn{2}{|c|}{0,126} & \multicolumn{2}{|c|}{0,132} \\
\hline Tolerance & \multicolumn{2}{|c|}{1 até 0,10} & \multicolumn{2}{|c|}{1 até 0,10} \\
\hline VIF & \multicolumn{2}{|c|}{1 até 10} & \multicolumn{2}{|c|}{1 até 10} \\
\hline DW & \multicolumn{2}{|c|}{1,991} & \multicolumn{2}{|c|}{1,996} \\
\hline K-S (sig.) & \multicolumn{2}{|c|}{0,634} & \multicolumn{2}{|l|}{0,485} \\
\hline Pesarán-Pesarán (sig.) & \multicolumn{2}{|c|}{0,287} & \multicolumn{2}{|c|}{0,325} \\
\hline $\mathrm{N}$ & \multicolumn{2}{|c|}{661} & \multicolumn{2}{|c|}{661} \\
\hline Significativo ao nível & $; 5 \% * * ; 1 \% * * *$ & & & \\
\hline
\end{tabular}

Fonte: Dados da pesquisa.

Os resultados da coluna (1) e (2) indicaram que as variáveis ALAV e TAM apresentaram, conforme o esperado, relações negativas e significativas ao nível de $1 \%$ com o ranking dos atributos da QIC. Também de acordo com as predições empíricas prévias, as variáveis NDF, IND e COM demonstraram-se positiva e estatisticamente significativas para explicar a QIC das empresas investigadas, todas a 5\% e com sinal igual ao esperado.

A variável G_INTER apresentou resultados estatisticamente significativos com a variável dependente ao nível de 5\%, reforçando sua importância em explicar o posicionamento das empresas no ranking da QIC.

A Tabela 6 evidencia os resultados da amostra que inclui 745 empresas localizadas na Alemanha, na Austrália, no Canadá, na China, na Holanda, no Japão, no Reino Unido e na Suíça. Os resultados dos modelos utilizados demonstram relação positiva e estatisticamente significativa com a variável dependente, ao nível de 1\% (estatística F). Os resultados apresentados para as variáveis ALAV, NDF e IND se comportaram de forma semelhante àqueles da Tabela 5 , indicando que servem de estímulos em ambos os ambientes de transparência institucional dos países.

Em ambientes mais transparentes (Tabela 6), a variável DPFCO mostrou-se negativa e estatisticamente significativa, conforme o esperado, somente no modelo que contém a variável de internacionalização das empresas (coluna 2). Uma explicação possível reside na 
predição empírica de que as empresas mais internacionalizadas possuem lucros e fluxos de caixa mais estáveis em relação às demais empresas.

Tabela 6 - Determinantes do ranking agregado da QIC: IPC $\geq$ da mediana

\begin{tabular}{|c|c|c|c|c|}
\hline \multicolumn{5}{|c|}{ Variável dependente: Qualidade da Informação Contábil (QIC) } \\
\hline \multirow[b]{2}{*}{ Variáveis explicativas } & \multicolumn{2}{|c|}{ (1) NORMAS E INCENTIVOS } & \multicolumn{2}{|c|}{ (2) NORMAS E INCENTIVOS + GI } \\
\hline & Coeficiente B & Estatística $t$ & Coeficiente B & Estatística $t$ \\
\hline Constante & $-2,455$ & $-5,293$ & $-1,237$ & $-2,393$ \\
\hline AMBIENTE & 0,333 & $3,653 * * *$ & 0,130 & 1,319 \\
\hline ALAV & $-0,121$ & $-2,922 * * *$ & $-0,112$ & $-2,751 * * *$ \\
\hline ROA & $-0,018$ & $-0,266$ & $-0,041$ & $-0,604$ \\
\hline NDF & 0,003 & $2,345^{* *}$ & 0,002 & $1,708^{*}$ \\
\hline TAM & 0,030 & 0,875 & 0,019 & 0,541 \\
\hline CVEND & 0,070 & 1,570 & 0,070 & 1,586 \\
\hline IND & 0,320 & $3,591 * * *$ & 0,208 & $2,298^{* *}$ \\
\hline $\mathrm{COM}$ & 0,124 & 1,169 & 0,100 & 0,956 \\
\hline AUDITORIA & $-0,009$ & $-0,091$ & $-0,001$ & $-0,011$ \\
\hline DPFCO & $-0,026$ & $-0,630$ & $-0,103$ & $-2,360 * *$ \\
\hline G_INTER & & & 0,202 & $5,022 * * *$ \\
\hline Estatística F & \multicolumn{2}{|c|}{$6,517 * * *$} & \multicolumn{2}{|c|}{$8,413^{* * *}$} \\
\hline $\mathrm{R}^{2}$ ajustado & \multicolumn{2}{|c|}{0,069} & \multicolumn{2}{|c|}{0,099} \\
\hline Tolerance & \multicolumn{2}{|c|}{1 até 0,10} & \multicolumn{2}{|c|}{1 até 0,10} \\
\hline VIF & \multicolumn{2}{|c|}{1 até 10} & \multicolumn{2}{|c|}{1 até 10} \\
\hline DW & \multicolumn{2}{|c|}{2,073} & \multicolumn{2}{|c|}{2,093} \\
\hline K-S (sig.) & \multicolumn{2}{|c|}{0,056} & \multicolumn{2}{|c|}{0,030} \\
\hline Pesarán-Pesarán (sig.) & \multicolumn{2}{|c|}{0,283} & \multicolumn{2}{|c|}{0,201} \\
\hline $\mathrm{N}$ & \multicolumn{2}{|c|}{745} & \multicolumn{2}{|c|}{745} \\
\hline Significativo ao nível d & $5 \%^{* *} ; 1 \%^{* * *}$. & & & \\
\hline
\end{tabular}

Repetindo os resultados da amostra com empresas localizadas em países de menor índice de transparência (Tabela 5), a variável G_INTER apresenta relação positiva e significativa com o ranking agregado da qualidade da informação contábil, conforme o esperado, ao nível de $1 \%$ (Tabela 6).

Conforme já apresentado no item 4.1, as empresas localizadas em países com maior nível de transparência, diferentemente do esperado, demonstraram níveis mais baixos no escore do ranking dos atributos de QIC. Os resultados da Tabela 6 (países mais transparentes) corroboram esses achados ao apresentar um poder explicativo menor que o do modelo da Tabela 5 (países menos transparentes). Uma possível explicação decorre da necessidade de as empresas localizadas em países menos transparentes evitarem possíveis problemas de agência e reduzirem litígios de risco moral e seleção adversa ao se tornarem mais internacionalizadas.

\subsection{Origem Legal}


Nessa análise, a amostra foi separada em dois grupos de acordo com a origem legal do país sede das empresas. A Tabela 7 apresenta os resultados para as empresas localizadas nos países com sistema jurídico code law. A amostra inclui 524 empresas sediadas na Alemanha, no Brasil, na China, na Holanda, na Indonésia, no Japão e na Suíça.

Tabela 7 - Determinantes do ranking agregado da QIC: code law

\begin{tabular}{|c|c|c|c|c|}
\hline \multicolumn{5}{|c|}{ Variável dependente: Qualidade da Informação Contábil (QIC) } \\
\hline \multirow[b]{2}{*}{ Variáveis explicativas } & \multicolumn{2}{|c|}{ (1) NORMAS E INCENTIVOS } & \multicolumn{2}{|c|}{ (2) NORMAS E INCENTIVOS + G INTER } \\
\hline & Coeficiente B & Estatística $t$ & Coeficiente B & Estatística $t$ \\
\hline Constante & $-0,988$ & $-1,237$ & 0,634 & 0,771 \\
\hline AMBIENTE & 0,339 & $2,286^{* *}$ & $-0,118$ & $-0,723$ \\
\hline CTRIB & 0,010 & 0,193 & 0,019 & 0,366 \\
\hline ALAV & $-0,132$ & $-2,623 * * *$ & $-0,116$ & $-2,391 * *$ \\
\hline $\mathrm{ROA}$ & 0,009 & 0,089 & $-0,035$ & $-0,358$ \\
\hline NDE & $-0,311$ & $-1,341$ & $-0,109$ & $-0,479$ \\
\hline TAM & 0,026 & 0,626 & 0,012 & 0,309 \\
\hline CVEND & $-0,015$ & $-0,219$ & 0,000 & 0,006 \\
\hline IND & 0,295 & $2,645 * * *$ & 0,064 & 0,561 \\
\hline $\mathrm{COM}$ & 0,005 & 0,041 & $-0,017$ & $-0,131$ \\
\hline AUDITORIA & 0,107 & 0,985 & 0,125 & 1,185 \\
\hline DPFCO & 0,044 & 0,812 & $-0,099$ & $-1,706^{*}$ \\
\hline G_INTER & & & 0,352 & $5,899 * * *$ \\
\hline Estatística F & \multicolumn{2}{|c|}{$2,891 * * *$} & \multicolumn{2}{|c|}{$5,725 * * *$} \\
\hline $\mathrm{R}^{2}$ ajustado & \multicolumn{2}{|c|}{0,038} & \multicolumn{2}{|c|}{0,098} \\
\hline Tolerance & \multicolumn{2}{|c|}{1 até 0,10} & \multicolumn{2}{|c|}{1 até 0.10} \\
\hline VIF & \multicolumn{2}{|c|}{1 até 10} & \multicolumn{2}{|c|}{1 até 10} \\
\hline DW & \multicolumn{2}{|c|}{2,183} & \multicolumn{2}{|c|}{2,207} \\
\hline K-S (sig.) & \multicolumn{2}{|c|}{0,047} & \multicolumn{2}{|c|}{0,014} \\
\hline Pesarán-Pesarán (sig.) & \multicolumn{2}{|c|}{0,328} & \multicolumn{2}{|c|}{0,848} \\
\hline $\mathrm{N}$ & \multicolumn{2}{|c|}{524} & \multicolumn{2}{|c|}{524} \\
\hline
\end{tabular}

Fonte: Dados da pesquisa.

A Tabela 8 apresenta os resultados da amostra que considera as empresas localizadas em países com tradição common law, incluindo 882 empresas com sede na Austrália, no Canadá, nos Estados Unidos, na Índia e no Reino Unido.

Tabela 8 - Determinantes do ranking agregado da QIC: common law

\begin{tabular}{l|r|r|r|r}
\hline \multicolumn{2}{l}{ Variável dependente: Qualidade da Informação Contábil (QIC) } \\
\hline \multirow{2}{*}{ Variáveis explicativas } & \multicolumn{1}{|c}{ (1) NORMAS E INCENTIVOS } & (2) NORMAS E INCENTIVOS + G INTER \\
\cline { 2 - 5 } & Coeficiente B & Estatística $t$ & Coeficiente B & Estatística $t$ \\
\hline Constante & $-2,649$ & $-1,443$ & $-2,532$ & $-1,383$ \\
AMBIENTE & 0,117 & 0,430 & 0,097 & 0,356 \\
CTRIB & 0,051 & 1,108 & 0,072 & 1,556 \\
ALAV & $-0,144$ & $-3,682^{* * *}$ & $-0,133$ & $-3,396^{* * *}$ \\
ROA & 0,010 & 0,207 & 0,011 & 0,225 \\
NDE & 0,305 & $3,936^{* * *}$ & 0,281 & $3,600^{* * *}$ \\
TAM & $-0,101$ & $-3,211^{* * *}$ & $-0,102$ & $-3,252^{* * *}$ \\
CVEND & 0,012 & 0,335 & 0,011 & 0,299 \\
IND & 0,463 & $6,048^{* * *}$ & 0,417 & $5,307^{* * *}$ \\
COM & 0,297 & $3,242^{* * *}$ & 0,270 & $2,934^{* * *}$ \\
AUDITORIA & 0,116 & 1,203 & 0,101 & 1,051 \\
DPFCO & $-0,037$ & $-1,006$ & $-0,062$ & $-1,631$ \\
& & & &
\end{tabular}

21 ISSN 2175-8069, UFSC, Florianópolis, v. 13, n. 29, p. 03-32, mai./ago. 2016 


\begin{tabular}{l|c|c} 
G_INTER & & 0,089 \\
\hline Estatística F & $9.920 * * *$ & $9,628 * * *$ \\
$\mathrm{R}^{2}$ ajustado & 0,100 & 0,105 \\
\hline Tolerance & 1 até 0.10 & 1 até 0.10 \\
VIF & 1 até 10 & 1 até 10 \\
DW & 1,961 & 1,966 \\
K-S (sig.) & 0,523 & 0,259 \\
Pesarán-Pesarán (sig.) & 0,340 & 0,417 \\
\hline N & 882 & 882 \\
\hline
\end{tabular}

Significativo ao nível de $10 \% * ; 5 \% * * ; 1 \%$ ***.

Fonte: Dados da pesquisa.

Para a coluna (1) das Tabelas 7 e 8, o modelo utilizado foi o da Equação (8), e para a coluna (2) utilizou-se a Equação (9). A coluna (1) das Tabelas 7 e 8 considera as variáveis de normas reguladoras, de incentivos e de controle conjuntamente, e a coluna (2) adiciona a variável de internacionalização, cujos modelos mostraram-se significativos para explicar a variável dependente ao nível de 1\% (estatística F), em ambas as projeções.

Nos países code law, as empresas menores, aquelas localizadas em países com ambiente legal mais robusto e do setor industrial, apresentaram escores mais elevados da qualidade da informação contábil. Ao se inserir a variável de grau de internacionalização (G_INTER), as empresas menos alavancadas e aquelas com menor volatilidade no fluxo de caixa indicaram níveis superiores de qualidade da informação contábil reportada (coluna 2). A inserção da variável G_INTER ampliou substancialmente o poder explicativo do modelo (coluna 2 em comparação com coluna 1) e confirmou a importância relativa da variável também na segregação da amostra pela origem legal dos países.

Nas duas configurações de análises com empresas localizadas em países common law, apresentadas na Tabela 8 , as empresas menores, menos alavancadas, localizadas em países com maior desenvolvimento econômico e pertencentes aos setores industrial e comercial, apresentaram escores mais elevados da qualidade da informação contábil.

Os resultados indicam que a variável G_INTER apresenta relação positiva e significativa com o ranking agregado da qualidade da informação contábil, ao nível de 5\% nos países common law, confirmando os resultados já encontrados nas demais projeções.

\subsection{Normas Reguladoras e Incentivos Empresariais}

Para a coluna (1) da Tabela 9, utilizou-se o modelo da Equação (10), enquanto na coluna (2) o modelo utilizado foi o da Equação (11).

Tabela 9 - Influência das normas reguladoras, incentivos e G_INTER no ranking agregado da QIC

\begin{tabular}{l|r|r|r|r}
\hline Variável dependente: Qualidade da Informação Contábil (QIC) \\
\hline \multirow{3}{*}{ Variáveis explicativas } & \multicolumn{1}{|c}{ (1) NORMAS E INCENTIVOS } & (2) NORMAS E INCENTIVOS + G INTER \\
\cline { 2 - 5 } Constante & Coeficiente B & Estatística $t$ & Coeficiente B & Estatística $t$ \\
\hline ORIGEM & $-2,151$ & $-3,629$ & $-1,368$ & $-2,270$ \\
AMBIENTE & 0,327 & $4,288^{* * *}$ & 0,318 & $4,211^{* * *}$ \\
CTRIB & 0,062 & 0,670 & $-0,073$ & $-0,773$ \\
IPC & 0,047 & $1,645^{*}$ & 0,067 & $2,350^{* *}$ \\
ALAV & 0,025 & 0,655 & 0,005 & 0,128 \\
& $-0,144$ & $-4,691 * * *$ & $-0,129$ & $-4,260^{* * *}$ \\
\hline
\end{tabular}

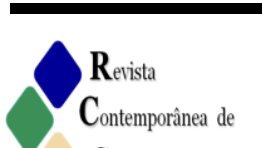


Determinantes da qualidade da informação contábil no contexto internacional.

\begin{tabular}{|c|c|c|c|c|}
\hline ROA & 0,019 & 0,427 & 0,010 & 0,232 \\
\hline NDE & 0,156 & 1,384 & 0,188 & $1,689 *$ \\
\hline NDF & 0,001 & 0,389 & 0,000 & $-0,233$ \\
\hline TAM & $-0,054$ & $-2,148 * *$ & $-0,057$ & $-2,317 * *$ \\
\hline CVEND & 0,012 & 0,372 & 0,013 & 0,429 \\
\hline IND & 0,394 & $6,338 * * *$ & 0,302 & $4,752 * * *$ \\
\hline $\mathrm{COM}$ & 0,182 & $2,436 * *$ & 0,151 & $2,034 * *$ \\
\hline AUDITORIA & 0,100 & 1,390 & 0,087 & 1,227 \\
\hline DPFCO & $-0,005$ & $-0,152$ & $-0,062$ & $-1,973 *$ \\
\hline G_INTER & & & 0,174 & $5,592 * * *$ \\
\hline Estatística F & \multicolumn{2}{|c|}{$12,501 * * *$} & \\
\hline $\mathrm{R}^{2}$ ajustado & \multicolumn{2}{|c|}{0,103} & \multicolumn{2}{|c|}{0,122} \\
\hline Tolerance & \multicolumn{2}{|c|}{1 até 0,10} & \multicolumn{2}{|c|}{1 até 0,10} \\
\hline VIF & \multicolumn{2}{|c|}{1 até 10} & \multicolumn{2}{|l|}{1 até 10} \\
\hline DW & \multicolumn{2}{|c|}{2,018} & \multicolumn{2}{|l|}{2,034} \\
\hline K-S (sig.) & \multicolumn{2}{|c|}{0,104} & \multicolumn{2}{|l|}{0,060} \\
\hline Pesarán-Pesarán (sig.) & \multicolumn{2}{|c|}{0,171} & \multicolumn{2}{|l|}{0,669} \\
\hline $\mathrm{N}$ & \multicolumn{2}{|c|}{1.406} & \multicolumn{2}{|l|}{1.406} \\
\hline \multicolumn{5}{|c|}{ Significativo ao nível de $10 \% * ; 5 \% * * ; 1 \% * * *$. } \\
\hline
\end{tabular}

Nessa abordagem, são apresentados os resultados obtidos utilizando os dados da amostra total, considerando proxies de normas reguladoras, de incentivos empresariais e a intensidade de internacionalização das atividades econômicas, conjuntamente. Os resultados indicam que os modelos utilizados apresentaram relação positiva e significativa com a variável dependente ao nível de $1 \%$ (estatística $\mathrm{F}$ ).

Nessa configuração, a coluna (1) demonstra que, em relação às normas reguladoras, as variáveis da origem legal e carga tributária mostraram-se significativas para explicar o posicionamento no ranking da QIC. Empresas localizadas em países de origem common law e aquelas localizadas em países com menores cargas tributárias demonstraram níveis mais elevados na qualidade dos resultados contábeis reportados, com significância estatística ao nível de $1 \%$ e $10 \%$, respectivamente.

Quanto aos incentivos empresariais, somente a variável ALAV mostrou-se significativa para explicar a qualidade das informações contábeis, reiterando resultados anteriores que afirmavam que empresas com menor alavancagem financeira apresentam níveis mais elevados no ranking.

Na configuração da coluna (2), ocorreu a inserção da variável de interesse G_INTER, que demonstrou relação positiva e significativa com o ranking agregado da qualidade da informação contábil, ao nível de 1\%. As variáveis ORIGEM, CTRIB e ALAV apresentaram resultantes semelhantes ao modelo da coluna (1). Adicionalmente, a variável NDE passou a apresentar significância em relação à variável dependente, ao nível de $10 \%$.

Em relação às variáveis de controle, os dois modelos apresentaram resultados conforme o esperado. De um lado, TAM (colunas 1 e 2) e DPFCO (coluna 2) se mostraram negativa e significativamente relacionadas com maiores níveis de QIC. De outro lado, as variáveis IND e COM se mostraram positiva e significativamente relacionadas com maiores níveis de QIC, nas duas simulações.

Nas diversas simulações apresentadas, considerando as segregações da amostra pelos fatores relacionados ao ambiente legal, ao nível de percepção da corrupção, à tradição jurídica da origem legal, ou no modelo utilizando a amostra total, as duas determinantes que apresentaram resultados constantes e significativos para influenciar o posicionamento das 
empresas no ranking da qualidade da informação contábi foram o menor nível de alavancagem financeira e o maior grau de internacionalização das empresas. Considerando-se que a alavancagem financeira é um dos fatores ambientais que afetam as acumulações discricionárias das empresas (LANG; RAEDY; WILSON, 2006), os gestores de empresas com elevado nível de endividamento podem estar envolvidos com incentivos para praticar o gerenciamento de resultados, seja para evitar a violação das obrigações contratuais, seja para obter melhores termos nos contratos de dívidas, prejudicando a qualidade da informação reportada.

Os resultados da pesquisa sugerem que as empresas que apresentam menores níveis de alavancagem financeira podem ter riscos e custos de agência menores, influenciando positivamente a qualidade dos resultados contábeis.

Esse estudo sugere que uma empresa internacionalizada tem informação contábil de melhor qualidade em comparação com as empresas tipicamente domésticas. Isso pode ocorrer por causa de alguns fatores interligados. O sucesso da internacionalização exige, além de recursos financeiros substanciais, também experiência e capacidade acumulada, incluindo operações em vários locais e redes de investimentos estrangeiros, tornando-se, assim, vantagens intangíveis difíceis para os concorrentes imitarem (CHIN et al., 2012).

Essas condições geram maior desempenho e estabilidade dos resultados pela diversificação geográfica das atividades. Resultados positivos e estáveis reduzem as possibilidades de oportunismo gerencial para lidar com resultados indesejados ou se envolver em gerenciamento de resultados, em decorrência de desempenho deficitário.

A captação internacional de capital submete as empresas a enfrentar pressões adicionais dos mercados de capitais para a divulgação de informações, além daquelas enfrentadas pelas empresas que têm suas fontes de capital somente no país de origem.

Os resultados estão alinhados aos pressupostos teóricos de que empresas com atividades internacionais possuem lucros com menor volatilidade, portanto mais persistentes. E a persistência é um atributo desejável dos lucros. Dessa forma, a maior internacionalização das atividades empresariais indica a possibilidade de crescimento e continuidade dos lucros, aumentando a relevância dos lucros nas empresas internacionalizadas.

\section{Conclusões e Pesquisas Futuras}

O estudo analisou a influência do grau de internacionalização das empresas, em conjunto com as normas reguladoras e os incentivos empresariais, na qualidade das informações contábeis, contribuindo com a avaliação das características multidimensionais da temática. Embora não exista uma definição única de internacionalização, considerou-se uma abordagem econômica, ao considerar a intensidade da participação nos mercados internacionais.

Para identificar fatores determinantes da qualidade da informação contábil no contexto internacional, foram considerados fatores normativos (origem legal, ambiente legal e carga tributária) dos países que sediam as empresas investigadas. Também foram considerados incentivos empresariais (corrupção, alavancagem financeira, desenvolvimento econômico e do mercado financeiro) presentes nos países hospedeiros das empresas investigadas. Como variáveis de controle, utilizaram-se o tamanho, o crescimento de vendas, o setor econômico, o tipo da empresa de auditoria e a volatilidade do fluxo de caixa das empresas. Além dessas

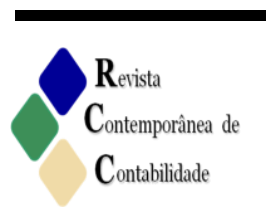

ISSN 2175-8069, UFSC, Florianópolis, v. 13, n. 29, p. 03-32, mai. /ago. 2016 
variáveis indicadas na literatura prévia consultada, o estudo introduziu, como fator determinante do posicionamento no ranking da qualidade da informação contábil, o grau de internacionalização das empresas, considerando o volume de vendas e de ativos no exterior em relação às vendas e aos ativos totais.

Os modelos utilizados não apresentaram elevado poder explicativo, contudo, na concepção de Goldberger (1998), o modelo clássico de regressão não exige que o $\mathrm{R}^{2}$ seja alto. Nesse sentido, um $\mathrm{R}^{2}$ elevado não é uma evidência favorável ao modelo, nem um $\mathrm{R}^{2}$ baixo constitui uma prova desfavorável. Gujarati (2006) considera mais importante a relevância lógica ou teórica das variáveis explanatórias em relação à variável dependente e sua significância estatística, do que necessariamente o poder explicativo do modelo. As variáveis utilizadas no modelo são recorrentes em estudos prévios e apresentam consistência teórica para seu uso.

Os resultados são decorrentes também do modelo utilizado para o estabelecimento do posicionamento das empresas no ranking de qualidade da informação contábil estabelecido. Ao utilizar a técnica da entropia, produziu vetores com maior peso para os atributos da suavização e da persistência dos lucros, ao apresentar maior diversidade de informação entre as empresas investigadas. Ao utilizar outras medidas para definição dos vetores, a exemplo de pesos lineares, podem ensejar condições divergentes no posicionamento das empresas.

Há coerência teórica na identificação de maiores pesos para os atributos de suavização e persistência dos lucros, pois um dos propósitos da suavização é justamente o de evitar a excessiva flutuação dos resultados. Resultados menos voláteis tornam-se mais persistentes e, portanto, mais desejáveis. Assim, os achados sugerem o uso da suavização pelas empresas investigadas para entregar resultados mais persistentes.

Dentre as diversas simulações realizadas, os resultados indicaram que o menor nível de alavancagem financeira e a maior intensidade de internacionalização foram os fatores determinantes que se mostraram estatisticamente significativos em todas as análises realizadas. Outros fatores como o menor tamanho e os setores de atuação, embora menos consistentes, também se mostraram significativos para explicar os números reportados. No âmbito de país, o desenvolvimento econômico e o do mercado financeiro mostraram-se relevantes apenas em situações mais específicas.

Os resultados da investigação corroboram os achados de Houqe et al. (2012) e Naranjo, Saavedra e Verdi (2015), que encontraram relação negativa da alavancagem financeira com a qualidade dos resultados contábeis, reforçando o entendimento de que empresas com menor alavancagem financeira podem apresentar menores riscos e menores custos de agência, constituindo-se em incentivo para produzir números mais condizentes com sua realidade econômica. Os resultados reforçam a perspectiva da Teoria da Agência de que as dívidas podem servir como mecanismos aos acionistas para monitorar e restringir o comportamento oportunista dos gestores (JENSEN, 1986).

Os resultados estão alinhados com os pressupostos teóricos de que a qualidade da informação contábil deve ser maior em empresas com menor alavancagem financeira, pois se constitui em incentivo aos gestores para divulgar números contábeis mais fidedignos, não atrelados aos compromissos contratuais, às dificuldades financeiras ou com necessidades de financiamento.

O resultado dessa pesquisa também corrobora o entendimento de que o tamanho da empresa é negativamente associado com a qualidade dos resultados contábeis, porque as 
grandes empresas podem escolher um método contábil para diminuir resultados, em resposta a um maior escrutínio político ou regulatório (WATTS; ZIMMERMAN, 1986).

Resta claro que, da mesma forma que a qualidade da informação contábil é um conceito multidimensional, os fatores explicativos que a impulsionam também são diversos e inter-relacionados. As evidências empíricas indicaram que a maior presença internacional conduziu as empresas para a evidenciação de resultados contábeis com atributos desejáveis pelos usuários das informações contábeis, utilizadas para decisões de investimentos e de avaliação patrimonial.

Os resultados apontam que a internacionalização das empresas gera incentivos para produzir informações contábeis de qualidade mais elevada, visando à redução de assimetrias informacionais com os diversos usuários. A intensidade da internacionalização das empresas, considerando o volume de vendas ao exterior e a presença de ativos no exterior, mostrou-se uma determinante relevante do melhor posicionamento no ranking da qualidade da informação contábil.

Essa condição pode estar atrelada ao fato de que empresas com tais características estão sujeitas a forças de mercado que exigem níveis mais elevados de informação contábil, quando comparadas com o ambiente doméstico. Os resultados mostram que a internacionalização das empresas gera incentivos para a produção de informações contábeis de maior qualidade, a fim de reduzir as assimetrias de informação entre os múltiplos usuários.

Essa investigação contribui para a pesquisa sobre a qualidade da informação contábil, fornecendo evidências adicionais sobre suas determinantes no cenário internacional. $\mathrm{O}$ estudo fornece evidências de que, ao se considerar a suavização como um atributo desejável ao produzir resultados mais persistentes, bem como ao se considerar os atributos da qualidade da informação contábil de forma conjunta, o (maior) grau de internacionalização está positivamente associado com melhores posições no escore da qualidade da informação contábil das empresas.

Para estudos futuros, recomenda-se considerar a análise dos atributos dos lucros baseados no mercado, a exemplo da relevância, tempestividade e conservadorismo para cada empresa. Essa abordagem se constitui relevante, pois tais atributos podem estar relacionados com incentivos diversos daqueles dos atributos de base contábil considerados nesse estudo.

\section{Referências}

ALFORD, A.; JONES, J.; LEFTWICH, R.; ZMIJEWSKI, M. The relative informativeness of accounting disclosures in different countries. Journal of Accounting Research, v. 31, supplement, p. 183-223, 1993.

ALMEIDA, J. E. F.; SARLO NETO, A.; BASTIANELLO, R. F.; MONEQUE, E. Z. Alguns aspectos das práticas de suavização de resultados no conservadorismo das companhias abertas listadas na BM\&FBOVESPA. Revista Contabilidade \& Finanças, v. 23, n. 58, p. 65-75, 2012.

ANTUNES, G. A.; MENDONÇA, M. M.; AZEVEDO, F. B., ALENCAR, R. C. Empresas estatais federais e empresas do novo mercado da Bovespa: um estudo comparativo acerca da 
qualidade da informação contábil utilizando dados em painel. In: CONGRESSO USP, 8., 2008, São Paulo. Anais... São Paulo: USP, 2008.

ARMSTRONG, C. S.; BARTH, M. E.; JAGOLINZER, A. D.; RIEDL, E. J. Market reaction to the adoption of IFRS in Europe. The Accounting Review, v. 85, n. 1, p. 31-61, 2010.

BALL, R. Infrastructure requirements for and economically efficient system of public financial reporting and disclosure. In: LITAN, R.; HERRING, R. (Eds.). Brookings-

Wharton Papers on Financial Services. Washington: Brookings Institute Press, p. 127-169, 2001 .

BALL, R.; KOTHARI, S. P.; ROBIN, A. The effect of international institutional factors on properties of accounting earnings. Journal of Accounting and Economics, v. 29, n. 1, p. 1$51,2000$.

BALL, R.; ROBIN, A.; WU, J. Incentives versus standards: properties of accounting income in four East Asian Countries. Journal of Accounting \& Economics, v. 36, p. 235-70, 2003.

BALL, R.; SHIVAKUMAR, L. Earnings quality in U.K. Private firms: comparative loss recognition timeliness. Journal of Accounting and Economics, v. 39, n. 1, p. 83-128, 2005.

BARTH, M. E; LANDSMAN, W. R; LANG, M. H. International Accounting Standards and accounting quality. Journal of Accounting Research, v. 46, n. 3, p. 467-498, 2008.

BENITEZ, J. M.; MARTIN, J. C.; ROMAN, C. Using fuzzy number for measuring quality of service in the hotel industry. Tourism Management, v. 28, n. 2, p. 544-555, 2007.

BIDDLE, G. C.; HILARY, G. Accounting quality and firm-level capital investment. The Accounting Review, v. 81, n. 5, p. 963-982, 2006.

BRADSHAW, M.; BUSHEE, B.; MILLER, G. Accounting choice, home bias, and U.S. investment in non-U.S. firms. Journal of Accounting Research, v. 42, n. 5, p. 795-838, 2004.

BULGURCU, B. K. Application of TOPSIS Technique for financial performance evaluation of technology firms in Istanbul Stock Exchange Market. Procedia - Social and Behavioral Sciences, v. 62, n. 24, p. 1033-1040, 2012.

BURGSTAHLER, D.; DICHEV, I. Earnings management to avoid earnings decreases and losses. The Accounting Review, v. 72, n. 2, p. 187-215, 1997.

BURGSTAHLER, D.; HAIL, L.; LEUZ, C. The importance of reporting incentives: earnings management in European private and public firms. The Accounting Review, v. 81, n. 5, p. 983-1016, 2006. 
BUSHMAN, R. M.; PIOTROSKI, J. D. Financial reporting incentives for conservative accounting: The influence of legal and political institutions. Journal of Accounting and Economics, v. 42, n.1-2, p. 107-148, 2006.

CHEN, H.; TANG, Q.; JIANG, Y.; LIN, Z. The role of accounting standards: evidence from the European Union. Journal of International Financial Management \& Accounting, v. 21, n. 3, p. 1-57, 2010.

CHIN, C-L.; CHEN, Y-J.; KLEINMAN, G.; LEE, P. The relationship of development status of investee countries and investor perceptions of foreign earnings. International Business \& Economics Research Journal, v. 11, n. 7, p. 787-794, 2012.

DASKE, H.; HAIL, L.; LEUZ, C.; VERDI, R. Mandatory IFRS adoption around the world: early evidence on the economic consequences. Journal of Accounting Research, v. 46, n. 5, p. 1085-1142, 2008.

DECHOW, P. Accounting earnings and cash flows as measures of firm performance: the role of accounting accruals. Journal of Accounting and Economics, v. 18, n. 1, p. 3-42, 1994.

DECHOW, P.; DICHEV, I. The quality of accruals and earnings: the role of accrual estimation errors. The Accounting Review, v. 77, n. 4, p. 35-59, 2002.

DECHOW, P.; GE, W.; SCHRAND, C. Understanding earnings quality: a review of the proxies, their determinants and their consequences. Journal of Accounting and Economics, v. 50, n. 2-3, p. 344-401, 2010.

DEFOND, M. L.; JIAMBALVO, J. Debt covenant violation and manipulation of accruals. Journal of Accounting and Economics, v. 17, n. 1-2, p. 145-176, 1994.

DING, Y.; JEANJEAN, T.; STOLOWY, H. The impact of firms' internationalization on financial statement presentation: some French evidence. Advances in Accounting, incorporating Advances in International Accounting, v. 24, n. 1, p. 145-156, 2008.

DOYLE, J.; GE, W.; MCVAY, S. Accruals quality and internal control over financial reporting. The Accounting Review, v. 82, n. 5, p. 1141-1170, 2007.

ECONOMIC FREEDOM OF THE WORLD. 2013 Dataset. Fraser Institute. Disponível em: http://www.freetheworld.com/release.html Acesso em: 20 fev. 2014.

FRANCIS, J.; LAFOND, R.; OLSSON, P. M.; SCHIPPER, K. Costs of equity and earnings attributes. The Accounting Review, v. 79, n. 4, p. 967-1010, 2004.

FRANCIS, J.; LAFOND, R.; OLSSON, P.; SCHIPPER, K. The market pricing of accruals quality. Journal of Accounting and Economics, v. 39, p. 295-327, 2005. 
FREEMAN, R.; OHLSON, J.; PENMAN, S. Book rate of return and prediction of earnings changes: an empirical investigation. Journal of Accounting Research, v. 20, n. 2, p. 639$653,1982$.

GAIO, C. The relative importance of firm and country characteristics for earnings quality around the world. European Accounting Review, v. 19, n. 4, p. 693-738, 2010.

GOLDBERGER, A. S. Introductory econometrics. Harvard University Press, 1998.

GUJARATI, D. N. Econometria básica. 4. ed. Rio de Janeiro, Elsevier, 2006.

HAW, I.; HU, B.; KHWANG, L.; WU, W. Ultimate ownership, income management, and legal and extra-legal institutions. Journal of Accounting Research, v. 42, n. 2, p. 423-462, 2004.

HOUQE, M. N. H.; VAN ZIJL, T.; DUNSTAN, K.; KARIM, A. K. M. W. The effect of IFRS adoption and investor protection on earnings quality around the world. The International Journal of Accounting, v. 47, n. 3, p. 333-355, 2012.

HRIBAR, P.; KRAVET, T.; WILSON, R. A new measure of accounting quality. Review of Accounting Studies, v. 19, n. 1, p. 506-538, 2014.

IATRIDIS, G. International Financial Reporting Standards and the quality of financial statement information. International Review of Financial Analysis, v. 19, n. 3, p. 193-204, 2010 .

ISIDRO, H.; RAONIC, I. Firm incentives, institutional complexity and the quality of "harmonized" accounting numbers. The International Journal of Accounting, v. 47, n. 4, p. 407-436, 2012.

KHANNA, T.; PALEPU, K. G.; SRINIVASAN, S. Disclosure practices of foreign companies interacting with U.S. markets. Journal of Accounting Research, v. 42, n. 2, p. 475-508, 2004.

KOHLBECK, M.; WARFIELD, T. Accounting standard attributes and accounting quality: discussion and analysis. Research in Accounting Regulation, v. 22, n. 2, p. 59-70, 2010.

LAND, J.; LANG, M. H. Empirical evidence on the evolution of international earnings. The Accounting Review, v. 77 (Supplement), p. 115-133, 2002.

LANG, M.; RAEDY, J. S.; WILSON, W. Earnings management and cross listing: are reconciled earnings comparable to US earnings? Journal of Accounting and Economics, v. 42, n. 1-2, p. 255-283, 2006.

LA PORTA, R.; LOPEZ-DE-SILANES, F.; SHLEIFER, A.; VISHNY, R. W. Law and finance. Journal of Political Economy, v. 106, n. 6, p. 1113-1155, 1998. 
LA PORTA, R.; LOPEZ-DE-SILANES, F.; SHLEIFER, A. The economic consequences of legal origins. Journal of Economic Literature, v. 46, n. 2, p. 285-332, 2008.

LEUZ, C. IAS versus U.S. GAAP: Information asymmetry-based evidence from Germany's new market. Journal of Accounting Research, v. 41, n. 3, p. 445-472, 2003.

LEUZ, C.; NANDA; D.; WYSOCKI, P. Earnings management and investor protection: an international comparison. Journal of Financial Economics, v. 69, n. 3, p. 505-27, 2003.

LEV, B. Some economic determinants of time-series properties of earnings. Journal of Accounting and Economics, v. 5, n 1, p. 31-48, 1983.

LINDAHL, F. Dynamic analysis of inventory accounting choice. Journal of Accounting Research, v. 27, n. 2, p. 201-226, 1989.

LIPE, R. The relation between stock returns and accounting earnings given alternative information. The Accounting Review, v. 65, n. 1, p. 49-71, 1990.

LUO, Y. How does globalization affect corporate governance and accountability? A perspective from MNEs. Journal of International Management, v. 11, n. 1, p. 19-41, 2005.

MARTINEZ, A. L. Detectando earnings management no Brasil: estimando os accruals discricionários. Revista Contabilidade \& Finanças, v. 19, n. 46, p. 7-17, 2008.

MATTOS, R. S.; VEIGA, A. Otimização de entropia: implementação computacional dos princípios Maxent e Minxent. Revista Pesquisa Operacional, v. 22, n. 1, p. 37-59, 2002.

MCNICHOLS, M. Discussion of The quality of accruals and earnings: the role of accrual estimation errors. The Accounting Review, v. 77 (Supplement), p. 61-69, 2002.

MYERS, J. N.; MYERS, L. A.; SKINNER, D. J. Earnings momentum and earnings management. 2006. Available at SSRN: http://ssrn.com/abstract=741244.

NARANJO, P. L.; SAAVEDRA, D.; VERDI, R. S. Financial reporting regulation and financing decisions. 2015. Disponível em: http://ssrn.com/abstract=2147838. Acesso em: 3 jun. 2015.

PENMAN, S. H.; ZHANG, X-J. Accounting conservatism, the quality of earnings and stock returns. The Accounting Review, v. 77, n. 2, p. 237-264, 2002.

RUSANESCU, S. La internacionalización de la empresa y la calidad de la información contable: evidencia para España. Instituto de Contabilidad y Auditoría, p. 1-93, 2013.

SCHIEMANN, F.; GUENTHER, T. Earnings predictability, value relevance, and employee expenses. The International Journal of Accounting, v. 48, n. 2, p. 149-172, 2013. 
SODERSTROM, N. S.; SUN, K. J. IFRS adoption and accounting quality: a review. The European Accounting Review, v. 16, n. 4, p. 675-702, 2007.

THE WORLD BANK. Data. Indicators. 2014. Disponível em: http://data.worldbank.org/indicators Acesso em: 14 abr. 2014.

THOMSON ONE BANKER. Screening \& Targeting. 2014. Disponível em: http://banker.thomsonib.com/ta/TAdashboard.aspx Acesso em: 14 abr. 2014.

TRANSPARENCY INTERNATIONAL. Corruption perceptions index. 2012. Disponível em: http://www.transparency.org Acesso em: 20 fev. 2014.

UNITED NATIONS CONFERENCE ON TRADE AND DEVELOPMENT - UNCTAD. World Investment Report 1995. Transnational corporations and competitiveness. Geneva: United Nations, 1995.

ZELENY, M. Multiple criteria decision making. New York: McGraw-Hill, 1982.

WATTS, R. L.; ZIMMERMAN, J. L. Positive accounting theory. Prentice-Hall Inc., 1986.

WEBB, K. A.; CAHAN, S. F.; SUN, J. The effect of globalization and legal environment on voluntary disclosure. The International Journal of Accounting, v. 43, n. 3, p. 219-245, 2008 .

WORLD ECONOMIC FORUM. The Financial Development Report. 2013. Disponível em: http://www.weforum.org/issues/financial-development Acesso em: 20 jan. 2014.

YOON, S. Accounting quality and international accounting convergence. Dissertation (Doctor of Philosophy) - Oklahoma State University, Oklahoma, 2007, p.97. 


\title{
Resumo
}

O objetivo do estudo é analisar a influência do grau de internacionalização das empresas, em conjunto com as normas reguladoras e os incentivos empresariais, na qualidade das informações contábeis. Para tanto, foi realizada pesquisa descritiva, documental e quantitativa com 1.406 empresas localizadas em doze países. A amostra considerou empresas que divulgaram informações sobre suas receitas e ativos no exterior, além das demais informações necessárias para operacionalizar os atributos de qualidade dos accruals, persistência, previsibilidade e suavização dos resultados. Após a mensuração individual de cada atributo por empresa, elaborou-se um ranking da qualidade da informação contábil, com base no método de análise multicritério TOPSIS e da técnica da entropia. Os resultados indicaram que, ao se considerar o ambiente legal, o nível de percepção da corrupção e a origem legal dos países hospedeiros das empresas, a menor alavancagem financeira e a maior intensidade na internacionalização das empresas se mostraram fatores determinantes para o melhor posicionamento no ranking da qualidade da informação contábil.

Palavras-chave: Normas reguladoras. Incentivos empresariais. Internacionalização das empresas.

\begin{abstract}
The objective of the study is to analyze the influence of the degree of internationalization of companies, together with regulatory standards and business incentives, the quality of accounting. For this purpose, descriptive, documentary and quantitative survey was conducted with 1,406 companies located in twelve countries. The sample considered companies released information about their income and assets abroad, in addition to other information needed to operationalize the attributes quality of accruals, persistence, predictability and smoothing. After individual measurement of each attribute by company, elaborated a ranking of the quality of accounting information, from the multi-criteria analysis method TOPSIS and entropy technique. The results indicated that, when considering the legal environment, the level of perception of corruption and the legal origin of the host countries of companies, lower financial leverage and the greater intensity in the internationalization of companies have proved decisive factors for the better position in the ranking the quality of accounting information.
\end{abstract}

Keywords: Regulatory standards. Business incentives. Internationalization of the companies.

\section{Resumen}

El objetivo del estudio es analizar la influencia del grado de internacionalización de las empresas, junto con las normas reguladoras y con los incentivos empresariales, in la calidad de la información contable. Por lo tanto, la investigación descriptiva, documental y cuantitativa se realizó con 1.406 empresas ubicadas en doce países. La muestra fue considerada por las compañías con información sobre sus ingresos y activos en el exterior, además de otra información necesaria para poner en práctica los atributos de calidad de acumulaciones, la persistencia, la previsibilidad y suavización de los resultados. Después de la medición individual de cada atributo por compañía, fue elaborado un ranking de calidad de la información contable, desde el método de análisis multicriterio TOPSIS y la técnica de la entropía. Los resultados indicaron que, al considerar el entorno legal, el nivel de percepción de la corrupción y el origen legal de los países anfitriones de las empresas, un menor apalancamiento financiero y la mayor intensidad en la internacionalización de las empresas han demostrado ser factores decisivos para la mejor posición en el ranking la calidad de la información contable.

Palabras clave: Normas reguladoras. Incentivos empresariales. Internacionalización de las empresas.

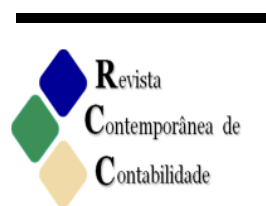

ISSN 2175-8069, UFSC, Florianópolis, v. 13, n. 29, p. 03-32, mai. /ago. 2016 


\section{Introdução}

A qualidade dos resultados contábeis ou, de modo mais geral, a qualidade das demonstrações contábeis não tem uma definição precisa, mas pode ser definida como a medida na qual os resultados divulgados representam fielmente a situação econômica subjacente da empresa reportada e o grau em que os resultados apresentados refletem os conceitos básicos de contabilidade (YOON, 2007; CHEN et al., 2010).

A análise da qualidade da informação contábil manifesta relevância pela aceitação de que a informação de qualidade reduz o grau de incerteza e a assimetria da informação entre preparadores e usuários das demonstrações contábeis, além de melhorar a eficiência do mercado de capitais relacionada à gestão do risco, dada a maior possibilidade de compreensão da informação contábil reportada (BIDDLE; HILARY, 2006). A qualidade da informação contábil está relacionada com o grau de funcionalidade da contabilidade como mecanismo para impedir a expropriação dos recursos (ANTUNES et al., 2008).

A qualidade da informação contábil é influenciada por diversos fatores regulatórios, a exemplo dos padrões de contabilidade de elevada qualidade, com destaque para a adoção das normas internacionais de contabilidade (BARTH; LANDSMAN; LANG, 2008; IATRIDIS, 2010; HOUQE et al., 2012), a origem do sistema legal do país (LA PORTA et al., 1998; BUSHMAN; PIOTROSKI, 2006; SODERSTROM; SUN, 2007; LA PORTA; LOPEZ-DESILANES; SHLEIFER, 2008), a existência de leis para proteção do mercado de valores mobiliários e sua efetiva aplicação (HOUQE et al., 2012), a proteção legal dos interesses de acionistas minoritários (LA PORTA et al., 1998; HOUQE et al., 2012), aplicação efetiva das normas de contabilidade e auditoria (HOUQE et al., 2012), eficiência e integridade do ambiente legal sobre os negócios (LA PORTA et al., 1998; HOUQE et al., 2012), a influência do sistema tributário na intensidade do alinhamento entre o lucro contábil e o lucro tributável (SODERSTROM; SUN, 2007; HOUQE et al., 2012).

Embora algumas evidências empíricas demostrem que padrões de alta qualidade (por exemplo, IFRS) geralmente melhoram a qualidade contábil (BARTH; LANDSMAN; LANG, 2008; DASKE et al., 2008), outros resultados investigativos sugerem que as normas têm um papel limitado para determinar a qualidade dos relatórios contábeis (BURGSTAHLER; HAIL; LEUZ, 2006; DASKE et al., 2007; LEUZ, 2003).

Padrões de contabilidade geralmente concedem substancial flexibilidade para as empresas. As mensurações são muitas vezes baseadas em informações privadas, e a aplicação das normas envolve julgamento. Gestores corporativos podem usar o poder discricionário nos relatórios para transmitir informações sobre o desempenho econômico da empresa, mas também podem fazer uso indevido dos critérios quando é do seu interesse. Por essa razão, os incentivos dos relatórios são suscetíveis de desempenhar um papel fundamental na determinação da informatividade dos números contábeis reportados (BURGSTAHLER; HAIL; LEUZ, 2006).

As empresas são motivadas por determinados incentivos na divulgação dos números contábeis que exercem influência sobre a qualidade dos relatórios, a exemplo da concentração de propriedade (BARTH; LANDSMAN; LANG, 2008; GAIO, 2010; CHEN et al., 2010; ISIDRO; RAONIC, 2012), da alavancagem financeira (BARTH; LANDSMAN; LANG, 2008; KOHLBECK; WARFIELD 2010), da presença em listagem estrangeira (DING; JEANJEAN; STOLOWY, 2008; BARTH; LANDSMAN; LANG, 2008; ISIDRO; RAONIC, 2012), do desempenho econômico (BURGSTAHLER; HAIL; LEUZ, 2006; IATRIDIS, 
2010), do nível de desenvolvimento econômico do país (BURGSTAHLER; HAIL; LEUZ, 2006; GAIO, 2010; ISIDRO; RAONIC, 2012), do nível de desenvolvimento financeiro do país (GAIO, 2010; ISIDRO; RAONIC, 2012) e do nível de combate à corrupção (LA PORTA et al., 1998), dentre outros incentivos influenciadores.

As empresas que têm operações diversificadas no exterior possuem maiores incentivos para fornecer informação financeira abrangente para seus clientes estrangeiros, fornecedores e potenciais investidores (ISIDRO; RAONIC, 2012). Além disso, a concorrência internacional para o capital criou incentivos para melhorar a qualidade e a comparabilidade da informação contábil (LAND; LANG, 2002), e os investidores institucionais e estrangeiros preferem as demonstrações financeiras de alta qualidade ao fazer investimentos internacionais (BRADSHAW; BUSHEE; MILLER, 2004).

A expansão internacional aumenta a complexidade do processamento de informações para analistas, investidores e auditores. Além disso, o elevado risco relacionado com a internacionalização não se relaciona apenas à empresa, mas tem implicações para os usuários das demonstrações financeiras. Desse modo, a diversificação internacional gera maior necessidade informativa que cria um incentivo para que as empresas proporcionem mais informações (RUSANESCU, 2013).

Nesse contexto, a investigação pretende responder ao seguinte problema de pesquisa: Qual a influência do grau de internacionalização das empresas, em conjunto com as normas reguladoras e os incentivos empresariais, na qualidade das informações contábeis? O objetivo é analisar a influência do grau de internacionalização das empresas, em conjunto com as normas reguladoras e os incentivos empresariais, na qualidade das informações contábeis.

A relevância da investigação está atrelada à produção de resultados que são de interesse de profissionais como contadores, consultores, analistas de mercado, auditores, responsáveis pela elaboração de normas contábeis e pesquisadores. Para as empresas, os resultados são importantes pela possibilidade de se avaliar como a interação com mercados externos causa influência nas escolhas das políticas contábeis, reforçando a premissa de que a informação contábil de elevada qualidade pode mitigar os problemas de agência decorrentes da assimetria de informação entre as empresas e os investidores (BALL; KOTHARI; ROBIN, 2000).

A investigação apresenta, ao menos, três importantes fatores distintos: (i) considera um contexto internacional, avaliando a influência de fatores normativos (origem e ambiente legal dos países e a carga tributária) e de incentivos empresariais (retorno sobre ativos, alavancagem financeira, nível de transparência, desenvolvimento econômico e financeiro dos países de origem das empresas) na qualidade da informação reportada; (ii) adicionalmente, utiliza a intensidade da internacionalização das atividades empresariais como uma determinante explicativa da qualidade da informação contábil; e (iii) os atributos da qualidade são tomados em conjunto, formando um ranking por empresa. Consideradas em conjunto, essas características do estudo representam uma contribuição importante para o debate sobre a qualidade da informação reportada no contexto internacional.

\section{Revisão da Literatura}

A subseção de atributos da qualidade da informação contábil aborda quatro atributos de base contábil utilizados no estudo: qualidade dos accruals, persistência, previsibilidade e

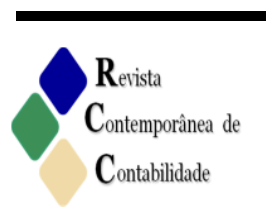

ISSN 2175-8069, UFSC, Florianópolis, v. 13, n. 29, p. 03-32, mai. /ago. 2016 
suavização dos lucros. Na subseção de determinantes da qualidade da informação contábil, discute-se a implicação dos fatores normativos e dos incentivos empresariais sobre a qualidade da informação contábil.

\subsection{Atributos da Qualidade da Informação Contábil}

A literatura contábil fornece evidências de que as características operacionais das empresas estão associadas com as várias proxies da qualidade dos resultados contábeis, incluindo a escolha dos princípios de contabilidade (LINDAHL, 1989), as propriedades dos lucros, como a persistência, a volatilidade (LEV, 1983) e os accruals (DECHOW, 1994).

Não há uma concordância ou abordagem superior geralmente aceita para medir a qualidade dos resultados contábeis em decorrência de que os atributos podem ser mutuamente incompatíveis ou sobrepostos, serem interligados e não poderem ser considerados separadamente (YOON, 2007). Embora não exista acordo sobre a definição de qualidade da informação contábil, os estudos geralmente desenvolvem medidas de qualidade pelo uso dos lucros divulgados e de componentes dos lucros, definindo o construto como "qualidade dos resultados contábeis" ou "qualidade dos accruals" (HRIBAR; KRAVET; WILSON, 2014).

As definições da qualidade dos resultados contábeis incluem a elevada persistência dos lucros em uma série temporal; lucros que representam com precisão as implicações econômicas das operações subjacentes; a proporção de lucros em relação aos fluxos de caixa operacionais; accruals de capital de giro mapeados nos fluxos de caixa do passado, presente e futuro (MCNICHOLS, 2002). Em relação à qualidade dos relatórios, em termos abstratos, pode ser interpretada como a utilidade das demonstrações financeiras para os investidores, credores, administradores e todas as outras partes contratantes com a empresa (BALL; SHIVAKUMAR, 2005).

Francis et al. (2004), seguidos por Yoon (2007) e Gaio (2010), examinaram a qualidade dos resultados contábeis com diversos fatores explicativos, segregando os atributos baseados em contabilidade (mensurados utilizando apenas informação contábil) dos atributos baseados em mercado (as proxies desses constructos são baseadas nas relações entre valores de mercado e dados contábeis). Nesse estudo, são considerados quatro atributos de base contábil, que consideram o caixa ou os lucros como o constructo de referência e, consequentemente, são mensurados utilizando apenas informação contábil.

Em termos de atributos baseados na Contabilidade, a literatura contábil considera a mensuração da qualidade dos accruals pelo mapeamento de accruals correntes nos fluxos de caixa ou alguma medida dos accruals anormais (DECHOW; DICHEV 2002; FRANCIS et al., 2005). As medidas de persistência dos lucros normalmente consideram o coeficiente de inclinação estimado em uma regressão de lucros correntes sobre os lucros defasados (LEV, 1983). As medidas de previsibilidade dos lucros focam sobre os erros de previsão de um modelo de séries temporais de lucros (LIPE, 1990), enquanto medidas de suavização são baseadas na volatilidade dos lucros em relação a algum ponto de referência, tais como os fluxos de caixa (LEUZ; NANDA; WYSOCKI, 2003).

Os accruals, ou as acumulações contábeis por regime de competência, podem ser entendidos como a diferença entre o lucro líquido e o fluxo de caixa operacional líquido, ou seja, são constituídos pelos valores integrantes das contas de resultado que entraram no cômputo do lucro, mas não implicam necessária movimentação de recursos financeiros (MARTINEZ, 2008). 
Os accruals refletem as escolhas para fins de reporte, enquanto os fluxos de caixa refletem, de modo mais fundamental, os ganhos e as perdas financeiras. Os accruals e a qualidade dos resultados contábeis estão relacionados, e as mudanças transitórias, no fluxo de caixa operacional, ocorrem pela manipulação gerencial provocada na variação dos itens de capital de giro ao longo do tempo, conduzindo para ganhos de menor qualidade (BALL; SHIVAKUMAR, 2005).

Embora uma correlação negativa com o fluxo de caixa seja um resultado "natural" dos accruals contábeis (DECHOW, 1994), maiores magnitudes dessa correlação podem indicar uma suavização dos lucros reportados que não refletem o desempenho econômico das empresas (MYERS; MYERS; SKINNER, 2006). A existência de acumulações contábeis (accruals) extremas se configura como de baixa qualidade, pois representa um componente menos persistente dos resultados (DECHOW; GE; SCHRAND, 2010).

A persistência dos lucros é vista como uma medida de sustentabilidade dos lucros, em que lucros persistentes são vistos como desejáveis porque são recorrentes, tornando-os mais previsíveis, reforçando seu papel na avaliação de capital e ajudando os analistas financeiros a prestar um serviço valioso para os investidores (PENMAN; ZHANG, 2002). A persistência também possui uma ligação direta com o risco da informação, porque mais persistência está associada a um fluxo de ganhos mais sustentável. Como consequência, se os ganhos são persistentes, os investidores demonstram menos preocupações sobre a extensão em que as alterações nos ganhos dos períodos futuros poderão ocorrer, e isso reduz incertezas (FRANCIS et al., 2004).

Os lucros atuais devem ser um bom indicador dos lucros futuros. Sua qualidade pode ser entendida como a probabilidade de que uma empresa possa ter lucros atuais persistentes no futuro (PENMAN; ZHANG, 2002). Mais persistência dos ganhos é considerada uma característica de qualidade superior de contabilidade (KOHLBECK; WARFIELD, 2010).

A previsibilidade dos lucros é definida como a habilidade de prever lucros futuros com base nos seus valores do passado (LIPE, 1990; FRANCIS et al., 2004; YOON, 2007). Isso é uma medida importante, uma vez que lida com o quão bem os lucros passados podem explicar os lucros atuais. Assim, a medida utiliza uma perspectiva puramente contábil, tornando-se um complemento ideal da relevância. Se os lucros do passado são boas estimativas dos lucros correntes, então a previsibilidade é tida para ser elevada. Essa característica está baseada na contabilidade, ou seja, considera as relações entre os números contábeis (lucros passados para lucros correntes), embora ignore as informações que estão fora do regime contábil, a exemplo da percepção do mercado sobre os lucros divulgados (SCHIEMANN; GUENTHER, 2013).

Os analistas financeiros visualizam os lucros como tendo alta qualidade quando se pode esperar uma repetição de forma consistente e com um alto grau de previsibilidade. Os ganhos voláteis possuem a tendência de serem ganhos extremos e tendem a reverter-se para a média mais rapidamente (FREEMAN; OHLSON; PENMAN, 1982), o que constituiu uma explicação alternativa para que ganhos voláteis sejam menos persistentes.

A suavização dos lucros é uma medida baseada na sua volatilidade em relação ao fluxo de caixa, considerando as diferenças temporais das entradas ou saídas dos recursos e o reconhecimento das receitas e despesas no resultado (DECHOW; DICHEV, 2002), tendo-se que uma relação mais baixa indica mais suavização do fluxo de lucros em relação aos fluxos de caixa (DECHOW; GE; SCHRAN, 2010).

Em uma perspectiva teórica, Almeida et al. (2012) argumentam que quanto maior for a suavização de resultados pela redução na variabilidade dos lucros com o uso de accruals,

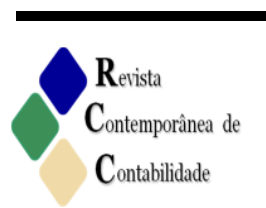

ISSN 2175-8069, UFSC, Florianópolis, v. 13, n. 29, p. 03-32, mai. /ago. 2016 
menor será a capacidade do retorno das ações em reconhecer oportunamente as perdas econômicas futuras contidas nos lucros. A suavização dos resultados é derivada da visão de que os gerentes usam as informações privadas sobre resultados futuros para suavizar as flutuações transitórias (FRANCIS et al., 2004).

A suavização é tipicamente vista como um atributo desejável dos lucros, pois os analistas financeiros e investidores observam a volatilidade dos lucros como indesejável e indicativo de baixa qualidade dos resultados contábeis. Os accruals permitem um adequado registro das transações econômicas e melhoram a qualidade dos resultados contábeis. Contudo, os gestores podem usá-los de um modo oportunista e assim comprometer a qualidade dos resultados contábeis (GAIO, 2010).

\subsubsection{Determinantes da Qualidade da Informação Contábil}

Com base na visão de que a contabilidade não existe no vácuo (HOUQE et al., 2012), mas é um produto do seu ambiente (ARMSTRONG et al., 2010), pode-se compreender melhor que a qualidade da informação contábil é influenciada por diversos fatores regulatórios, mas os incentivos empresariais também são proxies utilizadas para explicar os números contábeis reportados ao redor do mundo.

O Quadro 1 apresenta, resumidamente, algumas determinantes utilizadas na literatura prévia e consideradas nesse estudo, com as possíveis implicações na qualidade da informação contábil reportada pelas empresas.

Quadro 1 - Determinantes da qualidade da informação contábil

\begin{tabular}{|c|c|}
\hline Determinante & Implicação na Qualidade da Informação Contábil \\
\hline Origem Legal & $\begin{array}{l}\text { Em países de origem common law o propósito dos emissores de padrões contábeis é } \\
\text { satisfazer as necessidades de informação dos investidores (SODERSTROM; SUN, } \\
\text { 2007), ao passo que nos países code law a contabilidade serve de medida para dividir } \\
\text { os lucros entre o governo (impostos), acionistas (dividendos), bancos (juros) e } \\
\text { trabalhadores (salários e benefícios) (BALL; KOTHARI; ROBIN, 2000). }\end{array}$ \\
\hline Ambiente Legal & $\begin{array}{l}\text { A eficiência do sistema jurídico tem um efeito significativo na restrição do } \\
\text { gerenciamento de resultados pelo gestor, apresentando-se de forma mais reduzida em } \\
\text { países com um sistema jurídico eficiente (HAW et al., 2004). }\end{array}$ \\
\hline $\begin{array}{l}\text { Carga } \\
\text { Tributária }\end{array}$ & $\begin{array}{l}\text { Uma ligação estreita entre os resultados contábeis e os resultados tributáveis pode } \\
\text { comprometer os incentivos das empresas para reportar o verdadeiro desempenho } \\
\text { econômico (ALFORD et al., 1993). }\end{array}$ \\
\hline $\begin{array}{l}\text { Alavancagem } \\
\text { Financeira }\end{array}$ & $\begin{array}{l}\text { As empresas altamente alavancadas podem ter riscos e custos de agência mais } \\
\text { elevados, que podem contribuir negativamente para a qualidade dos resultados } \\
\text { contábeis (GAIO, 2010) e podem criar incentivos para manipular números contábeis, } \\
\text { a fim de demonstrar que possuem capacidade de cumprir os compromissos com as } \\
\text { dívidas (DEFOND; JIAMBALVO, 1994). }\end{array}$ \\
\hline $\begin{array}{c}\text { Retorno sobre } \\
\text { Ativos }\end{array}$ & $\begin{array}{l}\text { O fraco desempenho operacional fornece incentivos para as empresas envolverem-se } \\
\text { em gerenciamento de resultados (DOYLE; GE; MCVAY, 2007). Para evitar as } \\
\text { reações negativas, os gestores podem gerenciar propositadamente as informações } \\
\text { financeiras para retratar uma imagem melhor do desempenho empresarial } \\
\text { (BURGSTAHLER; DICHEV, 1997). }\end{array}$ \\
\hline Corrupção & $\begin{array}{l}\text { Em países com elevada corrupção, os contratos geralmente são realizados de forma } \\
\text { privada para evitar o controle social e político. Em tais ambientes, os relatórios } \\
\text { financeiros não são frequentemente utilizados para reduzir a assimetria de informação } \\
\text { (SODERSTROM; SUN, 2007). }\end{array}$ \\
\hline $\begin{array}{l}\text { Desenvolvimento } \\
\text { Econômico }\end{array}$ & $\begin{array}{l}\text { Os países com fraco desenvolvimento econômico não conseguem dispor de } \\
\text { infraestrutura adequada para suportar a verificação externa confiável da informação }\end{array}$ \\
\hline
\end{tabular}




\begin{tabular}{|c|l|}
\hline & contábil (BALL, 2001). \\
\hline $\begin{array}{c}\text { Desenvolvimento } \\
\text { do Mercado }\end{array}$ & Em sistemas financeiros orientados para o mercado há maior demanda por \\
Financeiro & finançães e divulgações públicas de alta qualidade, em relação aos sistemas \\
& financeiro pode limitar os benefícios para melhorar a qualidade dos ganhos, porque \\
& nesses ambientes é difícil e oneroso captar recursos (BALL; ROBIN; WU, 2003). \\
\hline
\end{tabular}

Fonte: Dados da pesquisa.

Adicionalmente às determinantes apresentadas no Quadro 1 e utilizadas na literatura, esse estudo considera a internacionalização das empresas como fator explicativo da qualidade da informação contábil. Nessa investigação, adota-se a abordagem econômica de internacionalização, baseada na intensidade da participação das atividades internacionais, representada pelo grau de internacionalização das empresas (UNCTAD, 1995), ou seja, considerou-se internacionalizada a empresa que divulgou, voluntariamente, informações sobre ativos no exterior e vendas para o exterior.

Empresas mais internacionalizadas em suas atividades podem ser requeridas a apresentar níveis mais elevados de evidenciação devido à sua maior complexidade operacional ou por exigência de seu arranjo de financiamento. A maior exposição ao mercado de capitais, de produtos ou de trabalho aumenta a demanda por melhor divulgação (WEBB; CAHAN; SUN, 2008).

A interação com mercados estrangeiros está associada com maior transparência e melhor evidenciação (KHANNA; PALEPU; SRINIVASAN, 2004). As empresas multinacionais, com atividades globalizadas, se mostraram mais dispostas a seguir as normas internacionais de Contabilidade para fortalecer a transparência, a confiabilidade e a consistência da Contabilidade (LUO, 2005).

Empresas com atuação em países com mercados de capitais mais desenvolvidos são mais propensas a levantar seus fundos externamente e escolher melhores padrões de qualidade dos lucros (GAIO, 2010). As forças de mercado enfrentadas por empresas de capital aberto provavelmente são maiores quando o mercado de capitais de um país é ativo e fortemente desenvolvido, incentivando as empresas a divulgar lucros de maior qualidade (BURGSTAHLER; HAIL; LEUZ, 2006).

Com base nessas considerações, apresenta-se a seguinte hipótese de estudo:

$\mathrm{H}_{1}$ - A qualidade da informação contábil é influenciada positivamente pelo grau de internacionalização das empresas, em conjunto com as normas reguladoras e os incentivos empresariais.

\section{Procedimentos Metodológicos}

A composição da população de pesquisa foi definida considerando-se as empresas de capital aberto, localizadas nos vinte países com maior Produto Interno Bruto (PIB), em 2013, conforme o World Development Indicators (2014), produzido pelo The World Bank. O critério para definição da amostra foi a exigência de a empresa possuir a divulgação dos dados necessários para operacionalizar as variáveis ao longo de todos os anos investigados.

A coleta do tipo documental ocorreu com base nos dados contábeis, financeiros, tributários e de mercado divulgados pelas empresas investigadas e aqueles produzidos por

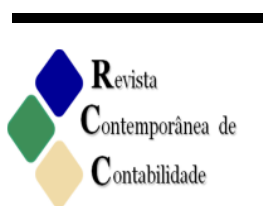

ISSN 2175-8069, UFSC, Florianópolis, v. 13, n. 29, p. 03-32, mai. /ago. 2016 
organismos internacionais, para o período de 2005 a 2012. Considerando a estrutura das variáveis, foram exigidos dados anteriores e posteriores a esses períodos.

Com base nas informações recuperadas na base de dados Thomson Datastream Index Service (2014), optou-se em considerar apenas os países que apresentaram mais de dez empresas com as variáveis necessárias para operacionalizar os modelos teóricos, resultando em uma amostra final composta por 1.406 empresas de doze países, a saber: Alemanha, Austrália, Brasil, Canadá, China, Estados Unidos, Holanda, Índia, Indonésia, Japão, Reino Unido, Suíça.

Pelos critérios adotados na pesquisa, Arábia Saudita, Coreia do Sul, Espanha, França, Itália, México, Turquia e Rússia não ficaram representados na amostra final. Uma das razões principais para o número final de empresas, considerado na pesquisa, é a utilização das informações relacionadas à intensidade de internacionalização das empresas. Ocorre que a divulgação das informações necessárias para operacionalizar tal variável é voluntária (montante de vendas no exterior e montante de ativos no exterior), conduzindo a um número reduzido de empresas em todos os países pesquisados.

O emprego da quantificação utilizou inicialmente a regressão linear múltipla, com a análise individual por empresa, para calcular cada um dos quatro atributos dos lucros. Para mensurar a qualidade dos accruals, utilizou-se a abordagem de Dechow e Dichev (2002):

$$
\mathrm{ACT}_{\mathrm{i}, \mathrm{t}}=\varphi_{0, \mathrm{i}}+\varphi_{1, \mathrm{i}} \mathrm{FCO}_{\mathrm{i}, \mathrm{t}-1}+\varphi_{2, \mathrm{i}} \mathrm{FCO}_{\mathrm{i}, \mathrm{t}}+\varphi_{3, \mathrm{~F}} \mathrm{FCO}_{\mathrm{i}, \mathrm{t}+1}+\varepsilon_{\mathrm{i}, \mathrm{t}}
$$

Em que:

$\mathrm{ACT}_{\mathrm{i}, \mathrm{t}}=$ accruals correntes totais da firma $i$ no ano $t\left(\Delta \mathrm{AC}_{\mathrm{i}, \mathrm{t}}-\Delta \mathrm{PC}_{\mathrm{i}, \mathrm{t}}-\Delta\right.$ caixa $\mathrm{i}, \mathrm{t}+$ $\left.\triangle \mathrm{FINCP}_{\mathrm{i}, \mathrm{t}}\right)$;

Ativos $_{\mathrm{i}, \mathrm{t}}=$ média dos ativos totais da firma $i$ no ano $t$ e $t-1$.

$\mathrm{FCO}_{\mathrm{i}, \mathrm{t}}=$ fluxo de caixa operacional no ano $t$ calculado como o lucro líquido antes dos itens extraordinários (LLO) menos total dos accruals (TA), onde:

$\mathrm{TA}=\Delta \mathrm{AC}_{\mathrm{i}, \mathrm{t}}-\Delta \mathrm{PC}_{\mathrm{i}, \mathrm{t}}-\Delta$ caixa $_{\mathrm{i}, \mathrm{t}}+\Delta \mathrm{FINCP}_{\mathrm{i}, \mathrm{t}}-$ DEPAM $_{\mathrm{i}, \mathrm{t}}$;

$\Delta \mathrm{AC}_{\mathrm{i}, \mathrm{t}}=$ variação no ativo circulante da firma $i$ entre o ano $t$-1 e o ano $t$;

$\Delta \mathrm{PC}_{\mathrm{i}, \mathrm{t}}=$ variação no passivo circulante da firma $i$ entre o ano $t-1$ e o ano $t$;

$\Delta$ Caixa $_{\mathrm{i}, \mathrm{t}}=$ variação no caixa e equivalentes de caixa da firma $i$ entre o ano $t-1$ e o ano $t$; $\Delta$ FINCP $_{\mathrm{i}, \mathrm{t}}=$ variação dos financiamentos de CP da firma $i$ entre o ano $t-1$ e o ano $t$; DEPAM $_{\mathrm{i}, \mathrm{t}}=$ despesas de depreciação e amortização da firma $i$ no ano $t$;

As variáveis $\mathrm{ACT}_{\mathrm{i}, \mathrm{t}}, \mathrm{FCO}_{\mathrm{i}, \mathrm{t}-1}, \mathrm{FCO}_{\mathrm{i}, \mathrm{t}}$ e $\mathrm{FCO}_{\mathrm{i}, \mathrm{t}+1}$ são escaladas pelos ativos totais.

Depois de estimar a Equação (1) para cada empresa $i$, utilizou-se, como medida de qualidade dos accruals, o desvio padrão dos resíduos: $\mathrm{QA}_{\mathrm{i}}=\sigma\left(\varepsilon_{\mathrm{it}}\right)$. Valores mais elevados de QA indicam accruals de menor qualidade, pois menor variação nos accruals correntes é explicada pelos fluxos de caixa operacionais realizados (FRANCIS et al., 2004). Accruals de menor qualidade implicam um nível de lucros de menor qualidade (GAIO, 2010).

Para computar a persistência dos lucros foi utilizada para cada empresa o modelo proposto por Francis et al. (2004):

$\mathrm{X}_{\mathrm{i}, \mathrm{t}}=\phi_{0, \mathrm{i}}+\phi_{1, \mathrm{i}} \mathrm{X}_{\mathrm{i}, \mathrm{t}-1}+\varepsilon_{\mathrm{i}, \mathrm{t}}$

(Equação 2) 
Em que:

$\mathrm{X}_{\mathrm{i}, \mathrm{t}}=$ lucro líquido antes dos itens extraordinários da firma $i$ no ano $t$ dividido pela média ponderada do número de ações em circulação durante o ano $t$.

$\mathrm{X}_{\mathrm{i}, \mathrm{t}-1}=$ lucro líquido antes dos itens extraordinários da firma $i$ no ano $t$ dividido pela média ponderada do número de ações em circulação durante o ano $t-1$.

Depois de estimar a Equação (2) para cada empresa $i$, a medida de persistência dos lucros é o coeficiente de inclinação estimado da regressão: PERS $=\phi_{1 \mathrm{i}}$. Os valores de $\phi_{1, \mathrm{i}}$ próximos de 1 implicam lucros altamente persistentes, enquanto que os valores de $\phi_{1, \mathrm{i}}$ perto de 0 implicam lucros altamente transitórios (FRANCIS et al., 2004). Lucros persistentes são vistos como lucros de qualidade mais elevada porque são mais sustentáveis (GAIO, 2010).

A medida da previsibilidade dos lucros utilizada nessa pesquisa considera o desvio padrão dos resíduos (PREV $=\varepsilon_{\mathrm{it}}$ ), a partir da aplicação da Equação (2) para cada empresa (FRANCIS et al., 2004; YOON, 2007). Valores menores de resíduos $\left(\varepsilon_{\mathrm{i}, t}\right)$ implicam lucros de qualidade mais elevada e mais previsíveis, enquanto valores maiores implicam resultados menos previsíveis.

Para o cálculo da suavização, utilizou-se o modelo proposto por Leuz, Nanda e Wysocki (2003):

$\mathrm{SUAV}=\sigma\left(\right.$ lucro operacional $\left._{\mathrm{it}}\right) / \sigma\left(\right.$ fluxo de caixa operacional $\left._{i t}\right)$

(Equação 3).

Em que:

$\mathrm{FCO}=$ Lucro Líquido - Accruals

Accruals $=\left\{\left[\mathrm{Ac}_{\mathrm{t}}-\mathrm{Disp}_{\mathrm{t}}\right)-\left(\mathrm{PC}_{\mathrm{t}}-\mathrm{EmpCP}_{\mathrm{t}}\right)\right]-\left[\left(\mathrm{Ac}_{\mathrm{t}-1}-\mathrm{Disp}_{\mathrm{t}-1}\right)-\left(\mathrm{PC}_{\mathrm{t}-1}-\mathrm{EmpCP}_{\mathrm{t}-1}\right)\right]-$ DeprAmort $\left.t_{t}\right\}$

$\mathrm{AC}_{\mathrm{t}}=$ Ativo circulante no ano $\mathrm{t}$; Disp $\mathrm{t}_{\mathrm{t}}=$ Disponibilidades no ano $\mathrm{t} ; \mathrm{PC}_{\mathrm{t}}=$ Passivo circulante no ano $t ; \mathrm{EmpCP}_{\mathrm{t}}=$ Empréstimos de curto prazo em $\mathrm{t} ; \mathrm{AC}_{\mathrm{t}-1}=$ Ativo circulante no ano $\mathrm{t}-1$; Disp $_{\mathrm{t}-1}=$ Disponibilidades no ano $\mathrm{t}-1 ; \mathrm{PC}_{\mathrm{t}-1}=$ Passivo circulante no ano $\mathrm{t}-1 ; \mathrm{EmpCP}_{\mathrm{t}-1}=$ Empréstimos de curto prazo em $\mathrm{t}-1$. As variáveis de lucro operacional e fluxo de caixa foram divididas pelos ativos totais do início do ano.

A medida de suavização (SUAV) indica que valores abaixo de 1 correspondem a maior variabilidade no fluxo de caixa operacional em relação aos lucros, implicando o uso de accruals para suavizar os resultados contábeis. Valores mais elevados dessa variável indicam lucros menos suavizados (GAIO, 2010). Para os propósitos deste estudo, é assumido que a suavização é um atributo desejado dos lucros e, assim, menor suavização dos lucros implica menor qualidade dos lucros (GAIO, 2010).

Após o cálculo de cada atributo individualmente, utilizou-se a análise multicritério Technique for Order Preference by Smilarity to Ideal Solution - TOPSIS (BULGURCU, 2012), com uso da técnica da entropia (ZELENY, 1982) para definição do peso de cada vetor, para construir o ranking agregado da qualidade da informação contábil, resultando em escores individuais entre 0 e 1 . O TOPSIS é baseado no ranking de alternativas para obter a melhor seleção alternativa, a qual está próxima da solução ideal, levando em consideração a distância 
da solução ideal e da solução anti-ideal (BULGURCU, 2012). De acordo com essa técnica, a melhor alternativa deveria ser aquela que está mais próxima da solução ideal e o mais distante da solução ideal negativa (BENITEZ; MARTIN; ROMAN, 2007).

Para a definição do peso de cada atributo no ranking da qualidade da informação contábil, utilizou-se o conceito da entropia associado ao método TOPSIS. A entropia refere-se à incerteza probabilística relacionada a uma distribuição de probabilidade, de modo que quanto mais dispersa a distribuição de probabilidade, maior incerteza refletirá. Nesse sentido, o grau de incerteza é reflexo de uma determinada distribuição, e distintas distribuições estão associadas a distintos graus de improbabilidade (MATTOS; VEIGA, 2002).

$\mathrm{O}$ ranking da qualidade dos lucros por empresa foi elaborado com base nos valores de cada uma das quatro variáveis individuais baseadas nos atributos de contabilidade. Com o uso da metodologia TOPSIS, os vetores (pesos) obtidos por meio da técnica da entropia foram: $\mathrm{QA}=0,0480 ; \mathrm{PERS}=0,3183 ; \mathrm{PREV}=0,0212 ; \mathrm{SUAV}=0,6125$.

Quanto menor a entropia no conjunto de dados, maior o peso do atributo. Assim, os atributos de SUAV e PERS demonstraram menor entropia e maior peso, evidenciando que a suavização dos lucros e a persistência, comparados com os demais indicadores, causaram o maior efeito surpresa ao apresentar maior diversidade de informação entre as empresas investigadas. As variáveis explicativas utilizadas são aquelas apresentadas na Tabela 1.

Tabela 1 - Variáveis Explicativas

\begin{tabular}{|c|c|c|}
\hline Variáveis Explicativas & Métrica & Fonte \\
\hline Origem Legal & $\begin{array}{l}\text { ORIGEM = variável dummy, sendo } 1 \text { para o país com sistema } \\
\text { common law e } 0 \text { para code law. }\end{array}$ & $\begin{array}{l}\text { Bushman e } \\
\text { Piotroski (2006) }\end{array}$ \\
\hline Carga Tributária & $\begin{array}{l}\text { CTRIB = Escala de } 0 \text { (alta) a } 10 \text { (baixa) para taxa de imposto } \\
\text { marginal; }\end{array}$ & $\begin{array}{l}\text { Economic Freedom } \\
\text { of the World (2013) }\end{array}$ \\
\hline Ambiente Legal & $\begin{array}{l}\text { AMBIENTE = Escala de } 1 \text { a } 7, \text { sendo } 1 \text { para ambiente pouco } \\
\text { desenvolvido e } 7 \text { para ambiente altamente desenvolvido. }\end{array}$ & $\begin{array}{l}\text { World Economic } \\
\text { Forum (2013) }\end{array}$ \\
\hline $\begin{array}{l}\text { Alavancagem } \\
\text { Financeira }\end{array}$ & $A L A V=\frac{\text { Passivo Circulante }+ \text { Passivo } N \text { äo Circulante }}{\text { Ativo total }}$ & $\begin{array}{l}\text { Isidro e Raonic } \\
(2012)\end{array}$ \\
\hline Retorno Sobre Ativos & ROA $=\frac{\text { Lucro Antes dos Juros } \mathrm{e} \text { dos Impostos }}{\text { Ativo total }}$ & Iatridis (2010) \\
\hline $\begin{array}{l}\text { Índice de Percepção } \\
\text { da Corrupção }\end{array}$ & $\begin{array}{l}\text { IPC }=\text { Escala de } 0 \text { a } 10, \text { sendo } 0 \text { para países altamente } \\
\text { corruptos e } 10 \text { para altamente transparentes. }\end{array}$ & $\begin{array}{l}\text { Transparency } \\
\text { International (2012) }\end{array}$ \\
\hline $\begin{array}{l}\text { Desenvolvimento } \\
\text { Econômico }\end{array}$ & $\mathrm{NDE}=$ Logaritmo natural do produto interno bruto per capita & $\begin{array}{l}\text { The World Bank } \\
\text { (2014) }\end{array}$ \\
\hline $\begin{array}{l}\text { Desenvolvimento do } \\
\text { Mercado Financeiro }\end{array}$ & $\begin{array}{l}\text { NDF = Capitalização no mercado de ações dividido pelo } \\
\text { produto interno bruto. }\end{array}$ & $\begin{array}{l}\text { The World Bank } \\
\text { (2014) }\end{array}$ \\
\hline $\begin{array}{l}\text { Grau de } \\
\text { Internacionalização }\end{array}$ & $\begin{array}{l}\text { Ranking da relação: } \\
G_{-} I N T E R=\left(\frac{\text { Vendas Exterior }}{\text { Vendas Totais }}+\frac{\text { Ativos no Exterior }}{\text { Ativos Totais }}\right) / 2\end{array}$ & UNCTAD (1995). \\
\hline
\end{tabular}

Fonte: Dados da pesquisa.

As variáveis de controle utilizadas são aquelas apresentadas na Tabela 2. 
Tabela 2 - Variáveis de Controle

\begin{tabular}{|c|c|c|}
\hline Variáveis de controle & Métrica & Fonte \\
\hline Tamanho & $\begin{array}{l}\text { TAM = Logaritmo natural do valor contábil do ativo total no } \\
\text { final do período. }\end{array}$ & Gaio (2010) \\
\hline $\begin{array}{l}\text { Crescimento das } \\
\text { vendas }\end{array}$ & $\begin{array}{l}\text { Logaritmo natural da relação: } \\
C V E N D=\left(\frac{\text { Vendas ano } 2-\text { Vendas ano } 1}{\text { Vendas ano } 1} \times 100\right)\end{array}$ & Gaio (2010) \\
\hline Setor econômico & $\begin{array}{l}\text { Variáveis dummies indicando o setor econômico de cada } \\
\text { empresa. }\end{array}$ & $\begin{array}{l}\text { Ball e Shivakumar } \\
(2005)\end{array}$ \\
\hline Empresa de auditoria & $\begin{array}{l}\text { AUDITORIA = variável } d u m m y \text {, sendo } 1 \text { para empresa } \\
\text { auditada por big four e } 0 \text { para as demais; }\end{array}$ & Barth et al. (2008) \\
\hline $\begin{array}{l}\text { Volatilidade do fluxo } \\
\text { de caixa }\end{array}$ & DPFCO $=\left(\frac{\text { Desvio padräo do FCO }}{\text { Ativo total }}\right)$ & Gaio (2010) \\
\hline
\end{tabular}

Fonte: Dados da pesquisa.

A variável AMBIENTE foi construída com base na média linear dos indicadores de aplicação das leis para valores mobiliários, proteção dos interesses de acionistas minoritários, aplicação das normas de contabilidade e auditoria, independência judicial, publicados pelo World Economic Forum (2013). Variáveis dummies também foram utilizadas para considerar a presença de empresas pertencentes aos diferentes setores econômicos (indústria, comércio, serviços).

O modelo econométrico, utilizado para verificar a influência das normas reguladoras e dos incentivos empresariais com a segregação das empresas em diferentes níveis de ambiente legal, é aquele explicitado na Equação (4). Na Equação (5), ocorre a inclusão da variável de internacionalização das empresas.

$\mathrm{QIC}_{\mathrm{i}}=\alpha_{0}+\alpha_{1} \mathrm{CTRIB}_{\mathrm{j}}+\alpha_{2} \mathrm{ALAV}_{\mathrm{i}}+\alpha_{3} \mathrm{ROA}_{\mathrm{i}}+\alpha_{4} \mathrm{NDE}_{\mathrm{j}}+\alpha_{5} \mathrm{TAM}_{\mathrm{i}}+\alpha_{6} \mathrm{CVEND}_{\mathrm{i}}+\alpha_{7} \mathrm{IND}_{\mathrm{i}}+$ $\alpha_{8} \mathrm{COM}_{\mathrm{i}}+\alpha_{9}$ AUDITORIA $_{\mathrm{i}}+\alpha_{10}$ DPFCO $_{\mathrm{i}}+\varepsilon_{\mathrm{i}}$

(Equação 4).

$\mathrm{QIC}_{\mathrm{i}}=\alpha_{0}+\alpha_{1} \mathrm{CTRIB}_{\mathrm{j}}+\alpha_{2} \mathrm{ALAV}_{\mathrm{i}}+\alpha_{3} \mathrm{ROA}_{\mathrm{i}}+\alpha_{4} \mathrm{NDE}_{\mathrm{j}}+\alpha_{5} \mathrm{TAM}_{\mathrm{i}}+\alpha_{6} \mathrm{CVEND}_{\mathrm{i}}+\alpha_{7} \mathrm{IND}_{\mathrm{i}}+$ $\alpha_{8}$ COM $_{i}+\alpha_{9}$ AUDITORIA $_{i}+\alpha_{10}$ DPFCO $_{i}+\alpha_{11} \mathbf{G}_{-}$INTER $_{\mathbf{i}}+\varepsilon_{\mathrm{i}}$

(Equação 5).

$\mathrm{Na}$ Equação (6), é apresentado o modelo econométrico que analisa a influência das normas reguladoras e dos incentivos empresariais com a segregação das empresas em diferentes níveis de percepção de corrupção do país de origem das empresas. Na Equação (7), ocorre a inclusão da variável de internacionalização das empresas.

QIC $_{i}=\alpha_{0}+\alpha_{1}$ AMBIENTE $_{\mathrm{i}}+\alpha_{2}$ ALAV $_{\mathrm{i}}+\alpha_{3} \mathrm{ROA}_{\mathrm{i}}+\alpha_{4} \mathrm{NDF}_{\mathrm{j}}+\alpha_{5} \mathrm{TAM}_{\mathrm{i}}+\alpha_{6} \mathrm{CVEND}_{\mathrm{i}}+\alpha_{7} \mathrm{IND}_{\mathrm{i}}+$ $\alpha_{8} \mathrm{COM}_{\mathrm{i}}+\alpha_{9}$ AUDITORIA $_{\mathrm{i}}+\alpha_{10}$ DPFCO $_{\mathrm{i}}+\varepsilon_{\mathrm{i}}$

(Equação 6). 
QIC $_{i}=\alpha_{0}+\alpha_{1}$ AMBIENTE $_{\mathrm{i}}+\alpha_{2}$ ALAV $_{\mathrm{i}}+\alpha_{3} \mathrm{ROA}_{\mathrm{i}}+\alpha_{4} \mathrm{NDF}_{\mathrm{j}}+\alpha_{5} \mathrm{TAM}_{\mathrm{i}}+\alpha_{6} \mathrm{CVEND}_{\mathrm{i}}+\alpha_{7} \mathrm{IND}_{\mathrm{i}}+$ $\alpha_{8}$ COM $_{\mathrm{i}}+\alpha_{9}$ AUDITORIA $_{\mathrm{i}}+\alpha_{10}$ DPFCO $_{\mathrm{i}}+\alpha_{11} \mathbf{G}_{-}$INTER $_{\mathbf{i}}+\varepsilon_{\mathrm{i}}$

(Equação 7).

$\mathrm{Na}$ Equação (8), tem-se o modelo que analisa a influência das normas reguladoras e incentivos empresariais, com a segregação pela origem legal dos países de origem das empresas. Na Equação (9), ocorre a inclusão da variável de internacionalização das empresas.

$\mathrm{QIC}_{\mathrm{i}}=\alpha_{0}+\alpha_{1} \mathrm{AMBIENTE}_{\mathrm{i}}+\alpha_{2} \mathrm{CTRIB}_{\mathrm{i}}+\alpha_{3} \mathrm{ALAV}_{\mathrm{i}}+\alpha_{4} \mathrm{ROA}_{\mathrm{i}}+\alpha_{5} \mathrm{NDE}_{\mathrm{j}}+\alpha_{6} \mathrm{TAM}_{\mathrm{i}}+$ $\alpha_{7}$ CVEND $_{\mathrm{i}}+\alpha_{8}$ IND $_{\mathrm{i}}+\alpha_{9} \mathrm{COM}_{\mathrm{i}}+\alpha_{10}$ AUDITORIA $_{\mathrm{i}}+\alpha_{11}$ DPFCO $_{\mathrm{i}}+\varepsilon_{\mathrm{i}}$

(Equação 8).

QIC $_{\mathrm{i}}=\alpha_{0}+\alpha_{1}$ AMBIENTE $_{\mathrm{i}}+\alpha_{2}$ CTRIB $_{\mathrm{i}}+\alpha_{3} \mathrm{ALAV}_{\mathrm{i}}+\alpha_{4} \mathrm{ROA}_{\mathrm{i}}+\alpha_{5} \mathrm{NDE}_{\mathrm{j}}+\alpha_{6} \mathrm{TAM}_{\mathrm{i}}+\alpha_{7} \mathrm{CVEND}_{\mathrm{i}}+$ $\alpha_{8}$ IND $_{\mathrm{i}}+\alpha_{9}$ COM $_{\mathrm{i}}+\alpha_{10}$ AUDITORIA $_{\mathrm{i}}+\alpha_{11}$ DPFCO $_{\mathrm{i}}+\alpha_{12} \mathrm{G}_{-}$INTER $_{1}+\varepsilon_{\mathrm{i}}$

(Equação 9).

A Equação (10) apresenta a especificação do modelo da relação entre a QIC, normas reguladoras e os incentivos empresariais. Na Equação (11), ocorre a inclusão da variável de internacionalização das empresas.

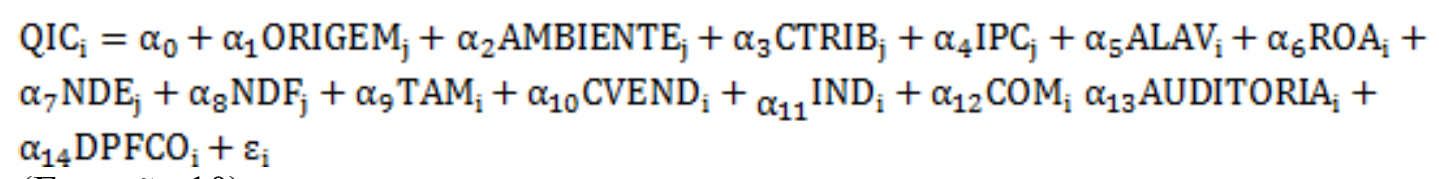

(Equação 10).

$\mathrm{QIC}_{\mathrm{i}}=\alpha_{0}+\alpha_{1}$ ORIGEM $_{\mathrm{j}}+\alpha_{2}$ AMBIENTE $_{\mathrm{j}}+\alpha_{3}$ CTRIB $_{\mathrm{j}}+\alpha_{4}$ IPC $_{\mathrm{j}}+\alpha_{5} \mathrm{ALAV}_{\mathrm{i}}+\alpha_{6} \mathrm{ROA}_{\mathrm{i}}+$ $\alpha_{7} \mathrm{NDE}_{\mathrm{j}}+\alpha_{8} \mathrm{NDF}_{\mathrm{j}}+\alpha_{9} \mathrm{TAM}_{\mathrm{i}}+\alpha_{10} \mathrm{CVEND}_{\mathrm{i}}+\alpha_{11} \mathrm{IND}_{\mathrm{i}}+\alpha_{12} \mathrm{COM}_{\mathrm{i}}+\alpha_{13}$ AUDITORIA $_{\mathrm{i}}+$ $\alpha_{14}$ DPFCO $_{\mathrm{i}}+\alpha_{15} \mathrm{G}_{-}$INTER $_{\mathrm{i}}+\varepsilon_{\mathrm{i}}$

(Equação 11).

Para a análise dos resultados foi utilizada a regressão linear multivariada com análise cross-section (transversal). Os modelos econométricos utilizados atenderam aos pressupostos da homoscedasticidade, multicolinearidade e autocorrelação de resíduos. O pressuposto da normalidade ficou abaixo da $\alpha, 5 \%$ em algumas estimativas, porém, considerando o tamanho da amostra, esse pressuposto pode ser relaxado (STEVENSON, 2001).

\section{Análise e Interpretação dos Resultados}

Essa seção contém a descrição e análise dos dados coletados. Inicialmente apresentase o teste de médias para verificar a existência de diferenças na qualidade da informação contábil com base em diferentes contextos. Em seguida, apresentam-se os resultados da aplicação dos modelos econométricos. 


\subsection{Teste de Médias}

O cálculo do Teste t de Student a partir de amostras independentes (não evidenciado) foi elaborado para verificar a existência de diferenças nas médias da qualidade da informação contábil entre os grupos. Para agrupar as empresas, foi utilizado, como critério, a mediana de cada variável, em que o grupo 1 contém as empresas com escores abaixo da mediana, e o grupo 2, as empresas com escore igual ou superior à mediana. Também foram agrupadas as empresas localizadas em países de origem common law (grupo 1) e code law (grupo 2).

Os resultados indicaram que as empresas localizadas em países com carga tributária menor, ambiente legal mais forte, maior desenvolvimento econômico, maior desenvolvimento do mercado financeiro e de origem legal common law apresentaram médias mais elevadas no ranking agregado da QIC. Por outro lado, empresas localizadas em países com menor transparência, apresentaram melhores escores no ranking de QIC. As empresas com maior grau de internacionalização apresentaram níveis mais elevados no ranking da QIC.

Ao se aplicar o teste de Levene e o teste $t$ de igualdade de médias, verificou-se que as características dos países de origem, a exemplo da carga tributária, do ambiente legal, do nível de desenvolvimento econômico e do mercado financeiro, da origem legal e do nível de transparência, conduziram para diferenças estatisticamente significativas entre as empresas no ranking da QIC reportada. Além disso, observa-se que o maior grau de internacionalização das empresas também se constitui em determinante significativa a ser considerada para explicar o posicionamento no ranking da QIC.

\subsection{Ambiente Legal}

Para investigar o comportamento dos resultados em diferentes níveis de ambiente legal, a amostra foi separada em dois grupos, a partir da mediana da variável AMBIENTE $(5,35)$. A Tabela 3 apresenta os resultados para as empresas dos países com nível abaixo da mediana, e a Tabela 4 contempla as empresas localizadas em países com nível igual ou acima da mediana da variável representativa do ambiente legal. Para a coluna (1) das Tabelas 3 e 4, o modelo utilizado é aquele apresentado na Equação (4), e para a coluna (2) a Equação (5).

A Tabela 3 apresenta os resultados da amostra que inclui 446 empresas localizadas no Brasil, na China, na Indonésia e no Japão. Os resultados da Tabela 3 indicam que os modelos utilizados na coluna (1) e na coluna (2) apresentaram relação estatisticamente significativa com a variável dependente ao nível de $5 \%$ e $1 \%$, respectivamente (estatística $\mathrm{F}$ ).

Os resultados da coluna (1) indicaram que a variável ALAV apresentou relação negativa e significativa, e a variável IND demonstrou-se positiva e significativa com o ranking da QIC, ambas a 5\% e com sinal igual ao esperado. A coluna (2) indica que as variáveis ALAV e DPFCO apresentaram relação negativa e significativa com o ranking da QIC, a $10 \%$ e $5 \%$, conforme o esperado.

A variável G_INTER apresentou resultados estatisticamente significativos com a variável dependente ao nível de $1 \%$, reforçando a importância relativa da internacionalização das empresas para explicar o posicionamento no ranking da QIC. 
Determinantes da qualidade da informação contábil no contexto internacional.

Tabela 3 - Determinantes do ranking agregado QIC: ambiente legal < da mediana

\begin{tabular}{|c|c|c|c|c|}
\hline \multicolumn{5}{|c|}{ Variável dependente: Qualidade da Informação Contábil (QIC) } \\
\hline \multirow[b]{2}{*}{ Variáveis explicativas } & \multicolumn{2}{|c|}{ (1) NORMAS E INCENTIVOS } & \multicolumn{2}{|c|}{ (2) NORMAS E INCENTIVOS + G INTER } \\
\hline & Coeficiente B & Estatística $t$ & Coeficiente B & Estatística $t$ \\
\hline Constante & $-1,244$ & $-0,418$ & $-0,686$ & $-0,239$ \\
\hline CTRIB & 0,133 & 0,487 & 0,184 & 0,698 \\
\hline ALAV & $-0,120$ & $-2,282 * *$ & $-0,097$ & $-1,907 *$ \\
\hline ROA & $-0,125$ & $-1,042$ & $-0,154$ & $-1,329$ \\
\hline NDE & $-0,013$ & $-0,035$ & $-0,129$ & $-0,361$ \\
\hline TAM & 0,049 & 1,099 & 0,046 & 1,071 \\
\hline CVEND & $-0,050$ & $-0,653$ & $-0,019$ & $-0,260$ \\
\hline IND & 0,271 & $2,180 * *$ & 0,009 & 0,074 \\
\hline $\mathrm{COM}$ & $-0,016$ & $-0,115$ & $-0,060$ & $-0,436$ \\
\hline AUDITORIA & 0,126 & 1,103 & 0,131 & 1,187 \\
\hline DPFCO & $-0,002$ & $-0,029$ & $-0,142$ & $-2,178 * *$ \\
\hline G_INTER & & & 0,404 & $5,840 * * *$ \\
\hline Estatística F & \multicolumn{2}{|c|}{$1,967 * *$} & \multicolumn{2}{|l|}{$5,024 * * *$} \\
\hline $\mathrm{R}^{2}$ ajustado & \multicolumn{2}{|c|}{0,021} & \multicolumn{2}{|l|}{0,090} \\
\hline Tolerance & \multicolumn{2}{|c|}{1 até 0,10} & \multicolumn{2}{|l|}{1 até 0,10} \\
\hline VIF & \multicolumn{2}{|c|}{1 até 10} & \multicolumn{2}{|l|}{1 até 10} \\
\hline DW & \multicolumn{2}{|c|}{2,266} & \multicolumn{2}{|l|}{2,303} \\
\hline K-S (sig.) & \multicolumn{2}{|c|}{0,111} & \multicolumn{2}{|l|}{0,058} \\
\hline Pesarán-Pesarán (sig.) & \multicolumn{2}{|c|}{0,434} & \multicolumn{2}{|l|}{0,141} \\
\hline $\mathrm{N}$ & \multicolumn{2}{|c|}{446} & \multicolumn{2}{|l|}{446} \\
\hline
\end{tabular}

Fonte: Dados da pesquisa.

A Tabela 4 apresenta os resultados da amostra que inclui 960 empresas localizadas na Alemanha, na Austrália, no Canadá, nos Estados Unidos, na Índia, na Holanda, no Reino Unido e na Suíça. Os resultados da Tabela 4 indicam que os modelos utilizados na coluna (1) e na coluna (2) apresentaram relação estatisticamente significativa com a variável dependente ao nível de $1 \%$ (estatística $\mathrm{F}$ ).

Tabela 4 - Determinantes do ranking agregado da QIC: ambiente legal $\geq$ da mediana

\begin{tabular}{|c|c|c|c|c|}
\hline \multicolumn{5}{|c|}{ Variável dependente: Qualidade da Informação Contábil (QIC) } \\
\hline \multirow[b]{2}{*}{ Variáveis explicativas } & \multicolumn{2}{|c|}{ (1) NORMAS E INCENTIVOS } & \multicolumn{2}{|c|}{ (2) NORMAS E INCENTIVOS + GI } \\
\hline & Coeficiente B & Estatística $t$ & Coeficiente B & Estatística $t$ \\
\hline Constante & $-1,749$ & $-4,647$ & $-1,746$ & $-4,647$ \\
\hline CTRIB & 0,021 & 0,942 & 0,042 & $1,706^{*}$ \\
\hline ALAV & $-0,157$ & $-4,112 * * *$ & $-0,148$ & $-3,882 * * *$ \\
\hline ROA & 0,013 & 0,268 & 0,012 & 0,257 \\
\hline NDE & 0,291 & $3,830 * * *$ & 0,267 & $3,484 * * *$ \\
\hline TAM & $-0,102$ & $-3,414 * * *$ & $-0,104$ & $-3,476 * * *$ \\
\hline CVEND & 0,021 & 0,621 & 0,021 & 0,616 \\
\hline IND & 0,456 & $6,208 * * *$ & 0,412 & $5,428 * * *$ \\
\hline $\mathrm{COM}$ & 0,296 & $3,336 * * *$ & 0,275 & $3,083 * * *$ \\
\hline
\end{tabular}




\begin{tabular}{|c|c|c|c|c|}
\hline AUDITORIA & 0,106 & 1,147 & 0,093 & 1,000 \\
\hline DPFCO & $-0,021$ & $-0,603$ & $-0,043$ & $-1,177$ \\
\hline G_INTER & & & 0,074 & $2,153^{* *}$ \\
\hline Estatística F & \multicolumn{2}{|c|}{$11,777^{* * *}$} & \multicolumn{2}{|c|}{$11,169^{* * *}$} \\
\hline $\mathrm{R}^{2}$ ajustado & \multicolumn{2}{|c|}{0,101} & \multicolumn{2}{|c|}{0,104} \\
\hline Tolerance & \multicolumn{2}{|c|}{1 até 0,10} & \multicolumn{2}{|c|}{1 até 0,10} \\
\hline VIF & \multicolumn{2}{|c|}{1 até 10} & \multicolumn{2}{|c|}{1 até 10} \\
\hline DW & \multicolumn{2}{|c|}{1,945} & \multicolumn{2}{|c|}{1,944} \\
\hline K-S (sig.) & \multicolumn{2}{|c|}{0,499} & \multicolumn{2}{|c|}{0,462} \\
\hline Pesarán-Pesarán (sig.) & \multicolumn{2}{|c|}{0,300} & \multicolumn{2}{|c|}{0,365} \\
\hline $\mathrm{N}$ & \multicolumn{2}{|c|}{960} & \multicolumn{2}{|c|}{960} \\
\hline \multicolumn{5}{|c|}{ Significativo ao nível de $10 \% * ; 5 \% * * ; 1 \% * * *$} \\
\hline
\end{tabular}

Os resultados da coluna (1) e da coluna (2) indicaram que as variáveis ALAV e TAM apresentaram relações negativas e significativas com a QIC, ao nível de $1 \%$. Já as variáveis NDE, IND e COM corroboram as predições empíricas e manifestaram-se positivamente relacionadas de forma significativa a $1 \%$ com a variável dependente.

A variável G_INTER apresentou resultados estatisticamente significativos com a variável dependente ao nível de 5\%. Assim, uma vez mais se constata a importância relativa da intensidade da internacionalização das empresas para explicar o posicionamento no ranking da QIC. As variáveis de retorno sobre ativos (ROA) e crescimento de vendas (CVEND), não se constituíram em fator explicativo para o posicionamento das empresas no ranking agregado da QIC, tanto em ambientes legais mais fracos (Tabela 3), quanto em ambientes legais mais robustos (Tabela 4).

Conforme o esperado, o poder explicativo das abordagens com empresas localizadas nos países com ambiente legal mais robusto (Tabela 4) se mostrou mais elevado que o daquelas empresas localizadas em países com ambiente legal mais fraco (Tabela 3). Uma possível explicação para os resultados é que, em países com ambiente legal mais robusto, as instituições possuem estruturas mais condizentes para realizar o escrutínio público, tornando mais oneroso para as empresas divulgar números contábeis que não estão atrelados à sua realidade econômica e financeira.

\section{3 Índice de Percepção da Corrupção}

Nessa análise, a amostra foi separada em dois grupos com base na mediana da variável IPC $(7,30)$, com o intuito de investigar os resultados em ambientes com diferentes níveis de percepção da corrupção. A Tabela 5 apresenta os resultados para os países com nível abaixo da mediana, enquanto a Tabela 6 evidencia as empresas localizadas em países com nível igual ou acima da mediana do nível de percepção da corrupção. Para a coluna (1) das Tabelas 5 e 6 , o modelo utilizado é aquele apresentado na Equação (6), enquanto para a coluna (2) foi utilizado o modelo da Equação (7).

A Tabela 5 apresenta os resultados da amostra que inclui 661 empresas do Brasil, dos Estados Unidos, da Índia e da Indonésia. Os resultados da Tabela 5 indicam que os modelos utilizados na coluna (1) e na coluna (2) apresentaram relação estatisticamente significativa com a variável dependente ao nível de $1 \%$ (estatística $\mathrm{F}$ ).

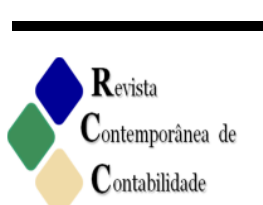

ISSN 2175-8069, UFSC, Florianópolis, v. 13, n. 29, p. 03-32, mai. /ago. 2016 
Determinantes da qualidade da informação contábil no contexto internacional.

Tabela 5 - Determinantes do ranking agregado da QIC: IPC < da mediana

\begin{tabular}{|c|c|c|c|c|}
\hline \multicolumn{5}{|c|}{ Variável dependente: Qualidade da Informação Contábil (QIC) } \\
\hline \multirow[b]{2}{*}{ Variáveis explicativas } & \multicolumn{2}{|c|}{ (1) NORMAS E INCENTIVOS } & \multicolumn{2}{|c|}{ (2) NORMAS, INCENTIVOS + G_INTER } \\
\hline & Coeficiente B & Estatística $t$ & Coeficiente B & Estatística $t$ \\
\hline Constante & 0,031 & 0,025 & 0,286 & 0,237 \\
\hline AMBIENTE & $-0,269$ & $-1,081$ & $-0,282$ & $-1,139$ \\
\hline ALAV & $-0,160$ & $-3,560 * * *$ & $-0,148$ & $-3,290 * * *$ \\
\hline ROA & 0,021 & 0,369 & 0,022 & 0,380 \\
\hline NDF & 0,010 & $3,908 * * *$ & 0,009 & $3,468 * * *$ \\
\hline TAM & $-0,131$ & $-3,648 * * *$ & $-0,130$ & $-3,644 * * *$ \\
\hline CVEND & $-0,004$ & $-0,087$ & $-0,003$ & $-0,075$ \\
\hline IND & 0,480 & $5,365 * * *$ & 0,420 & $4,523 * * *$ \\
\hline $\mathrm{COM}$ & 0,246 & $2,305^{* *}$ & 0,211 & $1,969 * *$ \\
\hline AUDITORIA & 0,170 & 1,588 & 0,154 & 1,434 \\
\hline DPFCO & $-0,010$ & $-0,223$ & $-0,038$ & $-0,853$ \\
\hline G_INTER & & & 0,114 & $2,349 * *$ \\
\hline Estatística F & \multicolumn{2}{|c|}{$10,512 * * *$} & \multicolumn{2}{|c|}{$10,124 * * *$} \\
\hline $\mathrm{R}^{2}$ ajustado & \multicolumn{2}{|c|}{0,126} & \multicolumn{2}{|c|}{0,132} \\
\hline Tolerance & \multicolumn{2}{|c|}{1 até 0,10} & \multicolumn{2}{|c|}{1 até 0,10} \\
\hline VIF & \multicolumn{2}{|c|}{1 até 10} & \multicolumn{2}{|c|}{1 até 10} \\
\hline DW & \multicolumn{2}{|c|}{1,991} & \multicolumn{2}{|c|}{1,996} \\
\hline K-S (sig.) & \multicolumn{2}{|c|}{0,634} & \multicolumn{2}{|l|}{0,485} \\
\hline Pesarán-Pesarán (sig.) & \multicolumn{2}{|c|}{0,287} & \multicolumn{2}{|c|}{0,325} \\
\hline $\mathrm{N}$ & \multicolumn{2}{|c|}{661} & \multicolumn{2}{|c|}{661} \\
\hline Significativo ao nível & $; 5 \% * * ; 1 \% * * *$ & & & \\
\hline
\end{tabular}

Fonte: Dados da pesquisa.

Os resultados da coluna (1) e (2) indicaram que as variáveis ALAV e TAM apresentaram, conforme o esperado, relações negativas e significativas ao nível de $1 \%$ com o ranking dos atributos da QIC. Também de acordo com as predições empíricas prévias, as variáveis NDF, IND e COM demonstraram-se positiva e estatisticamente significativas para explicar a QIC das empresas investigadas, todas a 5\% e com sinal igual ao esperado.

A variável G_INTER apresentou resultados estatisticamente significativos com a variável dependente ao nível de 5\%, reforçando sua importância em explicar o posicionamento das empresas no ranking da QIC.

A Tabela 6 evidencia os resultados da amostra que inclui 745 empresas localizadas na Alemanha, na Austrália, no Canadá, na China, na Holanda, no Japão, no Reino Unido e na Suíça. Os resultados dos modelos utilizados demonstram relação positiva e estatisticamente significativa com a variável dependente, ao nível de 1\% (estatística F). Os resultados apresentados para as variáveis ALAV, NDF e IND se comportaram de forma semelhante àqueles da Tabela 5 , indicando que servem de estímulos em ambos os ambientes de transparência institucional dos países.

Em ambientes mais transparentes (Tabela 6), a variável DPFCO mostrou-se negativa e estatisticamente significativa, conforme o esperado, somente no modelo que contém a variável de internacionalização das empresas (coluna 2). Uma explicação possível reside na 
predição empírica de que as empresas mais internacionalizadas possuem lucros e fluxos de caixa mais estáveis em relação às demais empresas.

Tabela 6 - Determinantes do ranking agregado da QIC: IPC $\geq$ da mediana

\begin{tabular}{|c|c|c|c|c|}
\hline \multicolumn{5}{|c|}{ Variável dependente: Qualidade da Informação Contábil (QIC) } \\
\hline \multirow[b]{2}{*}{ Variáveis explicativas } & \multicolumn{2}{|c|}{ (1) NORMAS E INCENTIVOS } & \multicolumn{2}{|c|}{ (2) NORMAS E INCENTIVOS + GI } \\
\hline & Coeficiente B & Estatística $t$ & Coeficiente B & Estatística $t$ \\
\hline Constante & $-2,455$ & $-5,293$ & $-1,237$ & $-2,393$ \\
\hline AMBIENTE & 0,333 & $3,653 * * *$ & 0,130 & 1,319 \\
\hline ALAV & $-0,121$ & $-2,922 * * *$ & $-0,112$ & $-2,751 * * *$ \\
\hline ROA & $-0,018$ & $-0,266$ & $-0,041$ & $-0,604$ \\
\hline NDF & 0,003 & $2,345^{* *}$ & 0,002 & $1,708^{*}$ \\
\hline TAM & 0,030 & 0,875 & 0,019 & 0,541 \\
\hline CVEND & 0,070 & 1,570 & 0,070 & 1,586 \\
\hline IND & 0,320 & $3,591 * * *$ & 0,208 & $2,298^{* *}$ \\
\hline $\mathrm{COM}$ & 0,124 & 1,169 & 0,100 & 0,956 \\
\hline AUDITORIA & $-0,009$ & $-0,091$ & $-0,001$ & $-0,011$ \\
\hline DPFCO & $-0,026$ & $-0,630$ & $-0,103$ & $-2,360 * *$ \\
\hline G_INTER & & & 0,202 & $5,022 * * *$ \\
\hline Estatística F & \multicolumn{2}{|c|}{$6,517 * * *$} & \multicolumn{2}{|c|}{$8,413^{* * *}$} \\
\hline $\mathrm{R}^{2}$ ajustado & \multicolumn{2}{|c|}{0,069} & \multicolumn{2}{|c|}{0,099} \\
\hline Tolerance & \multicolumn{2}{|c|}{1 até 0,10} & \multicolumn{2}{|c|}{1 até 0,10} \\
\hline VIF & \multicolumn{2}{|c|}{1 até 10} & \multicolumn{2}{|c|}{1 até 10} \\
\hline DW & \multicolumn{2}{|c|}{2,073} & \multicolumn{2}{|c|}{2,093} \\
\hline K-S (sig.) & \multicolumn{2}{|c|}{0,056} & \multicolumn{2}{|c|}{0,030} \\
\hline Pesarán-Pesarán (sig.) & \multicolumn{2}{|c|}{0,283} & \multicolumn{2}{|c|}{0,201} \\
\hline $\mathrm{N}$ & \multicolumn{2}{|c|}{745} & \multicolumn{2}{|c|}{745} \\
\hline Significativo ao nível d & $5 \%^{* *} ; 1 \%^{* * *}$. & & & \\
\hline
\end{tabular}

Repetindo os resultados da amostra com empresas localizadas em países de menor índice de transparência (Tabela 5), a variável G_INTER apresenta relação positiva e significativa com o ranking agregado da qualidade da informação contábil, conforme o esperado, ao nível de $1 \%$ (Tabela 6).

Conforme já apresentado no item 4.1, as empresas localizadas em países com maior nível de transparência, diferentemente do esperado, demonstraram níveis mais baixos no escore do ranking dos atributos de QIC. Os resultados da Tabela 6 (países mais transparentes) corroboram esses achados ao apresentar um poder explicativo menor que o do modelo da Tabela 5 (países menos transparentes). Uma possível explicação decorre da necessidade de as empresas localizadas em países menos transparentes evitarem possíveis problemas de agência e reduzirem litígios de risco moral e seleção adversa ao se tornarem mais internacionalizadas.

\subsection{Origem Legal}


Nessa análise, a amostra foi separada em dois grupos de acordo com a origem legal do país sede das empresas. A Tabela 7 apresenta os resultados para as empresas localizadas nos países com sistema jurídico code law. A amostra inclui 524 empresas sediadas na Alemanha, no Brasil, na China, na Holanda, na Indonésia, no Japão e na Suíça.

Tabela 7 - Determinantes do ranking agregado da QIC: code law

\begin{tabular}{|c|c|c|c|c|}
\hline \multicolumn{5}{|c|}{ Variável dependente: Qualidade da Informação Contábil (QIC) } \\
\hline \multirow[b]{2}{*}{ Variáveis explicativas } & \multicolumn{2}{|c|}{ (1) NORMAS E INCENTIVOS } & \multicolumn{2}{|c|}{ (2) NORMAS E INCENTIVOS + G INTER } \\
\hline & Coeficiente B & Estatística $t$ & Coeficiente B & Estatística $t$ \\
\hline Constante & $-0,988$ & $-1,237$ & 0,634 & 0,771 \\
\hline AMBIENTE & 0,339 & $2,286^{* *}$ & $-0,118$ & $-0,723$ \\
\hline CTRIB & 0,010 & 0,193 & 0,019 & 0,366 \\
\hline ALAV & $-0,132$ & $-2,623 * * *$ & $-0,116$ & $-2,391 * *$ \\
\hline $\mathrm{ROA}$ & 0,009 & 0,089 & $-0,035$ & $-0,358$ \\
\hline NDE & $-0,311$ & $-1,341$ & $-0,109$ & $-0,479$ \\
\hline TAM & 0,026 & 0,626 & 0,012 & 0,309 \\
\hline CVEND & $-0,015$ & $-0,219$ & 0,000 & 0,006 \\
\hline IND & 0,295 & $2,645 * * *$ & 0,064 & 0,561 \\
\hline $\mathrm{COM}$ & 0,005 & 0,041 & $-0,017$ & $-0,131$ \\
\hline AUDITORIA & 0,107 & 0,985 & 0,125 & 1,185 \\
\hline DPFCO & 0,044 & 0,812 & $-0,099$ & $-1,706^{*}$ \\
\hline G_INTER & & & 0,352 & $5,899 * * *$ \\
\hline Estatística F & \multicolumn{2}{|c|}{$2,891 * * *$} & \multicolumn{2}{|c|}{$5,725 * * *$} \\
\hline $\mathrm{R}^{2}$ ajustado & \multicolumn{2}{|c|}{0,038} & \multicolumn{2}{|c|}{0,098} \\
\hline Tolerance & \multicolumn{2}{|c|}{1 até 0,10} & \multicolumn{2}{|c|}{1 até 0.10} \\
\hline VIF & \multicolumn{2}{|c|}{1 até 10} & \multicolumn{2}{|c|}{1 até 10} \\
\hline DW & \multicolumn{2}{|c|}{2,183} & \multicolumn{2}{|c|}{2,207} \\
\hline K-S (sig.) & \multicolumn{2}{|c|}{0,047} & \multicolumn{2}{|c|}{0,014} \\
\hline Pesarán-Pesarán (sig.) & \multicolumn{2}{|c|}{0,328} & \multicolumn{2}{|c|}{0,848} \\
\hline $\mathrm{N}$ & \multicolumn{2}{|c|}{524} & \multicolumn{2}{|c|}{524} \\
\hline
\end{tabular}

Fonte: Dados da pesquisa.

A Tabela 8 apresenta os resultados da amostra que considera as empresas localizadas em países com tradição common law, incluindo 882 empresas com sede na Austrália, no Canadá, nos Estados Unidos, na Índia e no Reino Unido.

Tabela 8 - Determinantes do ranking agregado da QIC: common law

\begin{tabular}{|c|c|c|c|c|}
\hline \multirow[b]{2}{*}{ Variáveis explicativas } & \multicolumn{2}{|c|}{ (1) NORMAS E INCENTIVOS } & \multicolumn{2}{|c|}{ (2) NORMAS E INCENTIVOS + G INTER } \\
\hline & Coeficiente B & Estatística $t$ & Coeficiente B & Estatística $t$ \\
\hline Constante & $-2,649$ & $-1,443$ & $-2,532$ & $-1,383$ \\
\hline AMBIENTE & 0,117 & 0,430 & 0,097 & 0,356 \\
\hline CTRIB & 0,051 & 1,108 & 0,072 & 1,556 \\
\hline ALAV & $-0,144$ & $-3,682 * * *$ & $-0,133$ & $-3,396 * * *$ \\
\hline ROA & 0,010 & 0,207 & 0,011 & 0,225 \\
\hline NDE & 0,305 & $3,936 * * *$ & 0,281 & $3,600 * * *$ \\
\hline TAM & $-0,101$ & $-3,211 * * *$ & $-0,102$ & $-3,252 * * *$ \\
\hline CVEND & 0,012 & 0,335 & 0,011 & 0,299 \\
\hline IND & 0,463 & $6,048 * * *$ & 0,417 & $5,307 * * *$ \\
\hline $\mathrm{COM}$ & 0,297 & $3,242 * * *$ & 0,270 & $2,934 * * *$ \\
\hline AUDITORIA & 0,116 & 1,203 & 0,101 & 1,051 \\
\hline DPFCO & $-0,037$ & $-1,006$ & $-0,062$ & $-1,631$ \\
\hline
\end{tabular}

21 ISSN 2175-8069, UFSC, Florianópolis, v. 13, n. 29, p. 03-32, mai./ago. 2016 


\begin{tabular}{l|c|c} 
G_INTER & & 0,089 \\
\hline Estatística F & $9.920 * * *$ & $9,628 * * *$ \\
$\mathrm{R}^{2}$ ajustado & 0,100 & 0,105 \\
\hline Tolerance & 1 até 0.10 & 1 até 0.10 \\
VIF & 1 até 10 & 1 até 10 \\
DW & 1,961 & 1,966 \\
K-S (sig.) & 0,523 & 0,259 \\
Pesarán-Pesarán (sig.) & 0,340 & 0,417 \\
\hline N & 882 & 882 \\
\hline
\end{tabular}

Significativo ao nível de $10 \% * ; 5 \% * * ; 1 \% * * *$.

Fonte: Dados da pesquisa.

Para a coluna (1) das Tabelas 7 e 8, o modelo utilizado foi o da Equação (8), e para a coluna (2) utilizou-se a Equação (9). A coluna (1) das Tabelas 7 e 8 considera as variáveis de normas reguladoras, de incentivos e de controle conjuntamente, e a coluna (2) adiciona a variável de internacionalização, cujos modelos mostraram-se significativos para explicar a variável dependente ao nível de 1\% (estatística F), em ambas as projeções.

Nos países code law, as empresas menores, aquelas localizadas em países com ambiente legal mais robusto e do setor industrial, apresentaram escores mais elevados da qualidade da informação contábil. Ao se inserir a variável de grau de internacionalização (G_INTER), as empresas menos alavancadas e aquelas com menor volatilidade no fluxo de caixa indicaram níveis superiores de qualidade da informação contábil reportada (coluna 2). A inserção da variável G_INTER ampliou substancialmente o poder explicativo do modelo (coluna 2 em comparação com coluna 1) e confirmou a importância relativa da variável também na segregação da amostra pela origem legal dos países.

Nas duas configurações de análises com empresas localizadas em países common law, apresentadas na Tabela 8 , as empresas menores, menos alavancadas, localizadas em países com maior desenvolvimento econômico e pertencentes aos setores industrial e comercial, apresentaram escores mais elevados da qualidade da informação contábil.

Os resultados indicam que a variável G_INTER apresenta relação positiva e significativa com o ranking agregado da qualidade da informação contábil, ao nível de 5\% nos países common law, confirmando os resultados já encontrados nas demais projeções.

\subsection{Normas Reguladoras e Incentivos Empresariais}

Para a coluna (1) da Tabela 9, utilizou-se o modelo da Equação (10), enquanto na coluna (2) o modelo utilizado foi o da Equação (11).

Tabela 9 - Influência das normas reguladoras, incentivos e G_INTER no ranking agregado da QIC

\begin{tabular}{l|r|r|r|r}
\hline Variável dependente: Qualidade da Informação Contábil (QIC) \\
\hline \multirow{3}{*}{ Variáveis explicativas } & \multicolumn{1}{|c}{ (1) NORMAS E INCENTIVOS } & (2) NORMAS E INCENTIVOS + G INTER \\
\cline { 2 - 5 } & Coeficiente B & Estatística $t$ & Coeficiente B & \multicolumn{1}{c}{ Estatística $t$} \\
\hline Constante & $-2,151$ & $-3,629$ & $-1,368$ & $-2,270$ \\
ORIGEM & 0,327 & $4,288^{* * *}$ & 0,318 & $4,211^{* * *}$ \\
AMBIENTE & 0,062 & 0,670 & $-0,073$ & $-0,773$ \\
CTRIB & 0,047 & $1,645^{*}$ & 0,067 & $2,350^{* *}$ \\
IPC & 0,025 & 0,655 & 0,005 & 0,128 \\
ALAV & $-0,144$ & $-4,691^{* * *}$ & $-0,129$ & $-4,260^{* * *}$
\end{tabular}

\footnotetext{
Rerista 
Determinantes da qualidade da informação contábil no contexto internacional.

\begin{tabular}{|c|c|c|c|c|}
\hline ROA & 0,019 & 0,427 & 0,010 & 0,232 \\
\hline NDE & 0,156 & 1,384 & 0,188 & $1,689 *$ \\
\hline NDF & 0,001 & 0,389 & 0,000 & $-0,233$ \\
\hline TAM & $-0,054$ & $-2,148 * *$ & $-0,057$ & $-2,317 * *$ \\
\hline CVEND & 0,012 & 0,372 & 0,013 & 0,429 \\
\hline IND & 0,394 & $6,338 * * *$ & 0,302 & $4,752 * * *$ \\
\hline $\mathrm{COM}$ & 0,182 & $2,436 * *$ & 0,151 & $2,034 * *$ \\
\hline AUDITORIA & 0,100 & 1,390 & 0,087 & 1,227 \\
\hline DPFCO & $-0,005$ & $-0,152$ & $-0,062$ & $-1,973 *$ \\
\hline G_INTER & & & 0,174 & $5,592 * * *$ \\
\hline Estatística F & \multicolumn{2}{|c|}{$12,501 * * *$} & \\
\hline $\mathrm{R}^{2}$ ajustado & \multicolumn{2}{|c|}{0,103} & \multicolumn{2}{|c|}{0,122} \\
\hline Tolerance & \multicolumn{2}{|c|}{1 até 0,10} & \multicolumn{2}{|c|}{1 até 0,10} \\
\hline VIF & \multicolumn{2}{|c|}{1 até 10} & \multicolumn{2}{|c|}{1 até 10} \\
\hline DW & \multicolumn{2}{|c|}{2,018} & \multicolumn{2}{|l|}{2,034} \\
\hline K-S (sig.) & \multicolumn{2}{|c|}{0,104} & \multicolumn{2}{|l|}{0,060} \\
\hline Pesarán-Pesarán (sig.) & \multicolumn{2}{|c|}{0,171} & \multicolumn{2}{|l|}{0,669} \\
\hline $\mathrm{N}$ & \multicolumn{2}{|c|}{1.406} & \multicolumn{2}{|l|}{1.406} \\
\hline \multicolumn{5}{|c|}{ Significativo ao nível de $10 \% * ; 5 \% * * ; 1 \% * * *$. } \\
\hline
\end{tabular}

Nessa abordagem, são apresentados os resultados obtidos utilizando os dados da amostra total, considerando proxies de normas reguladoras, de incentivos empresariais e a intensidade de internacionalização das atividades econômicas, conjuntamente. Os resultados indicam que os modelos utilizados apresentaram relação positiva e significativa com a variável dependente ao nível de 1\% (estatística F).

Nessa configuração, a coluna (1) demonstra que, em relação às normas reguladoras, as variáveis da origem legal e carga tributária mostraram-se significativas para explicar o posicionamento no ranking da QIC. Empresas localizadas em países de origem common law e aquelas localizadas em países com menores cargas tributárias demonstraram níveis mais elevados na qualidade dos resultados contábeis reportados, com significância estatística ao nível de $1 \%$ e $10 \%$, respectivamente.

Quanto aos incentivos empresariais, somente a variável ALAV mostrou-se significativa para explicar a qualidade das informações contábeis, reiterando resultados anteriores que afirmavam que empresas com menor alavancagem financeira apresentam níveis mais elevados no ranking.

Na configuração da coluna (2), ocorreu a inserção da variável de interesse G_INTER, que demonstrou relação positiva e significativa com o ranking agregado da qualidade da informação contábil, ao nível de 1\%. As variáveis ORIGEM, CTRIB e ALAV apresentaram resultantes semelhantes ao modelo da coluna (1). Adicionalmente, a variável NDE passou a apresentar significância em relação à variável dependente, ao nível de $10 \%$.

Em relação às variáveis de controle, os dois modelos apresentaram resultados conforme o esperado. De um lado, TAM (colunas 1 e 2) e DPFCO (coluna 2) se mostraram negativa e significativamente relacionadas com maiores níveis de QIC. De outro lado, as variáveis IND e COM se mostraram positiva e significativamente relacionadas com maiores níveis de QIC, nas duas simulações.

Nas diversas simulações apresentadas, considerando as segregações da amostra pelos fatores relacionados ao ambiente legal, ao nível de percepção da corrupção, à tradição jurídica da origem legal, ou no modelo utilizando a amostra total, as duas determinantes que apresentaram resultados constantes e significativos para influenciar o posicionamento das 
empresas no ranking da qualidade da informação contábi foram o menor nível de alavancagem financeira e o maior grau de internacionalização das empresas. Considerando-se que a alavancagem financeira é um dos fatores ambientais que afetam as acumulações discricionárias das empresas (LANG; RAEDY; WILSON, 2006), os gestores de empresas com elevado nível de endividamento podem estar envolvidos com incentivos para praticar o gerenciamento de resultados, seja para evitar a violação das obrigações contratuais, seja para obter melhores termos nos contratos de dívidas, prejudicando a qualidade da informação reportada.

Os resultados da pesquisa sugerem que as empresas que apresentam menores níveis de alavancagem financeira podem ter riscos e custos de agência menores, influenciando positivamente a qualidade dos resultados contábeis.

Esse estudo sugere que uma empresa internacionalizada tem informação contábil de melhor qualidade em comparação com as empresas tipicamente domésticas. Isso pode ocorrer por causa de alguns fatores interligados. O sucesso da internacionalização exige, além de recursos financeiros substanciais, também experiência e capacidade acumulada, incluindo operações em vários locais e redes de investimentos estrangeiros, tornando-se, assim, vantagens intangíveis difíceis para os concorrentes imitarem (CHIN et al., 2012).

Essas condições geram maior desempenho e estabilidade dos resultados pela diversificação geográfica das atividades. Resultados positivos e estáveis reduzem as possibilidades de oportunismo gerencial para lidar com resultados indesejados ou se envolver em gerenciamento de resultados, em decorrência de desempenho deficitário.

A captação internacional de capital submete as empresas a enfrentar pressões adicionais dos mercados de capitais para a divulgação de informações, além daquelas enfrentadas pelas empresas que têm suas fontes de capital somente no país de origem.

Os resultados estão alinhados aos pressupostos teóricos de que empresas com atividades internacionais possuem lucros com menor volatilidade, portanto mais persistentes. E a persistência é um atributo desejável dos lucros. Dessa forma, a maior internacionalização das atividades empresariais indica a possibilidade de crescimento e continuidade dos lucros, aumentando a relevância dos lucros nas empresas internacionalizadas.

\section{Conclusões e Pesquisas Futuras}

O estudo analisou a influência do grau de internacionalização das empresas, em conjunto com as normas reguladoras e os incentivos empresariais, na qualidade das informações contábeis, contribuindo com a avaliação das características multidimensionais da temática. Embora não exista uma definição única de internacionalização, considerou-se uma abordagem econômica, ao considerar a intensidade da participação nos mercados internacionais.

Para identificar fatores determinantes da qualidade da informação contábil no contexto internacional, foram considerados fatores normativos (origem legal, ambiente legal e carga tributária) dos países que sediam as empresas investigadas. Também foram considerados incentivos empresariais (corrupção, alavancagem financeira, desenvolvimento econômico e do mercado financeiro) presentes nos países hospedeiros das empresas investigadas. Como variáveis de controle, utilizaram-se o tamanho, o crescimento de vendas, o setor econômico, o tipo da empresa de auditoria e a volatilidade do fluxo de caixa das empresas. Além dessas

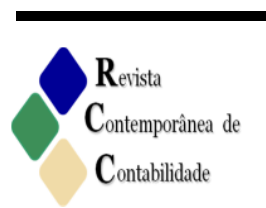

ISSN 2175-8069, UFSC, Florianópolis, v. 13, n. 29, p. 03-32, mai. /ago. 2016 
variáveis indicadas na literatura prévia consultada, o estudo introduziu, como fator determinante do posicionamento no ranking da qualidade da informação contábil, o grau de internacionalização das empresas, considerando o volume de vendas e de ativos no exterior em relação às vendas e aos ativos totais.

Os modelos utilizados não apresentaram elevado poder explicativo, contudo, na concepção de Goldberger (1998), o modelo clássico de regressão não exige que o $\mathrm{R}^{2}$ seja alto. Nesse sentido, um $\mathrm{R}^{2}$ elevado não é uma evidência favorável ao modelo, nem um $\mathrm{R}^{2}$ baixo constitui uma prova desfavorável. Gujarati (2006) considera mais importante a relevância lógica ou teórica das variáveis explanatórias em relação à variável dependente e sua significância estatística, do que necessariamente o poder explicativo do modelo. As variáveis utilizadas no modelo são recorrentes em estudos prévios e apresentam consistência teórica para seu uso.

Os resultados são decorrentes também do modelo utilizado para o estabelecimento do posicionamento das empresas no ranking de qualidade da informação contábil estabelecido. Ao utilizar a técnica da entropia, produziu vetores com maior peso para os atributos da suavização e da persistência dos lucros, ao apresentar maior diversidade de informação entre as empresas investigadas. Ao utilizar outras medidas para definição dos vetores, a exemplo de pesos lineares, podem ensejar condições divergentes no posicionamento das empresas.

Há coerência teórica na identificação de maiores pesos para os atributos de suavização e persistência dos lucros, pois um dos propósitos da suavização é justamente o de evitar a excessiva flutuação dos resultados. Resultados menos voláteis tornam-se mais persistentes e, portanto, mais desejáveis. Assim, os achados sugerem o uso da suavização pelas empresas investigadas para entregar resultados mais persistentes.

Dentre as diversas simulações realizadas, os resultados indicaram que o menor nível de alavancagem financeira e a maior intensidade de internacionalização foram os fatores determinantes que se mostraram estatisticamente significativos em todas as análises realizadas. Outros fatores como o menor tamanho e os setores de atuação, embora menos consistentes, também se mostraram significativos para explicar os números reportados. No âmbito de país, o desenvolvimento econômico e o do mercado financeiro mostraram-se relevantes apenas em situações mais específicas.

Os resultados da investigação corroboram os achados de Houqe et al. (2012) e Naranjo, Saavedra e Verdi (2015), que encontraram relação negativa da alavancagem financeira com a qualidade dos resultados contábeis, reforçando o entendimento de que empresas com menor alavancagem financeira podem apresentar menores riscos e menores custos de agência, constituindo-se em incentivo para produzir números mais condizentes com sua realidade econômica. Os resultados reforçam a perspectiva da Teoria da Agência de que as dívidas podem servir como mecanismos aos acionistas para monitorar e restringir o comportamento oportunista dos gestores (JENSEN, 1986).

Os resultados estão alinhados com os pressupostos teóricos de que a qualidade da informação contábil deve ser maior em empresas com menor alavancagem financeira, pois se constitui em incentivo aos gestores para divulgar números contábeis mais fidedignos, não atrelados aos compromissos contratuais, às dificuldades financeiras ou com necessidades de financiamento.

O resultado dessa pesquisa também corrobora o entendimento de que o tamanho da empresa é negativamente associado com a qualidade dos resultados contábeis, porque as 
grandes empresas podem escolher um método contábil para diminuir resultados, em resposta a um maior escrutínio político ou regulatório (WATTS; ZIMMERMAN, 1986).

Resta claro que, da mesma forma que a qualidade da informação contábil é um conceito multidimensional, os fatores explicativos que a impulsionam também são diversos e inter-relacionados. As evidências empíricas indicaram que a maior presença internacional conduziu as empresas para a evidenciação de resultados contábeis com atributos desejáveis pelos usuários das informações contábeis, utilizadas para decisões de investimentos e de avaliação patrimonial.

Os resultados apontam que a internacionalização das empresas gera incentivos para produzir informações contábeis de qualidade mais elevada, visando à redução de assimetrias informacionais com os diversos usuários. A intensidade da internacionalização das empresas, considerando o volume de vendas ao exterior e a presença de ativos no exterior, mostrou-se uma determinante relevante do melhor posicionamento no ranking da qualidade da informação contábil.

Essa condição pode estar atrelada ao fato de que empresas com tais características estão sujeitas a forças de mercado que exigem níveis mais elevados de informação contábil, quando comparadas com o ambiente doméstico. Os resultados mostram que a internacionalização das empresas gera incentivos para a produção de informações contábeis de maior qualidade, a fim de reduzir as assimetrias de informação entre os múltiplos usuários.

Essa investigação contribui para a pesquisa sobre a qualidade da informação contábil, fornecendo evidências adicionais sobre suas determinantes no cenário internacional. $\mathrm{O}$ estudo fornece evidências de que, ao se considerar a suavização como um atributo desejável ao produzir resultados mais persistentes, bem como ao se considerar os atributos da qualidade da informação contábil de forma conjunta, o (maior) grau de internacionalização está positivamente associado com melhores posições no escore da qualidade da informação contábil das empresas.

Para estudos futuros, recomenda-se considerar a análise dos atributos dos lucros baseados no mercado, a exemplo da relevância, tempestividade e conservadorismo para cada empresa. Essa abordagem se constitui relevante, pois tais atributos podem estar relacionados com incentivos diversos daqueles dos atributos de base contábil considerados nesse estudo.

\section{Referências}

ALFORD, A.; JONES, J.; LEFTWICH, R.; ZMIJEWSKI, M. The relative informativeness of accounting disclosures in different countries. Journal of Accounting Research, v. 31, supplement, p. 183-223, 1993.

ALMEIDA, J. E. F.; SARLO NETO, A.; BASTIANELLO, R. F.; MONEQUE, E. Z. Alguns aspectos das práticas de suavização de resultados no conservadorismo das companhias abertas listadas na BM\&FBOVESPA. Revista Contabilidade \& Finanças, v. 23, n. 58, p. 65-75, 2012.

ANTUNES, G. A.; MENDONÇA, M. M.; AZEVEDO, F. B., ALENCAR, R. C. Empresas estatais federais e empresas do novo mercado da Bovespa: um estudo comparativo acerca da 
qualidade da informação contábil utilizando dados em painel. In: CONGRESSO USP, 8., 2008, São Paulo. Anais... São Paulo: USP, 2008.

ARMSTRONG, C. S.; BARTH, M. E.; JAGOLINZER, A. D.; RIEDL, E. J. Market reaction to the adoption of IFRS in Europe. The Accounting Review, v. 85, n. 1, p. 31-61, 2010.

BALL, R. Infrastructure requirements for and economically efficient system of public financial reporting and disclosure. In: LITAN, R.; HERRING, R. (Eds.). Brookings-

Wharton Papers on Financial Services. Washington: Brookings Institute Press, p. 127-169, 2001 .

BALL, R.; KOTHARI, S. P.; ROBIN, A. The effect of international institutional factors on properties of accounting earnings. Journal of Accounting and Economics, v. 29, n. 1, p. 1$51,2000$.

BALL, R.; ROBIN, A.; WU, J. Incentives versus standards: properties of accounting income in four East Asian Countries. Journal of Accounting \& Economics, v. 36, p. 235-70, 2003.

BALL, R.; SHIVAKUMAR, L. Earnings quality in U.K. Private firms: comparative loss recognition timeliness. Journal of Accounting and Economics, v. 39, n. 1, p. 83-128, 2005.

BARTH, M. E; LANDSMAN, W. R; LANG, M. H. International Accounting Standards and accounting quality. Journal of Accounting Research, v. 46, n. 3, p. 467-498, 2008.

BENITEZ, J. M.; MARTIN, J. C.; ROMAN, C. Using fuzzy number for measuring quality of service in the hotel industry. Tourism Management, v. 28, n. 2, p. 544-555, 2007.

BIDDLE, G. C.; HILARY, G. Accounting quality and firm-level capital investment. The Accounting Review, v. 81, n. 5, p. 963-982, 2006.

BRADSHAW, M.; BUSHEE, B.; MILLER, G. Accounting choice, home bias, and U.S. investment in non-U.S. firms. Journal of Accounting Research, v. 42, n. 5, p. 795-838, 2004.

BULGURCU, B. K. Application of TOPSIS Technique for financial performance evaluation of technology firms in Istanbul Stock Exchange Market. Procedia - Social and Behavioral Sciences, v. 62, n. 24, p. 1033-1040, 2012.

BURGSTAHLER, D.; DICHEV, I. Earnings management to avoid earnings decreases and losses. The Accounting Review, v. 72, n. 2, p. 187-215, 1997.

BURGSTAHLER, D.; HAIL, L.; LEUZ, C. The importance of reporting incentives: earnings management in European private and public firms. The Accounting Review, v. 81, n. 5, p. 983-1016, 2006. 
BUSHMAN, R. M.; PIOTROSKI, J. D. Financial reporting incentives for conservative accounting: The influence of legal and political institutions. Journal of Accounting and Economics, v. 42, n.1-2, p. 107-148, 2006.

CHEN, H.; TANG, Q.; JIANG, Y.; LIN, Z. The role of accounting standards: evidence from the European Union. Journal of International Financial Management \& Accounting, v. 21, n. 3, p. 1-57, 2010.

CHIN, C-L.; CHEN, Y-J.; KLEINMAN, G.; LEE, P. The relationship of development status of investee countries and investor perceptions of foreign earnings. International Business \& Economics Research Journal, v. 11, n. 7, p. 787-794, 2012.

DASKE, H.; HAIL, L.; LEUZ, C.; VERDI, R. Mandatory IFRS adoption around the world: early evidence on the economic consequences. Journal of Accounting Research, v. 46, n. 5, p. 1085-1142, 2008.

DECHOW, P. Accounting earnings and cash flows as measures of firm performance: the role of accounting accruals. Journal of Accounting and Economics, v. 18, n. 1, p. 3-42, 1994.

DECHOW, P.; DICHEV, I. The quality of accruals and earnings: the role of accrual estimation errors. The Accounting Review, v. 77, n. 4, p. 35-59, 2002.

DECHOW, P.; GE, W.; SCHRAND, C. Understanding earnings quality: a review of the proxies, their determinants and their consequences. Journal of Accounting and Economics, v. 50, n. 2-3, p. 344-401, 2010.

DEFOND, M. L.; JIAMBALVO, J. Debt covenant violation and manipulation of accruals. Journal of Accounting and Economics, v. 17, n. 1-2, p. 145-176, 1994.

DING, Y.; JEANJEAN, T.; STOLOWY, H. The impact of firms' internationalization on financial statement presentation: some French evidence. Advances in Accounting, incorporating Advances in International Accounting, v. 24, n. 1, p. 145-156, 2008.

DOYLE, J.; GE, W.; MCVAY, S. Accruals quality and internal control over financial reporting. The Accounting Review, v. 82, n. 5, p. 1141-1170, 2007.

ECONOMIC FREEDOM OF THE WORLD. 2013 Dataset. Fraser Institute. Disponível em: http://www.freetheworld.com/release.html Acesso em: 20 fev. 2014.

FRANCIS, J.; LAFOND, R.; OLSSON, P. M.; SCHIPPER, K. Costs of equity and earnings attributes. The Accounting Review, v. 79, n. 4, p. 967-1010, 2004.

FRANCIS, J.; LAFOND, R.; OLSSON, P.; SCHIPPER, K. The market pricing of accruals quality. Journal of Accounting and Economics, v. 39, p. 295-327, 2005. 
FREEMAN, R.; OHLSON, J.; PENMAN, S. Book rate of return and prediction of earnings changes: an empirical investigation. Journal of Accounting Research, v. 20, n. 2, p. 639$653,1982$.

GAIO, C. The relative importance of firm and country characteristics for earnings quality around the world. European Accounting Review, v. 19, n. 4, p. 693-738, 2010.

GOLDBERGER, A. S. Introductory econometrics. Harvard University Press, 1998.

GUJARATI, D. N. Econometria básica. 4. ed. Rio de Janeiro, Elsevier, 2006.

HAW, I.; HU, B.; KHWANG, L.; WU, W. Ultimate ownership, income management, and legal and extra-legal institutions. Journal of Accounting Research, v. 42, n. 2, p. 423-462, 2004.

HOUQE, M. N. H.; VAN ZIJL, T.; DUNSTAN, K.; KARIM, A. K. M. W. The effect of IFRS adoption and investor protection on earnings quality around the world. The International Journal of Accounting, v. 47, n. 3, p. 333-355, 2012.

HRIBAR, P.; KRAVET, T.; WILSON, R. A new measure of accounting quality. Review of Accounting Studies, v. 19, n. 1, p. 506-538, 2014.

IATRIDIS, G. International Financial Reporting Standards and the quality of financial statement information. International Review of Financial Analysis, v. 19, n. 3, p. 193-204, 2010 .

ISIDRO, H.; RAONIC, I. Firm incentives, institutional complexity and the quality of "harmonized" accounting numbers. The International Journal of Accounting, v. 47, n. 4, p. 407-436, 2012.

KHANNA, T.; PALEPU, K. G.; SRINIVASAN, S. Disclosure practices of foreign companies interacting with U.S. markets. Journal of Accounting Research, v. 42, n. 2, p. 475-508, 2004.

KOHLBECK, M.; WARFIELD, T. Accounting standard attributes and accounting quality: discussion and analysis. Research in Accounting Regulation, v. 22, n. 2, p. 59-70, 2010.

LAND, J.; LANG, M. H. Empirical evidence on the evolution of international earnings. The Accounting Review, v. 77 (Supplement), p. 115-133, 2002.

LANG, M.; RAEDY, J. S.; WILSON, W. Earnings management and cross listing: are reconciled earnings comparable to US earnings? Journal of Accounting and Economics, v. 42, n. 1-2, p. 255-283, 2006.

LA PORTA, R.; LOPEZ-DE-SILANES, F.; SHLEIFER, A.; VISHNY, R. W. Law and finance. Journal of Political Economy, v. 106, n. 6, p. 1113-1155, 1998. 
LA PORTA, R.; LOPEZ-DE-SILANES, F.; SHLEIFER, A. The economic consequences of legal origins. Journal of Economic Literature, v. 46, n. 2, p. 285-332, 2008.

LEUZ, C. IAS versus U.S. GAAP: Information asymmetry-based evidence from Germany's new market. Journal of Accounting Research, v. 41, n. 3, p. 445-472, 2003.

LEUZ, C.; NANDA; D.; WYSOCKI, P. Earnings management and investor protection: an international comparison. Journal of Financial Economics, v. 69, n. 3, p. 505-27, 2003.

LEV, B. Some economic determinants of time-series properties of earnings. Journal of Accounting and Economics, v. 5, n 1, p. 31-48, 1983.

LINDAHL, F. Dynamic analysis of inventory accounting choice. Journal of Accounting Research, v. 27, n. 2, p. 201-226, 1989.

LIPE, R. The relation between stock returns and accounting earnings given alternative information. The Accounting Review, v. 65, n. 1, p. 49-71, 1990.

LUO, Y. How does globalization affect corporate governance and accountability? A perspective from MNEs. Journal of International Management, v. 11, n. 1, p. 19-41, 2005.

MARTINEZ, A. L. Detectando earnings management no Brasil: estimando os accruals discricionários. Revista Contabilidade \& Finanças, v. 19, n. 46, p. 7-17, 2008.

MATTOS, R. S.; VEIGA, A. Otimização de entropia: implementação computacional dos princípios Maxent e Minxent. Revista Pesquisa Operacional, v. 22, n. 1, p. 37-59, 2002.

MCNICHOLS, M. Discussion of The quality of accruals and earnings: the role of accrual estimation errors. The Accounting Review, v. 77 (Supplement), p. 61-69, 2002.

MYERS, J. N.; MYERS, L. A.; SKINNER, D. J. Earnings momentum and earnings management. 2006. Available at SSRN: http://ssrn.com/abstract=741244.

NARANJO, P. L.; SAAVEDRA, D.; VERDI, R. S. Financial reporting regulation and financing decisions. 2015. Disponível em: http://ssrn.com/abstract=2147838. Acesso em: 3 jun. 2015.

PENMAN, S. H.; ZHANG, X-J. Accounting conservatism, the quality of earnings and stock returns. The Accounting Review, v. 77, n. 2, p. 237-264, 2002.

RUSANESCU, S. La internacionalización de la empresa y la calidad de la información contable: evidencia para España. Instituto de Contabilidad y Auditoría, p. 1-93, 2013.

SCHIEMANN, F.; GUENTHER, T. Earnings predictability, value relevance, and employee expenses. The International Journal of Accounting, v. 48, n. 2, p. 149-172, 2013. 
SODERSTROM, N. S.; SUN, K. J. IFRS adoption and accounting quality: a review. The European Accounting Review, v. 16, n. 4, p. 675-702, 2007.

THE WORLD BANK. Data. Indicators. 2014. Disponível em: http://data.worldbank.org/indicators Acesso em: 14 abr. 2014.

THOMSON ONE BANKER. Screening \& Targeting. 2014. Disponível em: http://banker.thomsonib.com/ta/TAdashboard.aspx Acesso em: 14 abr. 2014.

TRANSPARENCY INTERNATIONAL. Corruption perceptions index. 2012. Disponível em: http://www.transparency.org Acesso em: 20 fev. 2014.

UNITED NATIONS CONFERENCE ON TRADE AND DEVELOPMENT - UNCTAD. World Investment Report 1995. Transnational corporations and competitiveness. Geneva: United Nations, 1995.

ZELENY, M. Multiple criteria decision making. New York: McGraw-Hill, 1982.

WATTS, R. L.; ZIMMERMAN, J. L. Positive accounting theory. Prentice-Hall Inc., 1986.

WEBB, K. A.; CAHAN, S. F.; SUN, J. The effect of globalization and legal environment on voluntary disclosure. The International Journal of Accounting, v. 43, n. 3, p. 219-245, 2008 .

WORLD ECONOMIC FORUM. The Financial Development Report. 2013. Disponível em: http://www.weforum.org/issues/financial-development Acesso em: 20 jan. 2014.

YOON, S. Accounting quality and international accounting convergence. Dissertation (Doctor of Philosophy) - Oklahoma State University, Oklahoma, 2007, p.97. 
